\title{
MERCADO DE TRABALHO NA AGRICULTURA BRASILEIRA: DÉCADA DOS OITENTA
}

\author{
DULCEMARIS DE CARVALHO \\ Engenheira Agrônoma \\ Administradora de Empresas
}

Orientador: Prof. Dr. CARLOS JOSÉ CAETANO BACHA

Dissertação apresentada à Escola Superior de Agricultura "Luiz de Queiróz", da Universidade de São Paulo, para obtenção do título de Mestre em Agronomia, Área de Concentração: Economia Agrária.

PI R A C I C A B A

Estado de São Paulo - Brasil

Julho - 1993 
Ficha catalografica preparada pela Secao de Livros da Divisao de Eiblioteca e Documentạăa - FClQ/USF

Carvalho, Dulcemaris de c331m Mercado de trabalio na agriclitura brasileira: decada dos aitenta. Firacicaba, 1993.

$160 \mathrm{p}$.

Diss. (Mestre) - ESALQ

Eibliografia.

1. Máa-de-obra - Erasil 2. Mercado de trataltio agricola - Erasil 3 . Froduça agricola - Erasil I. Escola Superior de Agricultura Luiz de Gueiroz; Firacicaba 


\title{
MERCADO DE TRABALHO NA AGRICULTURA BRASILEIRA: DÉCADA DOS OITENTA
}

\author{
DULCEMARIS DE CARVALHO
}

Aprovada em: 24.08 .93

Comissão julgadora:

Prof. Dr. Rodolfo Hoffmann

ESALQ/USP

Prof. Dr. Carlos José Caetano Bacha ESALQ/USP

Prof. Dr. Basília Maria Baptista Aguirre FEA/USP

Cadas foxi Cartano Bacha Prof. Dr. CARLOS JOSÉ CAETANO BACHA Orientador 
OFEREÇo À MINHA FAMÍliA 


\section{AGRADECIMENTOS}

Esta dissertação representa a conclusão de um longo processo de aprendizado. Este trabalho não poderia ter sido concluido sem a ajuda de muitas pessoas. A todas as pessoas e instituições, cuja contribuição direta ou indireta permitiu a realização desse trabalho, deixo aqui registrado os meus agradecimentos.

Inicialmente, gostaria de expressar meu sincero agradecimento ao meu orientador, Prof. Dr. Carlos José Caetano Bacha, pela dedicação e competência demonstrada em todas as fases desse estudo.

Agradeço aos professores Geraldo S. A. Camargo de Barros e Rodolfo Hoffmann pelas criticas e sugestões feitas a esse trabalho. As imperfeições que possam ainda existir são de minha própria responsabilidade.

Agradeço, também, ao professor Guilherme Leite da Silva Dias e à professora Basilia Maria B. Aguirre pela atenção e investigação inicial a respeito do tema a ser abordado.

Foram também de importância fundamental na conduta dessa pesquisa a dedicação e o empenho da equipe de professores que ministraram as disciplinas do curso de mestrado em Economia Agrária do Departamento de Economia e Sociologia Rural.

Quero manifestar meu agradecimento a todos os colegas do curso de mestrado com os quais tive a oportunidade de conviver e trocar idéias.

Aos funcionários do Departamento do DESR/ESALQ quero manifestar minha gratidão pelo auxilio que me forneceram durante esse período de mestrado. 
Agradeço o apoio financeiro recebido da CAPES e do CNPq ao longo de diversas etapas da pós-graduação. Por fim, agradeço todas as pessoas - muitas! que com sua amizade e carinho foram verdadeiro apoio e ânimo em todo o decorrer desse estudo. 


\section{SUMÁRIO}

LISTA DE TABELAS $\ldots \ldots \ldots \ldots \ldots \ldots \ldots \ldots \ldots \ldots \ldots$ viii

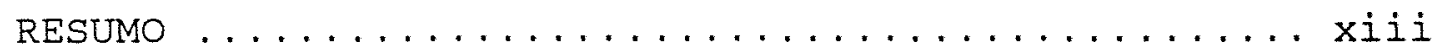

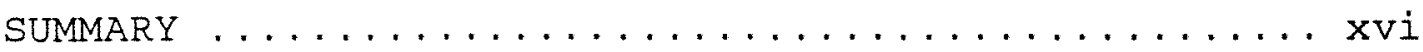

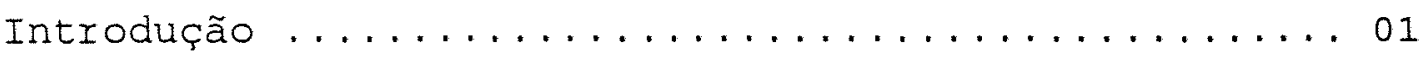

1. As análises sobre o setor agrícola e seu mercado

de trabalho ......................... 05

1.1. Revisão das análises sobre o comportamento do setor agrícola na década de $80 \ldots \ldots \ldots \ldots . \ldots 5$

1.2. Revisão das análises sobre a mão-de-obra rural na década dos oitenta .............. 11

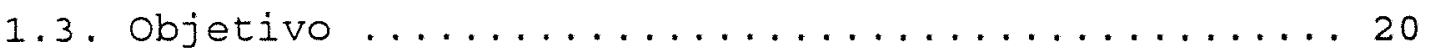

1.3.1. Objetivo geral ............... 20

1.3.2. Objetivos específicos $\ldots \ldots \ldots \ldots \ldots \ldots .21$

1.4. Hipóteses $\ldots \ldots \ldots \ldots \ldots \ldots \ldots \ldots \ldots \ldots \ldots \ldots .22$

2. Metodologia e Fontes de Dados .................. 24

2.1. Discussão sobre as fontes de dados .......... 24

2.1.1. O Censo Agropecuário (CA $\ldots \ldots \ldots \ldots .25$

2.1.2. A Pesquisa Nacional por Amostra de Domicílios (PNAD) . . . . . . . . . 28

2.2. Metodologia utilizada para o estudo da evolução e composição da mão-de-obra rural ... 41

2.3. Metodologia para o cálculo da produtividade e análise dos salários .................442

$2 \cdot 3.1$. Modelos que quantificam as relações entre uso de mão-de-obra, produtividade e produção .................. 43

2.3.2. Procedimentos adotados para a análise 
dos salários rural e urbano ......... 58

3. A evolução da mão-de-obra na agricultura segundo

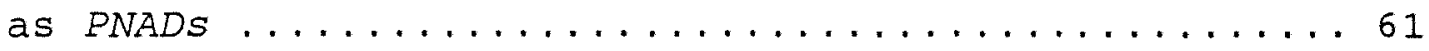

4. Análise dos dados sobre a mão-de-obra segundo os Censos Agropecuários ..................... 69

4.1. A evolução e a composição da mão-de-obra rural ............................. 69

4.2. Evolução da produtividade do trabalho na agricultura brasileira ...............73

4.3. Evolução dos salários rural e urbano .......... 81

5. Conclusão ........................... 90

Bibliografia ........................ 95

Apêndice 1. Decomposição por idade e por sexo das pessoas ocupadas na Agropecuária, segundo os Censos Agropecuários e as

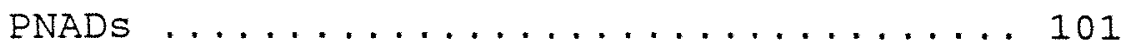

Apêndice 2. Variação das pessoas ocupadas na Agricultura entre 1980 e 1985, no Brasil, macrorregiões e estados, segundo os Censos Agropecuários ....... 109

Apêndice 3 . Cálculo do valor agregado por equivalente-homem ............... 111

Apêndice 4. Salário médio nominal do servente da construção civil, do empregado permanente e temporário da agricultura e salário mínimo médio nominal ... 156 


\section{LISTA DE TABELAS}

Página

Tabela 1. Evolução do total de pessoas ocupadas na agropecuária, segundo os Censos Agropecuários e as PNADs - Brasil,1975-86 ................ 30

Tabela 2. Evolução do total de homens na agropecuária, segundo os Censos Agropecuários e as PNADs -

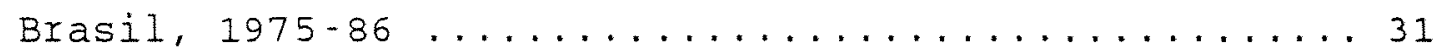

Tabela 3. Evolução do total de mulheres e crianças, segundo os censos Agropecuários e as PNADs -

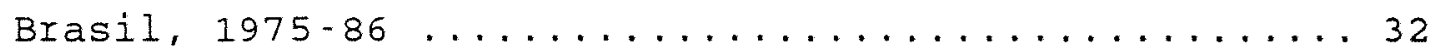

Tabela 4. Evolução do total de pessoas ocupadas na agropecuária das regiões: Nordeste, sudeste e

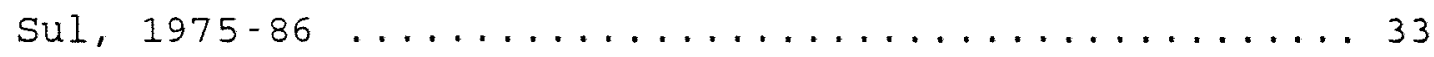

Tabela 5. Evolução do total de homens na agropecuária das regiões: Nordeste, Sudeste e Sul, 1975-86 . . 34

Tabela 6. Evolução do total de mulheres e crianças das regiões: Nordeste, Sudeste e sul, 1975-86 ..... 34

Tabela 7. Evolução do total de empregados na agropecuária, segundo os censos Agropecuários e as

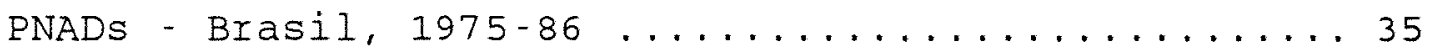

Tabela 8. Evolução do total de homens na categoria empregados na agropecuária, segundo os censos Agropecuários e as PNADs - Brasil, 1975-86 ....... 37 
Tabela 9. Evolução do total de mulheres na categoria empregados na agropecuária, segundo os censos Agropecuários e as PNADs - Brasil, 1975-86 ....... 37

Tabela 10. Evolução do total de empregados na agropecuária das regiões: Nordeste, sudeste e Sul,

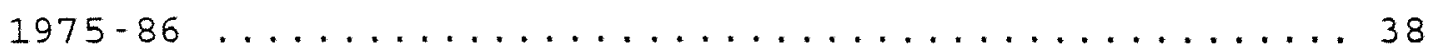

Tabela 11. Evolução do total de homens na categoria empregados na agropecuária das regiões: Nordeste,

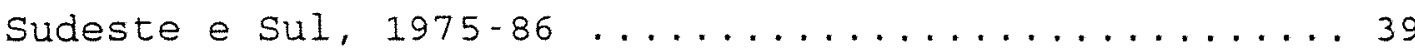

Tabela 12. Evolução do total de mulheres na categoria empregados na agropecuária das regiões: Nordeste, sudeste e sul, 1975-86 ............... 39

Tabela 13. Valor agregado dos estabelecimentos agrícolas versus PIB $_{c f}$ do setor agrícola (valores reais expressos em Cz\$ 1000 de 1985) - Brasil,

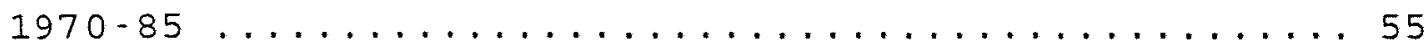

Tabela 14. Média da participação relativa do pessoal ocupado na agricultura, segundo cada categoria -

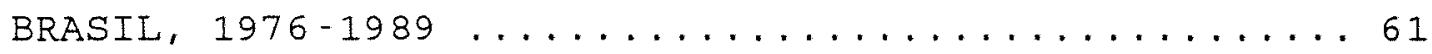

Tabela 15. Média da participação relativa do pessoal ocupado na agricultura, segundo a região e a ca-

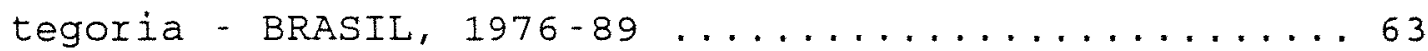

Tabela 16. Média da participação relativa do pessoal ocupado na agricultura, segundo o estado e a categoria - NORDESTE, $1976-1989 \ldots \ldots \ldots \ldots \ldots$......... 64 
Tabela 17. Média da participação relativa do pessoal ocupado na agricultura, segundo o estado e a categoria - SUDESTE, 1976-1989 .............. 66

Tabela 18. Média da participação relativa do pessoal ocupado na agricultura, segundo o estado e a categoria - SUL, 1976-1989 ...............67

Tabela 19. Variação das pessoas ocupadas na agropecuária no período 1980-85, segundo os Censos Agropecuários - Brasil e Regiões ..........70

Tabela 20. Variação das pessoas ocupadas na agropecuária no período 1980-85, nos estados que mais contribuíram para o aumento da mão-de-obra ........70

Tabela 21. Variação das pessoas ocupadas entre 1980 e 1985, segundo a categoria, na agropecuária brasileira e nos estados que mais contribuíram para o aumento da mão-de-obra ................71

Tabela 22. Contribuição da categoria Responsável no acréscimo total das pessoas ocupadas no país no qüinqüênio $1980-85$ e decomposição dessa contribuição por idade e sexo ................72

Tabela 23. Valor agregado (Cr\$ de 1985) por equivalente-homem no BRASIL - 1970, 1975, 1980 e $1985 \ldots . .74$

Tabela 24. Taxas médias qüinqüênais de crescimento do número de tratores e do consumo aparente de fertilizantes e de defensivos agrícolas - BRASIL,

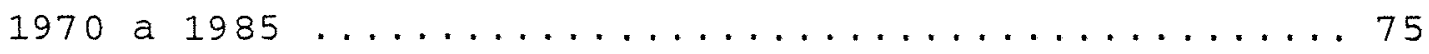


Tabela 25. Valor agregado (Cr\$ de 1985) por equivalente-homem em RONDÔNIA - 1970, 1975, 1980 e 1985 . . 75

Tabela 26. Valor agregado (Cr\$ de 1985) por equivalente-homem no PARÁ - 1970, 1975, 1980 e $1985 \ldots \ldots 76$

Tabela 27. Valor agregado (Cr\$ de 1985) por equivalente-homem no CEARÁ - 1970, 1975, 1980 e $1985 \ldots \ldots 76$

Tabela 28. Valor agregado (Cr\$ de 1985) por equivalente-homem na PARAIBA - 1970, 1975, 1980 e $1985 \ldots 77$

Tabela 29. Valor agregado (Cr\$ de 1985) por equivalente-homem na BAHIA - 1970, 1975, 1980 e $1985 \ldots 77$

Tabela 30. Valor agregado (Cr\$ de 1985) por equivalente-homem em MINAS GERAIS - 1970, 1975, $1980 \mathrm{e}$

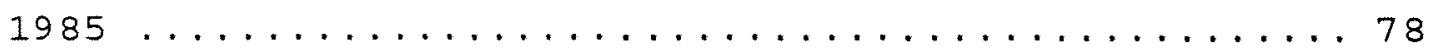

Tabela 31. Variação e taxas médias anuais de crescimento da produtividade média do trabalho (VA/EH), BRASIL e ESTADOS - 1970 a $1985 \ldots \ldots \ldots \ldots \ldots$

Tabela 32. Taxas médias qüinqüênais de crescimento do número de tratores nos estabelecimentos recenseados - BRASIL E ESTADOS - 1970 a $1985 \ldots \ldots \ldots \ldots$..... 80

Tabela 33. Indice do salário médio real - Brasil,

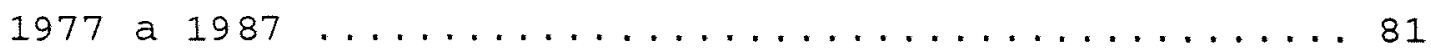

Tabela 34. Indice do salário médio real - Rondônia,

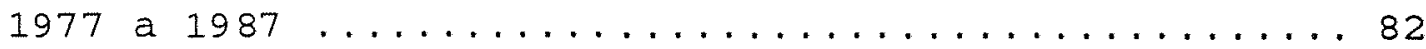

Tabela 35. Indice do salário médio real - Pará, 1977 


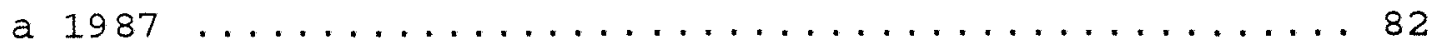

Tabela 36. Indice do salário médio real - Ceará,

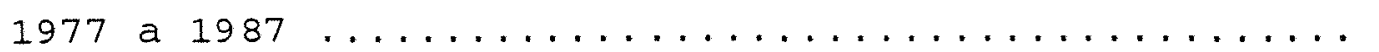

Tabela 37. Indice do salário médio real - Paraíba,

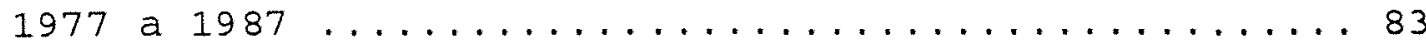

Tabela 38. Indice do salário médio real - Bahia,

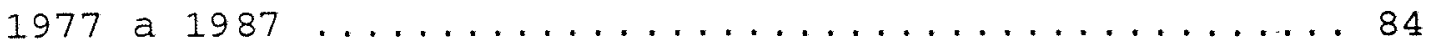

Tabela 39. Indice do salário médio real - Minas Gerais, 1977 a $1987 \ldots \ldots \ldots \ldots \ldots \ldots \ldots$. . . . . . . . . .

Tabela 40. Salário relativo: agricultura/mínimo e agricultura/servente - Brasil, 1977 a $1987 \ldots \ldots$... 86

Tabela 41. Salário relativo: agricultura/mínimo e agricultura/servente - Rondônia, 1977 a 1987 ..... 86

Tabela 42. Salário relativo: agricultura/mínimo e agricultura/servente - Pará, 1977 a 1987 ........ 87

Tabela 43. Salário relativo: agricultura/mínimo e agricultura/servente - Ceará, 1977 a 1987 ........ 87

Tabela 44. Salário relativo: agricultura/mínimo e agricultura/servente - Paraíba, 1977 a 1987 ...... 88

Tabela 45. Salário relativo: agricultura/mínimo e agricultura/servente - Bahia, 1977 a 1987 ...... 88

Tabela 46. Salário relativo: agricultura/mínimo e agricultura/servente - Minas Gerais, 1977 a 1987 . . 89 


\title{
MERCADO DE TRABALHO NA AGRICULTURA BRASILEIRA: DÉCADA DOS OITENTA
}

\author{
Autora: DULCEMARIS DE CARVALHO
} Orientador: Prof. Dr. CARLOS JOSÉ CAETANO BACHA

\section{RESUMO}

Diante do crescimento satisfatório da agricultura brasileira ocorrido na década de 80, da alteração no seu padrão de crescimento e da elevada participação do emprego rural no emprego total $(28,5 \%$ em 1985), pareceu-nos importante averiguar qual o tipo de trabalho que foi gerado no novo padrão de desenvolvimento agrícola.

A literatura consultada sobre o mercado de trabalho rural, na década dos oitenta, tem abrangido análises dos Censos Agropecuários para o período disponível: 1980-85 (MUELLER, 1987; GRAZIANO DA SILVA, 1987 e MARTINE, 1987) e das PNADs (Pesquisa Nacional por Amostra de Domicílios) para o período 1976-87 (AGUIRRE e BACHA, $1989 a, b)$.

Observaram-se divergências entre as conclusões dos autores que analisaram os dados censitários $e$ as conclusões dos autores que analisaram as PNADs. Para aqueles, houve um grande crescimento das pessoas ocupadas na agricultura, no período 1980-85, que se caracterizou por ser "uma volta à agricultura de subsistência", de modo que tínhamos, na verdade, aumentado a subocupção e o subemprego no campo. Os trabalhos de AGUIRRE e BACHA (1989a,b) 
ressaltam o avanço da categoria empregados entre as pessoas ocupadas na agricultura (o que, certamente, não corresponde a individuos ocupados em agricultura de subsistência).

com o intuito de analisar essas divergências, fez-se um estudo sobre a evolução e a composiç̃o das pessoas ocupadas na agricultura brasileira, segundo os dados disponíveis nos censos Agropecuários e nas PNADs.

Partiu-se da hipótese de que essas duas fontes de dados são elaboradas com metodologias diferentes. Portanto, a análise do mercado de trabalho rural deve ser feita separadamente com os dados das PNADs e dos censos Agropecuários.

Quanto à conclusão de AGUIRRE e BACHA (1989a,b) a respeito do avanço da categoria empregados, formulou-se a hipótese de que esse comportamento, observado com os dados agregados a nível de Brasil, pode não ser constatado em todos os estados.

Quanto à conclusão de MUELLER (1987), GRAZIANO DA SILVA (1987) e MARTINE (1987) de que o aumento de pessoas ocupadas, segundo os Censos Agropecuários de 1980 e 1985, foi uma volta à agricultura de subsistência, formulou-se a hipótese de que isso não seria toda a verdade do processo.

Para avaliar a primeira hipótese realiza-se uma discussão sobre as duas fontes de informações: censo Agropecuário e PNAD. Dessa discussão constata-se que os dados dessas duas fontes são elaborados com metodologias diferentes, o que nos leva a tratar separadamente os dados levantados pela PNAD e pelo censo Agropecuário a respeito das pessoas ocupadas na agricultura.

A análise sobre a evolução e composição da mão-de-obra rural segundo as PNADs mostrou que, com os dados disponíveis, não se evidencia de forma generalizada nos 
estados brasileiros, a tendência de avanço dos empregados e redução dos não remunerados. Com isso, confirma-se nossa segunda hipótese.

Os dados dos censos Agropecuários foram analisados sob o aspecto da decomposição da mão-de-obra rural por categoria de ocupação, por faixa etária e por sexo. Em seguida, analisou-se a evolução da produtividade do trabalho e dos salários rural e urbano.

Dessas análises concluiu-se que não se visualiza, com os dados analisados, a ocorrência de subocupação e subemprego da mão-de-obra rural no Brasil como um todo e nos seis estados que mais contribuiram para o aumento da mão-de-obra, no período 1980-85. Portanto, o aumento do emprego no campo, segundo o Censo Agropecuário de 1985, não foi de subocupados. Confirma-se, dessa maneira, nossa terceira hipótese. 


\section{BRAZILIAN AGRICULTURAL LABOR MARKET IN THE $1980^{\prime} \mathrm{S}$}

Author: DULCEMARIS DE CARVALHO Adviser: Prof. Dr. CARLOS JOSÉ CAETANO BACHA

SUMMARY

In view of the satisfactory growth of Brazilian agriculture in the 1980's, the change of this growth pattern and the large participation of rural labor in total labor (28.5\% in 1985), it seemed important to study what sort of labor was created in the new pattern of the agricultural development.

The literature on the agricultural labor market in the 1980's, which was reviewed, consisted in the Agricultural Census analysis for the period: 1980-85 (MUELLER, 1987; GRAZIANO DA SILVA, 1987 and MARTINE, 1987) and the PNAD's (National Census by Residencial sampling), for the period 1976-87 (AGUIRRE and BACHA, 1989a,b).

Divergences were observed between the papers that analysed census data and those which analysed the PNAD's data. For the former, there was an increase in the number of people occupied in agriculture in the period 1980-85, which was characterized as a "return to subsistence farming", identifying an increase of underemployment in agriculture. The papers by AGUIRRE and BACHA (1989a,b) show an increase in employment among those occupied in agriculture (which certainly does not correspond to individuals occupied in subsistence agriculture). In order 
to analyse such divergences, a study was carried out on the evolution and the composition of people occupied in agriculture, according to the data published in the Agricultural census and in the PNAD's.

The initial hypothesis was that data from both sources are treated differently and the analysis of the rural labor market must be made separately with data from the Census and the PNAD's.

With respect to the conclusions of AGUIRRE and BACHA $(1989 a, b)$ on the advance of the employeds relations, a hypothesis was formulated that this behavior, observed from the data aggregated for Brazil, cannot be confirmed in all states.

Concerning to the conclusion of MUELLER (1987), GRAZIANO DA SILVA (1987) and MARTINE (1987) that the increase in occupation, as observed in the agricultural census of 1980 and 1985, represents a return to subsistence farming, the hypothesis formulated was that this was not entirely true.

To evaluate the first hypothesis a discussion of the two sources of information is made. This discussion shows that the two sources are the results of two different methodologies, which leads us to treat the two sources differently whith respect to the population occupied in agriculture.

The analysis of the evolution and composition of the rural labor force as presented by the PNAD's do not show, in all states, an increase in the number of employed and reduction of the unpayed. Thus, our second hypothesis is confirmed.

The census data were analysed considering different decomposition (occupation, age and sex). The evolution of productivity and rural/urban salaries was also analysed. 
From the information above we conclude that for the 1980-85 period the underployment and underoccupation did not contributed to the increase of the rural labor force in Brazil (taken as a whole) and the six most important states (in terms of increase in rural labor force). Then, the increase in the rural labor force, following the 1985 agricultural census, was not due to the increase in underoccupied, confirming our third hypothesis. 


\section{INTRODUÇÃO}

Embora a economia como um todo tenha mostrado menor dinamismo na década dos oitenta em relação ao observado na década dos setenta, a comparação das taxas de crescimento dos produtos setoriais mostrou que a agricultura se expandiu satisfatoriamente, mantendo a trajetória de crescimento agrícola verificada nos anos setenta (REZENDE, 1989a; GASQUES e VILLA VERDE, 1990).

A agricultura apresentou na década dos oitenta um padrão de crescimento distinto dos até então verificados.

Nos anos oitenta ocorreu o enfraquecimento do modelo extensivo, baseado na expansão da área, em direção a outro, onde a produtividade agrícola é a principal fonte de aumento de produção (DIAS, 1989b; AGUIRRE e BACHA, 1989b;

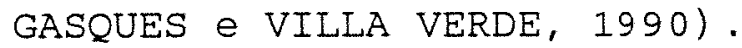

Quanto ao papel da agricultura no ajustamento da economia brasileira, DIAS (1989b) verificou que a principal contribuição da agricultura reside na melhora contínua do abastecimento interno. Foi evidenciado por REZENDE (1989a) que a produção agrícola vegetal destinada ao mercado interno(1) aumentou sua taxa de crescimento na década de 80 em comparação com a década de 70 .

Diante do crescimento satisfatório da agricultura brasileira na década de 80 e da alteração no seu padrão de

(1) Os produtos selecionados por REZENDE (1989a) a fim de analisar o comportamento da produção agrícola vegetal de mercado interno foram: feijão, milho, mandioca, arroz e algodão. 
crescimento, o objetivo desse trabalho consiste em verificar qual foi o comportamento do mercado de trabalho rural naquela década. Especificamente, analisamos se o crescimento das pessoas ocupadas no período 1980-85 foi realmente uma volta à agricultura de subsistência, gerando subocupação e subemprego no campo (conclusões a que chegaram os trabalhos de MUELLER, 1987; GRAZIANO DA SILVA, 1987 e MARTINE, 1987). Para isso, estudamos a evolução e a composição do total de pessoas ocupadas na agricultura brasileira, a evolução da produtividade da mão-de-obra rural e o comportamento dos salários nos setores rural e urbano.

Preocupações semelhantes encontramos nos trabalhos de FARIA (1986) e CACCIAMALI (1989). Frente às transformações ocorridas no Brasil, esses autores tiveram como intuito verificar a evolução do mercado de trabalho no País e as mudanças na sua composição setorial. Ambos os estudos realizaram a análise segundo os setores da atividade econômica - primário, secundário e terciário -, enfocando especialmente os setores da economia urbana.

FARIA (1986) utilizou os dados dos censos Demográficos, para o período 1950-80, enquanto CACCIAMALI (1989) utilizou os dados das PNADs, analisando-os para um período mais recente: 1979-85.

Dentre outros resultados, FARIA e CACCIAMALI verificaram a diminuição do emprego vinculado ao setor agropecuário: de 59,9\% do total de pessoas ocupadas no País em 1950 para $28,5 \%$ em 1985. FARIA ressalta que embora constatado esse fato, em termos absolutos, esse contingente ainda representava em 1980 mais de 13 milhões de pessoas ocupadas no setor agropecuário.

Assim, uma vez que a participação do emprego rural no emprego total é elevada - 28,5\% em 1985 -, pareceu-nos importante averiguar qual o tipo de trabalho 
que está sendo gerado no novo padrão de desenvolvimento agrícola e qual a sua relação com o crescimento do produto.

A Iiteratura consultada sobre o mercado de trabalho rural na década dos oitenta tem abrangido análises dos Censos Agropecuários para o período disponível: 1980-85 (MUELLER 1987; GRAZIANO DA SILVA, 1987 e MARTINE, 1987) e das PNADs (Pesquisa Nacional por Amostra de Domicilios), para o período 1976-87 (AGUIRRE e BACHA, 1989a,b). Observaram-se divergências entre as conclusões dos autores que analisaram os dados censitários e as conclusões dos autores que analisaram as PNADs.

com o intuito de pormenorizar essas divergências, realizamos, no primeiro capítulo, uma revisão da bibliografia a respeito das análises sobre o setor agrícola e sobre a sua mão-de-obra na década dos oitenta.

Posteriormente, no capítulo 2, procuramos constatar se as diferenças metodológicas entre o censo Agropecuário e a Pesquisa Nacional por Amostra de Domicilios explicam os distintos resultados encontrados nos trabalhos de MUELLER (1987), GRAZIANO DA SILVA (1987), MARTINE (1987) e AGUIRRE e BACHA (1989a,b).

Dessa discussão constatamos que os dados da PNAD e do Censo Agropecuário são elaborados com metodologias diferentes. Por isso se faz, separadamente para cada fonte de informação, o estudo das pessoas ocupadas no setor agrícola na década dos oitenta.

No terceiro capitulo analisamos a evolução e a composição da mão-de-obra rural segundo os dados das PNADs (Pesquisas Nacionais por Amostra de Domicilios). A análise é feita a nível de estados, a fim de averiguar se a conclusão de AGUIRRE e BACHA (1989a) sobre avanço da categoria empregados é válida para todos os estados do Brasil ou apenas para alguns deles.

Analisamos os dados dos Censos Agropecuários no 
quarto capítulo. Realizamos a decomposição da mão-de-obra rural por categoria de ocupação, por faixa etária e por sexo. No entanto, somente essa análise, a nosso ver, não é suficiente para averiguar se o crescimento das pessoas ocupadas no setor agropecuário brasileiro, no primeiro qüinqüênio da década de 80, significou na sua maioria um crescimento do subemprego e da subocupação no campo. Por isso, são examinados os comportamentos da produtividade da mão-de-obra e do salário rural.

Por fim, após essa avaliação, é feita a conclusão do trabalho no quinto capítulo. 


\title{
1. AS ANÁLISES SOBRE O SETOR AGRÍCOLA E SEU MERCADO DE TRABALHO
}

\begin{abstract}
Com o intuito de conhecer e melhor compreender o comportamento do mercado de trabalho rural, analisamos o que ocorreu de diferente no setor agrícola na década dos oitenta (item 1.1). Em seguida, analisamos os vários estudos realizados, nesse período, sobre a mão-de-obra agrícola (item 2.2).
\end{abstract}

\subsection{Revisão das análises sobre o comportamento do setor agrícola na década de 80}

BARROS, PASTORE e RIZZIERE (1977) mostraram que, até a década dos 50, o crescimento do produto agrícola se dava preponderantemente pela expansão da ocupação da mão-de-obra rural. Esse padrão de crescimento alterou-se nas décadas de 60 e 70, quando passou a predominar a expansão da área. AGUIRRE e BACHA (1989b) complementam dizendo que o crescimento da produção agrícola nos anos 70 foi fruto de um processo de modernização baseado na utilização de insumos modernos (aliados à mecanização) e na expansão da área.

$$
\text { No entanto, nos anos 80, ocorreu } 0
$$
enfraquecimento do modelo extensivo, baseado na expansão da 
área, em direção a outro, onde a produtividade agrícola é a principal fonte de aumento de produção (DIAS, 1989b; AGUIRRE e BACHA, 1989b; GASQUES e VILLA VERDE, 1990).

A discussão sobre o comportamento do setor agrícola na década de 80 mostrou uma mudança de enfoque dos temas em análise.

os primeiros trabalhos da década se preocuparam com a competição dos produtos exportáveis versus os domésticos. Diante do problema da produção de alimentos para o mercado interno, foram realizados vários estudos sobre os efeitos das politicas setoriais (crédito rural e preços mínimos) adotadas no país na primeira metade dos anos oitenta.

Na segunda metade da década de 80, os trabalhos passaram a analisar as interrelações da agricultura com as variáveis macroeconômicas. Procurou-se analisar não apenas os efeitos da agricultura sobre estas variáveis macroeconômicas (nível de preços, saldo do Balanço Comercial) mas, também, os efeitos de politicas macroeconômicas sobre a agricultura.

Analisamos, a seguir, alguns trabalhos que mostram essa discussão a respeito do setor agrícola na década de 80 .

HOMEM DE MELO (1985) realizou um estudo amplo sobre a evolução da produção agrícola brasileira e da disponibilidade de alimentos por habitante, bem como determinou os fatores alocativos dos recursos entre os diferentes subsetores da agricultura.

- trabalho concentrou e detalhou sua análise no período 1977-84, atendo-se à produção de alimentos de mercado interno (domésticos-alimentares), de exportação e de substituição de derivados de petróleo (energia). 
HOMEM DE MELO (1985, p.195) verificou que a produção per capita de alimentos domésticos decresceu em média 1,94\% ao ano; os exportáveis cresceram 2,56\% ao ano; as carnes ficaram estagnadas e a cana-de-açúcar cresceu $7,48 \%$ ao ano. Frente a esse panorama, HOMEM DE MELO comentou que "esse foi, sem dúvida, um desempenho fortemente desequilibrado da agricultura brasileira, caracterizando um sério problema na produção de alimentos de mercado interno".

$\mathrm{Na}$ opinião do autor em análise, os fatores que influenciaram a alocação dos recursos na agricultura entre os seus diversos subsetores foram: o desequilíbrio tecnológico entre culturas de exportação e de mercado interno - favorável às exportações; a politica cambial incentivadora das exportações; o comportamento dos preços internacionais dos nossos produtos de exportação; o Programa Nacional do Alcool (PROÁlCOOL); a queda da renda real da população; e a elevada instabilidade dos preços recebidos pelos produtores de culturas alimentares de mercado interno.

LOPES (1989) procurou investigar os efeitos das politicas macroeconômicas sobre a taxa de câmbio real, que é uma variável importante na determinação da lucratividade das exportações agrícolas. As exportações, por sua vez, comenta o autor - sempre foram um fator muito importante na determinação da rentabilidade agrícola brasileira.

De uma forma genérica, as conclusões do trabalho de LOPES podem ser assim sintetizadas: "até recentemente acreditava-se que a agricultura tinha impacto nas variáveis macroeconômicas, nos níveis dos preços, nos juros, nos saldos de balanço de pagamentos, etc. Agora, verifica-se que as variáveis macroeconômicas têm um impacto importante na agricultura também" (LOPES, 1989, p.54). 
DIAS (1989a,b) estudou o papel da agricultura no ajustamento da economia brasileira.

Inicialmente, o autor verificou uma mudança no padrão de crescimento do setor produtivo agrícola, caracterizando o primeiro qüinqüênio da década dos oitenta por um padrão de crescimento intensivo (DIAS, 1989a).

outro aspecto importante destacado por DIAS (1989a) está no "aumento expressivo da taxa de crescimento do pessoal ocupado (no setor produtivo agrícola) no periodo 1980-85, sendo que este processo ocorre com aumento da produtividade do trabalho e redução da área explorada por homem."

A principal contribuição da agricultura no ajustamento da economia brasileira - comenta DIAS (1989b) -, reside na contínua melhoria do abastecimento interno o que, além do mais, acabará pol fortalecer a própria competitividade externa do Brasil.

REZENDE (1989a,b) apresentou uma visão de conjunto do desempenho agrícola nos anos 80 . Verificou que, nesse período, a produção agrícola manteve a trajetória de crescimento observada nos anos 70, em franco contraste com - ocorrido no conjunto da economia e com o setor industrial em particular.

Esse comportamento foi explicado pelas peculiaridades do setor agrícola e pelas variáveis exógenas à economia brasileira. Essas variáveis - os preços externos das commodities agrícolas e do petróleo - afetam a rentabilidade relativa da agricultura, sem, porém, guardar qualquer relação sistemática com o ciclo doméstico.

Verificou-se também que o crescimento agrícola foi satisfatório, muito embora os preços agricolas se mantivessem baixos na década dos oitenta, com a exceção 
maior do ano de 1984, sobretudo para os produtos agricolas exportáveis. REZENDE (1989a,b) evidencia então outros fatos, também ocorridos neste período, que atuaram de maneira compensatória: a redução do custo da produção; a atuação eficaz da politica econômica (através de seus instrumentos de ação tanto setorial como global) promovendo - financiamento e a liquidez da agricultura; e a crise externa, que estimulou a produção de bens agrícolas de mercado interno.

$$
\text { REZENDE (1989a, p.1743) evidenciou que "a }
$$
produção agrícola vegetal de mercado interno(2) aumentou sua taxa de crescimento na década de 80, em comparação com a década de 70". O autor atribuiu esse comportamento ao incentivo da politica de preços mínimos mais favorável aos agricultores a partir de 1983 (REZENDE, 1989b).

GASQUES e VILLA VERDE (1990) também avaliaram o crescimento recente da agricultura e acrescentaram a contribuição do crescimento da produtividade agrícola às características já analisadas por REZENDE (1989a).

GASQUES e VILLA VERDE (1990) verificaram que os indicadores de crescimento da agricultura por região mostraram um dinamismo diferente no período 1981-88. Enquanto o produto real de lavouras no País como um todo cresceu 3,29\% ao ano, no Nordeste e centro-Oeste o crescimento anual foi de $7,25 \%$ e 10,8\%, respectivamente. No Norte cresceu $3,64 \%$ ao ano, no sul $1,36 \%$ ao ano e no Sudeste 2,63 ao ano.

Através da decomposição do produto real para o Brasil, verificou-se que houve o enfraquecimento do modelo extensivo baseado na expansão da área, em direção a outro,

(2) Os produtos selecionados por REZENDE (1989a) a fim de analisar o comportamento da producão agrícola vegetal de mercado interno foram: feijão, milho, mandioca, arroz e algodão. 
onde a produtividade agrícola é a principal fonte de aumento da produção. A taxa anual de crescimento da produtividade agrícola (ou seja, a produtividade por unidade de área cultivada) no período $1981-88$ foi de 1,41\%, que contribuiu com $43 \%$ do crescimento do produto real. 0 restante foi dividido em partes praticamente iguais entre a relação área/homem, que se expandiu de $0,98 \%$ ao ano e o aumento da mão-de-obra que foi de 0,90\% ao ano.

Chamamos a atenção que isto - a expansão da relação área/homem - é diferente do que foi observado por DIAS (1989a), no período 1980-85, que constatou redução da área explorada por homem.

GASQUES e VILLA VERDE (1990) mostraram que a mão-de-obra desempenhou um papel completamente diferente no crescimento do produto agrícola das regiões sul e Nordeste, no período de 1981-88. Na região sul houve redução da mão-de-obra rural, com efeito negativo sobre o produto. "No Nordeste, o aumento do pessoal ocupado teve papel decisivo na expansão do produto, o que contraria" - comentam GASQUES e VILLA VERDE (1990, p.194) - "a impressão que se teve pelo exame dos dados do Censo Agropecuário de 1985, de que teria havido aumento do subemprego nos estabelecimentos menores de 10 hectares".

No nosso parecer, a simples análise desses dados não explica a conclusão de GASQUES e VILLA VERDE. Pois, para que possamos dizer que não houve subemprego e subocupação na agricultura, faz-se necessário verificar se a taxa de crescimento da produção é igual ou maior que a taxa de crescimento das pessoas ocupadas. 


\subsection{Revisão das análises sobre a mão-de-obra rural na década dos oitenta}

Para os interesses desse trabalho, podemos decompor a literatura que analisa a mão-de-obra agrícola em quatro grupos:

a) os trabalhos que avaliam a evolução da mão-de-obra rural e sua composição nas décadas de 60 e 70;

b) os trabalhos que analisam os trabalhadores temporários (ou volantes);

c) os trabalhos que comparam as informações dos censos Agropecuário e Demográfico;

d) os trabalhos que avaliam a evolução da mão-de-obra rural e sua composição na década de 80 .

No primeiro grupo, temos os trabalhos de GRAZIANO DA SILVA e KAGEYAMA (1982, 1983a, 1983b). No segundo grupo, temos os trabalhos de GASQUES e PAIVA (1984), GUIMARÃES et alii (1984), AGUIRRE (1987) e VICENTE (1989). No terceiro grupo, temos, dentre outros, o trabalho de MARTINE e ARIAS (1987). No quarto grupo, temos os trabalhos de MUELLER (1987), GRAZIANO DA SILVA (1987), MARTINE (1987) e AGUIRRE e BACHA $(1989 a, b)$.

Vejamos, resumidamente, as constatações desses trabalhos.

GRAZIANO DA SILVA e KAGEYAMA (1983b), ao analisarem os Censos Agropecuários de 1960, 1970 e 1975, constataram um comportamento radicalmente distinto das taxas anuais de crescimento da mão-de-obra ocupada na agricultura paulista e brasileira, nos anos 1960, 70 e 75 . observou-se, entre 60 e 70, uma rápida redução do volume da mão-de-obra contratada diretamente pelos estabelecimentos agropecuários no estado de são paulo; 
enquanto que o seu volume apresentou expansão a taxas moderadas no Brasil como um todo.

$\mathrm{Na}$ primeira metade dos anos setenta, o nível de emprego mínimo na agricultura paulista continuava em declínio - embora este decréscimo fosse bem inferior ao registrado na década anterior -, enquanto se expandia rapidamente o volume da mão-de-obra contratada no restante do País.

Em outro artigo - utilizando as informações dos Censos Agropecuários de 1970 e 1975 e as tabulações avançadas do Censo Agropecuário de 1980 -, GRAzIANo DA SILVA e KAGEYAMA (1983a) apontam duas caracteristicas marcantes na passagem da primeira para a segunda metade dos anos setenta:

1) forte declínio da taxa de crescimento do número de pessoas ocupadas entre 1975-80 em relação a 1970-75, no Brasil e em quase todas as regiões;

2) redução da participação de mulheres e crianças (menores de 14 anos) na força de trabalho, em todas as regiões do País. As possíveis razões levantadas para este fato, pelos autores em análise, foram: modernização da agricultura, queda cíclica da atividade econômica do País e concentração fundiária (redução das pequenas unidades familiares).

Em outro trabalho de GRAzIANO DA SILVA e KAGEYAMA (1982), analisando os dados do Censo Demográfico de 1970 e as tabulações avançadas de 1980 deste mesmo censo, verificou-se que:

1) a taxa anual de crescimento, no período 1970-80, da População Economicamente Ativa (PEA) no Brasil foi de 4,01\%, enquanto que a taxa de crescimento da PEA agrícola foi de apenas 0,01\% ao ano; 
2) alguns estados do Nordeste e Sudeste, e todos os estados da Região Sul, apresentaram decréscimo absoluto da PEA agrícola. A região Norte e os estados de Mato Grosso e Mato Grosso do sul foram os absorvedores da PEA na agricultura nos anos setenta, em função direta da expansão da fronteira agrícola que ocorreu nessas áreas.

Os empregados são divididos em permanentes e temporários (volantes). Vários estudos foram feitos sobre os trabalhadores volantes. Dentre eles destacamos os estudos de GASQUES e PAIVA (1984), GUIMARÃES et alii (1984), AGUIRRE (1987) e VICENTE (1989).

GASQUES e PAIVA (1984) analisaram os dados dos Censos Agropecuários para o período 1970-80. Evidenciaram que $o$ emprego de mão-de-obra temporária tem crescido indistintamente em todos os segmentos do setor agropecuário (na agricultura voltada ao mercado interno, na agricultura voltada ao mercado externo e na pecuária), independente de seu nível tecnológico.

Verificou-se também que a expansão de culturas de exportação em áreas ocupadas por lavouras de mercado interno não leva necessariamente à redução do emprego. Tudo dependerá das tecnologias dos produtos que se substituem (esse fato também foi constatado posteriormente por GRAZIANO DA SILVA, 1989).

GUIMARÃEs et alii (1984) analisaram a situação dos volantes - domicilio, nivel de alfabetização, rendimento médio mensal, etc - no Estado do Paraná, são Paulo, Mato Grosso do sul, Goiás, Minas Gerais e nos Estados Nordestinos à exceção do Piauí e Maranhão, utilizando os dados das tabulações avançadas do censo Demográfico de 1980 . 
A situação de domicílio rural foi a que apresentou maior freqüência entre os trabalhadores volantes (exceto São Paulo, onde $85 \%$ dos volantes possuíam domicilio urbano). Em relação à composição da mão-de-obra volante, segundo sexo, os homens constituíram a parcela mais significativa. Os trabalhadores volantes na sua maioria eram analfabetos. Nos estados analisados, 82,18 dos volantes recebiam até 1 salário mínimo. Cerca de 85 q desses trabalhadores dispendiam 40 ou mais horas de trabalho por semana. Finalmente, $94,3 \%$ dos volantes não realizavam qualquer forma de contribuição à Previdência Social.

AGUIRRE (1987) também utilizou os dados do censo Demográfico de 1980, realizando a análise do mercado de trabalho rural para o Brasil como um todo e para o Estado de são paulo.

No final de 1980, a agropecuária brasileira contava com aproximadamente 13 milhões de pessoas ocupadas, das quais $24,4 \%$ eram empregados permanentes e 12,7\% eram volantes. No Estado de São Paulo, os volantes compunham $18,5 \%$ do pessoal ocupado na agropecuária e os permanentes $49,6 \%$.

A análise dos dados por regiões evidenciou que a composição das pessoas ocupadas na agropecuária varia em função das macrorregiões do País, sendo que o Estado de são paulo apresentou caracteristicas muito diferenciadas em relação às demais regiões.

A autora em análise chegou a conclusões semelhantes às do trabalho de GUIMARÃES et alii (1984) no que se refere à situação dos volantes no Brasil e no estado de são Paulo, e às do trabalho de GASQUES e PAIVA (1984) quanto ao uso indiscriminado de volantes em todos os segmentos do setor agrícola, independente do seu nivel tecnológico. 
VICENTE (1989), utilizando os dados do Instituto de Economia Agrícola (IEA), analisou o trabalho volante na agricultura paulista no perído 1968-87. A percentagem estimada dos volantes em 1970 era de $14,9 \%$ em relação ao total de pessoas ocupadas na agricultura, em 1979 era de 27,38 e em 1986/87 era aproximadamente de 30,0\%.

Através da análise da evolução da produção, mecanização e uso da mão-de-obra nas principais culturas da agricultura paulista, no período de 1974/75 a 1986/87, verificou-se que a utilização de mão-de-obra volante vem se concentrando nos meses de colheita de cana, café, laranja e culturas anuais (milho, feijão de inverno, etc).

A autora faz menção à Nova Constituição (promulgada em 05 de outubro de 1988) que estabeleceu igualdade de direitos entre trabalhadores com vínculo empregatício permanente e o trabalhador temporário, observando que este fato poderá ocasionar alterações no processo produtivo agrícola e nas relações de trabalho.

O trabalho de MARTINE e ARIAS (1987) se propôs a analisar a origem, a forma e o significado das diferenças entre o Censo Agropecuário (CA) e o Censo Demográfico (CD), no período 1940-80.

os autores comentam que levando em consideração as discrepâncias conceituais e as modificações de critérios através do tempo, "grande parte das divergências entre o CA e o CD resumem-se ao tratamento diferenciado dado às forças de trabalho secundária - mulheres e crianças de até 15 anos, especialmente a categoria de trabalhadores familiares não remunerados. A definição do CA é muito menos restritiva e, portanto, a força de trabalho secundária ocupa um papel muito mais importante nesses dados que nos do CD" (MARTINE e ARIAS, 1987, p.58). 
As análises sobre o mercado de trabalho rural, na primeira metade da década de 80 em relação ao observado na década de 70, revelaram alterações na evolução e na composição do pessoal ocupado.

A análise dos dados dos Censos Agropecuários de 1975, 1980 e 1985 mostrou que no qüinqüênio 1975-80 o número de pessoas ocupadas na agropecuária cresceu apenas $4 q$ e no qüinqüênio subsequente a expansão foi de $11 \%$. Em termos absolutos, o incremento do pessoal ocupado, que no período 1975-80 foi de pouco mais de 818 mil pessoas, atingiu mais de 2 milhões de pessoas entre 1980 e 1985 .

comentários sobre o mercado de trabalho rural neste período estão nos trabalhos de MUELLER (1987), GRAZIANO DA SILVA (1987), MARTINE (1987) e AGUIRRE e BACHA $(1989 a, b)$.

MUELLER (1987, p.37), ao analisar os dados da Sinopse do Censo Agropecuário de 1985, comenta que os novos pequenos estabelecimentos tiveram papel importante na absorção do incremento de mão-de-obra rural, ocorrida no período $1980-85$.

Para MUELLER (1987, p.36-37), não foram criadas em grande número, no período de 1980 a 1985, alternativas de ocupação em atividades da agricultura comercial no Nordeste, fazendo com que a "mão-de-obra disponível tivesse que se localizar em pequenas unidades agrícolas, desenvolvendo basicamente produção de subsistência. Ademais, foram os minifúndios que absorveram grande parte do incremento do pessoal ocupado em atividades agropecuárias."

GRAZIANO DA SILVA (1987, p.60), por sua vez, baseado na Sinopse do Censo Agropecuário de 1985, argumenta 
que ao se "confirmarem as hipóteses de minifundização e o crescimento apenas das categorias mão-de-obra familiar e dos assalariados temporários, esse aumento do número de pessoas ocupadas em 1985 pode indicar exatamente o contrário do que aparentemente mostram esses dados preliminares por nós analisados até o momento. ou seja, podemos concluir que o que aumentou não foi o nível de emprego, mas a subocupação e o subemprego no campo, nessa primeira metade da década dos oitenta."

MARTINE (1987), ao analisar os dados da sinopse do Censo Agropecuário de 1985, no que se refere à evolução do pessoal ocupado, registra em seu trabalho as seguintes conclusões:

1. o crescimento do pessoal ocupado não se associa necessariamente ao crescimento da produção ou da produtividade.

2. a relação entre crescimento da área total e aumento do pessoal ocupado não é linear.

3. verificou-se a relação inversa entre pessoal ocupado e tamanho do estabelecimento: $65 \%$ do pessoal ocupado trabalha em lavouras de até 10 hectares e $84 \%$ em lavouras de até 50 hectares.

"Embora as informações que permitiriam comprovar a hipótese ainda inexistam" - comenta MARTINE (1987, p.79) ", "é muito provável que grande parte desse aumento do pessoal ocupado esteja refletindo um crescimento entre os familiares não-remunerados de pequenos produtores."

4. possível rejuvenescência da parceria, de modo que esta "reprodução do setor informal rural, tenha contribuido para a sobrevivência de uma parcela significativa de trabalhadores repelidos das cidades pela crise econômica" (MARTINE, 1987, p.81). 
Utilizando os dados das PNADs (Pesquisa Nacional por Amostra de Domicilios), AGUIRRE e BACHA (1989a) evidenciaram que as pessoas ocupadas no setor agropecuário do Brasil apresentaram uma tendência decrescente de 1976 até 1983, seguida de elevações em 1984 e 1985 e novas reduções em 1986 e 1987. Contudo, a análise do volume total de emprego rural por regiões revelou-se distinta.

$$
\text { Verificou-se ainda, para o Brasil e suas }
$$
macrorregiões, no período 1976-87, a tendência do avanço das relações de trabalho assalariado: "esses dados evidenciam a elevação da importância dos empregados e a redução da importância dos conta-próprias e dos não remunerados" (1989a, p.12).

\section{Em outro trabalho, AGUIRRE e BACHA (1989b)}

fizeram a decomposição da taxa de crescimento do produto interno bruto a custo de fatores da agropecuária e constataram que entre 1980 e 1985 os preços contribuiram negativamente para a elevação do produto, que passou a depender principalmente do aumento da produtividade da mão-de-obra (que respondeu por $43 \%$ do aumento do produto) e do aumento da relação homem/área (que respondeu por 52,1\% do aumento do produto).

Segundo AGUIRRE e BACHA (1989b, p.572) "na década de 80 o padrão de desenvolvimento da agricultura foi alterado, não ocorrendo o mesmo ritmo de crescimento na utilização de insumos modernos" (verificado na década de 70). "A expansão da área também foi menor. Não obstante, a produção cresceu significativamente".

Os autores citam dois outros fatores que contribuíram para a modificação do perfil da agricultura: o maior "fechamento" da fronteira agrícola externa e a crise da economia brasileira. 
Para AGUIRRE e BACHA o aumento da produtividade do trabalho, no caso brasileiro, na década dos oitenta, "não pode ser buscado na incorporação de novas áreas" (AGUIRRE e BACHA, 1989b, p.573), contudo, "parece estar ligado, por um lado, às mudanças no tipo de fatores de produção em utilização, e por outro, às novas formas de organização do trabalho na atividade agrícola" (AGUIRRE e BACHA, 1989a, p.35).

"As evidências levantadas" - comentam AGUIRRE e BACHA (1989a, p.35-36) -, "apontam no sentido de uma maior utilização do trabalhador permanente em relação ao eventual. Existe uma correlação positiva entre o aumento da produtividade do trabalho e a maior utilização do trabalho permanente".

Contudo, AGUIRRE e BACHA (1989a) declaram a necessidade de mais investigações a este respeito, para uma melhor caracterização do tipo de emprego que vem sendo gerado no novo padrão de desenvolvimento agrícola.

Ao confrontar os apontamentos de AGUIRRE e BACHA (1989a,b), baseados na análise dos dados das PNADs, com as observações de MUELLER (1987), GRAZIANO DA SILVA (1987) e MARTINE (1987), a respeito dos dados do Censo Agropecuário de 1985, verifica-se uma clara discrepância nas suas conclusões.

Em resumo, as principais diferenças são:

1. AGUIRRE e BACHA (1989a) verificaram para o Brasil e suas macrorregiões a tendência do avanço dos empregados relativamente à redução dos conta-próprias e dos não remunerados.

MUELLER (1987), GRAZIANO DA SILVA (1987) e MARTINE (1987) assinalam o crescimento da mão-de-obra 
familiar e da parceria nas regiões mais pobres, sobretudo o Nordeste.

2. AGUIRRE e BACHA (1989b) apontam uma correlação positiva entre aumento da produtividade do trabalho $e$ a maior utilização do trabalho permanente; e ainda, a contribuição da produtividade do trabalho no crescimento do produto agrícola.

MUELLER (1987) verificou que não foram criadas em grande número, no período de 1980 a 1985, alternativas em atividades da agricultura comercial, fazendo com que a mão-de-obra disponível tivesse que se localizar em pequenas unidades agricolas, desenvolvendo basicamente a produção de subsistência.

GRAZIANO DA SILVA (1987) levantou a suspeita de que o aumento das pessoas ditas ocupadas na primeira metade da década dos oitenta significou, em sua grande maioria, um crescimento do subemprego e da subocupação no campo.

MARTINE (1987), ao analisar os dados do Censo de 1985, constatou que o crescimento do pessoal ocupado não se associa necessariamente ao crescimento da produção ou da produtividade.

\subsection{Objetivo}

\subsubsection{Objetivo geral}

Esses fatos nos mostram que não sabemos com precisão qual foi o comportamento do mercado de trabalho na agricultura brasileira na década de 80: o crescimento das pessoas ocupadas, no período 1980-85, de acordo com os dados dos censos Agropecuários, foi realmente uma volta à 
agricultura de subsistência? o que se gerou foi subocupação e subemprego no campo?

o objetivo desse trabalho é analisar a evolução do mercado de trabalho rural na década de 80, explicando as divergências acima citadas. Para isso, fazemos uso de mais informações do que as existentes no momento da execução daqueles trabalhos.

\subsubsection{Objetivos específicos}

Pretende-se com este trabalho analisar:

1 - a evolução e a composição do total de pessoas ocupadas no setor agropecuário na década de 80 , segundo os Censos Agropecuários e as PNADs, a nivel de estados;

2- a evolução da produtividade da mão-de-obra rural; e 3- o comportamento dos salários nos setores urbano e rural.

ocupadas e a composição da mão-de-obra rural, procuramos saber se as divergências entre MUELLER (1987), GRAZIANO DA SILVA (1987), MARTINE (1987) e AGUIRRE e BACHA (1989a,b) devem-se ao uso de fontes de dados diferentes ou a outros fatores.

Porém, a simples análise dos dados referentes à evolução e à composição da mão-de-obra rural, a nosso ver, não bastam para averiguar se o crescimento das pessoas ocupadas no setor agropecuário, no primeiro qüinqüênio da década de 80, significou na sua maioria um crescimento do subemprego e da subocupação no campo.

Faz-se necessário a análise de outros dados que possam ajudar a evidenciar esse fato. Utilizamos, para isso, a análise da produtividade do trabalho no setor 
agropecuário e a análise do comportamento dos salários nos setores rural e urbano.

\subsection{Hipóteses}

1. A respeito da evolução do total de pessoas ocupadas no setor agrícola, nossa hipótese é que as diferenças metodológicas explicam, em grande parte, a divergência entre os valores do censo Agropecuário e da Pesquisa Nacional por Amostra de Domicilios.

2. Ao analisar a composição da mão-de-obra rural, com os dados das PNADs, AGUIRRE e BACHA (1989a) verificaram para $\circ$ Brasil e suas macrorregiões, no período 1976-87, uma tendência de avanço dos empregados e redução dos não remunerados. A nossa hipótese é que - existindo diferentes padrões de desenvolvimento da agricultura nos estados brasileiros - este comportamento da composição da mão-de-obra não é observado em todos os estados.

3. DIAS (1989a) destacou que houve aumento da taxa de crescimento do pessoal ocupado no setor produtivo agrícola, no período 1980-85, juntamente com aumento da produtividade do trabalho.

GASQUES e VILLA VERDE (1990) verificaram que o aumento do pessoal ocupado na região Nordeste teve papel decisivo na expansão do produto, no período 1981-88.

o trabalho de REZENDE (1989a) ressalta o melhor desempenho da produção de mercado interno da agricultura nordestina após 1983. Houve expansão da área com feijão e aumento do rendimento físico do milho e do arroz.

Ao considerarmos as constatações desses três 
trabalhos, a nossa hipótese é que não foi predominante a participação de menores de 14 anos e de mulheres no aumento de pessoas ocupadas (ao menos na região Nordeste, no período 1980-85). A constatação desta hipótese compromete, em parte, as conclusões de MUELLER (1987), GRAZIANO DA SILVA (1987) e MARTINE (1987) quanto ao aumento do subemprego e da subocupação no campo, no período 1980-85. 


\section{METODOLOGIA E FONTES DE DADOS}

Para realizar a nossa análise é necessário, em primeiro lugar, discutir as fontes de dados (Censos Agropecuários e Pesquisas Nacionais por Amostra de Domicilios), procurando constatar se suas diferenças metodológicas explicam os resultados distintos encontrados nos trabalhos de MUELLER (1987), GRAZIANO DA SILVA (1987), MARTINE (1987) e AGUIRRE e BACHA (1989a,b). Para isso, utilizamos o trabalho de MARTINE e ARIAS (1987), seguindo sua metodologia para compararmos o Censo Agropecuário (CA) e a Pesquisa Nacional por Amostra de Domicílios (PNAD).

Discutimos também neste item os procedimentos a serem adotados para analisar o comportamento da mão-de-obra, para calcular sua produtividade e o seu salário.

\subsection{Discussão sobre as Fontes de Dados}

$$
\text { Segundo MARTINE e ARIAS (1987) as eventuais }
$$
discrepâncias entre as diversas fontes de dados decorrem, em boa medida, da própria natureza dos levantamentos e das suas propostas analíticas; o que, evidentemente, limita bastante as possibilidades de compatibilização de resultados entre as diferentes fontes de dados disponíveis, e mesmo entre dois anos da mesma fonte quando se implanta uma mudança metodológica significativa. 
As informações apresentadas pelos censos Agropecuários (CAs) e pelas Pesquisas Nacionais por Amostra de Domicílios (PNADs) diferem em alguns aspectos.

Em primeiro lugar, como verificamos a seguir, os valores absolutos do número de pessoas ocupadas são diferentes (conforme a tabela $1, \mathrm{p} .30$ ).

Um outro ponto ressaltado por AGUIRRE (1989) é que os levantamentos realizados pelo CA e pela PNAD possuem naturezas diversas, que recomendam certa cautela em sua comparação. O levantamento do $\mathrm{CA}$ é feito a nível de estabelecimento (sendo o questionário respondido pelo empregador); enquanto que o levantamento da PNAD é feito tomando-se como unidade de amostragem os domicílios (sendo - questionário respondido pelas pessoas empregadas ou por outros moradores do domicilio).

E ainda, os CAs possuem fragilidades especificas para a quantificação do tempo de trabalho dispendido na produção agropecuária. Entre outras, a principal é referente à não quantificação das horas diárias trabalhadas.

MARTINE e ARIAS (1987) fizeram um estudo onde sintetizaram os resultados de trabalhos que analisaram as características e limitações quanto à comparação de diferentes fontes de dados. Faremos uma sintese desse estudo no que se refere às características do censo Agropecuário e da Pesquisa Nacional por Amostra de Domicilios.

\subsubsection{O Censo Agropecuário (CA)}

1 - esse levantamento tem por base a unidade estabelecimento, onde se processa uma exploração 
agropecuária, excluindo tanto propriedades inexploradas, como quintais de residências e hortas domésticas.

2- esses levantamentos foram realizados e estão disponiveis para os anos de 1920, 1940, 1950, 1960, 1970, 1975, 1980 e 1985 .

3- a partir do Censo Agropecuário de 1970 foram recenseadas todas as pessoas, com ou sem remuneração, homens e mulheres de qualquer idade, que na data do Censo, encontravam-se executando serviços ligados às atividades do estabelecimento;

4- a data de referência para os Censos de 1970, 1975, 1980 e 1985 foi 31 de dezembro;

5- a partir do $C A$ de 1975, as parcelas não-confinantes exploradas pelo mesmo produtor - desde que localizadas no mesmo setor e utilizando os mesmos recursos humanos e técnicos - são consideradas como um único estabelecimento. Eliminou-se, assim, uma fonte de duplicação de trabalhadores (permanentes) no dia do Censo.

6- as pessoas ocupadas computadas pelos CAs de 1970, 1975, 1980 e 1985, tendem a ser sobreestimativas dos verdadeiros valores, porque contam duas ou mais vezes os pequenos produtores e seus familiares que prestam serviços remunerados fora de sua propriedade.

7- os trabalhadores temporários são contabilizados de duas maneiras. Na tabela pessoal ocupado por categoria temos o total de trabalhadores temporários empregados no dia 31 de dezembro. Na tabela empregados temporários por meses de emprego temos o número máximo de trabalhadores temporários 
empregados cada mês.

8- nos CAs de 1970, 1975, 1980 e 1985 o pessoal ocupado é distribuído segundo trabalhem em estabelecimentos administrados pelos proprietários, arrendatários, parceiros e ocupantes e são distribuidos nas categorias responsável e membros não-remunerados da familia, empregados permanentes, empregados temporários, parceiros e outra condição.

Ao se comparar as informações sobre o total de pessoas ocupadas do Censo Agropecuário com os dados de outras fontes, deve-se ter presente que o $\mathrm{CA}$ :

1 - não impõe limite de idade para os ocupados;

2- não restringe a presença de familiares não-remunerados em função de horas ou dias trabalhados;

3- não limita a condição de ocupado em função do caráter principal ou secundário da atividade exercida na agropecuária (exceto em 1950);

4 - apesar da mesma denominação de algumas categorias, o seu conteúdo é diferente das categorias utilizadas em outras fontes. Assim, o CA incorpora na condição de empregados ou parceiros, os trabalhadores familiares não-remunerados que ajudam, respectivamente, a empregados ou parceiros;

5- exclui a atividade extrativa animal (caça e pesca) habitualmente englobada no setor agrícola (como faz o Censo Demográfico e a PNAD);

6 - omite o emprego por empreitada(3).

(3) Pode ser estimado com base nas despesas com empreitada, como será visto a seguir na metodologia de cálculo do valor agregado por equivalente-homem (item 2.3.1). 


\subsubsection{A Pesquisa Nacional por Amostra de Domicilios (PNAD)}

1 - são pesquisas realizadas entre os períodos dos censos Demográficos (CD), porém seus resultados não são comparáveis com estes últimos. Isto porque as PNADs questionam o número de pessoas empregadas na semana de referência (semana que antecede o início de levantamento) e - $C D$ questiona o número de pessoas empregadas no ano de referência.

2- as PNADS (assim como os CD) quantificam como pessoas ocupadas apenas as pessoas empregadas de 10 anos ou mais e os não-remunerados que trabalham 15 horas ou mais por semana.

Assim, os trabalhadores com menos de 10 anos e os não remunerados que trabalham menos de 15 horas por semana não são quantificados pelas PNADs, mas o são pelo censo Agropecuário. Desse modo, deve-se esperar um número de pessoas ocupadas na agropecuária segundo a PNAD inferior ao levantado pelo CA.

3- os dados anuais das PNADs são comparáveis entre si desde que as semanas de referência das várias PNADs sejam próximas.

Relacionamos as semanas de referência das PNADs que serão utilizadas em nosso estudo(4): 22 a $28 / 11 / 76 ; 24$ a $30 / 10 / 77 ; 22$ a $28 / 10 / 78 ; 22$ a $28 / 10 / 79 ; 08$ a $14 / 11 / 81$; $19 / 09$ a $11 / 12 / 82 ; 25 / 09$ a $01 / 10 / 83 ; 23$ a $29 / 09 / 84 ; 22$ a $28 / 09 / 85 ; 28 / 09$ a $04 / 10 / 86 ; 27 / 09$ a $03 / 10 / 87 ; 25 / 09$ a $01 / 10 / 88 ; 24$ a $30 / 09 / 89$.

(4) O período de referência para 1982 é maior do que uma semana. 
4 - a cobertura geográfica do levantamento variou ao longo do tempo e ainda não atinge os 100\%. Este fato impõe restrições na comparação de totais nacionais através do tempo.

5 - os dados das pessoas ocupadas no setor agropecuário da região Norte refere-se apenas aos residentes nas áreas urbanas, não sendo levantados os residentes na zona rural;

6 - o pessoal ocupado levantado pelas PNADs é desagregado em: empregados, conta-próprias (até 1977 eram denominados autônomos), empregadores e não remunerados.

AGUIRRE e BACHA (1989a, p.48) constataram "que os parceiros do CA são contabilizados pelas pNADs parte como empregados, parte como conta-própria e outra parte como empregador".

com essas considerações podemos, mais seguramente, analisar e comparar os dados dessas duas fontes de informação.

observa-se (conforme a tabela 1) que $\circ$ censo Agropecuário (CA) apresenta um nível bem mais elevado de pessoas ocupadas no setor agropecuário do que a pesquisa Nacional por Amostra de Domicilio (PNAD) no período analisado $(1975-86)$.

Parte da explicação para essa divergência pode ser encontrada nas diretrizes metodológicas utilizadas para a realização de cada um destes levantamentos.

como vimos, o nível mais elevado de pessoas ocupadas no CA é, a principio, coerente com as diferenças na definição básica da variável mensurada. Recordamos que o CA não estabelece limite de idade nem limite mínimo de horas trabalhadas para registrar uma pessoa ocupada. Além 
disso, esta se refere tanto à ocupação principal como à secundária. Ao contrário, a PNAD só inclui pessoas de 10 anos ou mais, impondo um limite mínimo de 15 horas de trabalho por semana para trabalhadores familiares não remunerados e incluindo apenas a ocupação principal ou habitual.

Tabela 1. Evolução do total de pessoas ocupadas na agropecuária, segundo os censos Agropecuários e as PNADs - Brasil, 1975-86.

\begin{tabular}{lccc}
\hline ano & $\begin{array}{c}\text { Censo Agropecuário } \\
\text { pessoas ocupadas } \\
\text { total (A) }\end{array}$ & $\begin{array}{c}\text { PNAD } \\
\text { pessoas ocupadas } \\
\text { total (B) }\end{array}$ & $\begin{array}{c}\text { Relação } \\
(B) /(A)\end{array}$ \\
\hline 1975 & 20.345 .676 & 14.328 .219 & 0,70 \\
\hline 1976 & 21.163 .735 & 14.361 .653 & 0,68 \\
\hline 1979 & & 13.299 .837 & 0,63 \\
1980 & & 14.974 .441 & 0,65 \\
\hline 1981 & 23.543 .208 & 15.190 .393 & \\
1985 & & 14.330 .630 & \\
1986 & & &
\end{tabular}

Fonte: IBGE - Censo Agropecuário e PNAD

(1) buscou-se a relação (B)/(A) nos anos mais próximos dessas duas fontes.

MARTINE e ARIAS (1987), ao analisar as discrepâncias conceituais entre os Censos Demográfico e Agropecuário, conclurram que estas são particularmente significativas para a categoria familiares não remunerados, desaparecendo quando se compatibiliza a situação dessa categoria nas duas fontes.

Tendo em vista essa consideração, comparamos as informações do $\mathrm{CA}$ e da PNAD quanto a quantidade de homens, 
por um lado, e a de mulheres e crianças por um outro(5) (veja as tabelas 2 e 3 , respectivamente).

Tabela 2. Evolução do total de homens na agropecuária, segundo os Censos Agropecuários e as PNADs Brasil, 1975-86.

\begin{tabular}{|c|c|c|c|}
\hline ano & $\begin{array}{c}\text { Censo Agropecuário } \\
\text { homens maiores } \\
\text { de } 14 \text { anos (A) }\end{array}$ & $\begin{array}{l}\text { PNAD } \\
\text { homens maiores } \\
\text { de } 10 \text { anos (B) }\end{array}$ & $\begin{array}{l}\text { Relação1 } \\
\text { (B) /(A) }\end{array}$ \\
\hline $\begin{array}{l}1975 \\
1976\end{array}$ & 10.399 .289 & 11.267 .425 & 1,08 \\
\hline $\begin{array}{l}1979 \\
1980 \\
1981\end{array}$ & 12.030 .455 & $\begin{array}{l}10.965 .651 \\
10.494 .798\end{array}$ & $\begin{array}{l}0,91 \\
0,87\end{array}$ \\
\hline $\begin{array}{l}1984 \\
1985 \\
1986\end{array}$ & 13.194 .000 & $\begin{array}{l}11.812 .701 \\
11.913 .894 \\
11.567 .224\end{array}$ & 0,90 \\
\hline
\end{tabular}

Fonte: IBGE - Censo Agropecuário e PNAD

(1) buscou-se a relação (B)/(A) nos anos mais próximos dessas duas fontes.

Ao analisarmos os dados do Censo Agropecuário e da PNAD, nos diversos grupos, verificamos que a divergência maior se encontra na quantidade de mulheres e crianças, enquanto que a quantidade de homens nas duas fontes de dados se mostram mais próximas. Diante dessa evidência, podemos argumentar que, embora sejam distintos os dados referentes ao número de pessoas ocupadas no $\mathrm{CA}$ e na PNAD, a divergência é menor quando nos restringimos ao grupo de homens.

Aparentemente a quantidade de homens da PNAD

(5) Enquanto os dados do Censo Agropecuário, referente a pessoa ocupada na agropecuáría brasileira, estão disponf́veis segundo o sexo e a idade, não encontramos na PNAD os dados dispostos para essa atividade econômica em igual nível de detalhamento lexiste apenas a desagregação por sexol. o que limita em parte a profundidade no estudo. 
deveria ser maior que a quantidade do $C A$, uma vez que informam o número destes a partir dos 10 anos, enquanto que - CA a partir dos 14 anos. Recordamos, porém, que o CA não restringe a presença de familiares não remunerados em função das horas trabalhadas.

Tabela 3. Evolução do total de mulheres e crianças, segundo os Censos Agropecuários e as PNADs - Brasil, $1975-86$.

\begin{tabular}{|c|c|c|c|c|}
\hline \multirow{2}{*}{ ano } & \multicolumn{2}{|c|}{ Censo Agropecuário } & PNAD & \multirow{2}{*}{$\begin{array}{c}\text { Relação } \\
(B) /(A)\end{array}$} \\
\hline & $\begin{array}{c}\text { mulheres maiores } \\
\text { de } 14 \text { anos (A) }\end{array}$ & $\begin{array}{c}\text { menores } \\
\text { de } 14 \text { anos }\end{array}$ & $\begin{array}{l}\text { mulheres maiores } \\
\text { de } 10 \text { anos (B) }\end{array}$ & \\
\hline $\begin{array}{l}1975 \\
1976\end{array}$ & 5.556 .189 & 4.390 .214 & 3.060 .794 & 0,55 \\
\hline $\begin{array}{l}1979 \\
1980 \\
1981\end{array}$ & 5.393 .097 & 3.740 .183 & $\begin{array}{l}3.396 .002 \\
2.805 .039\end{array}$ & $\begin{array}{l}0.63 \\
0.52\end{array}$ \\
\hline $\begin{array}{l}1984 \\
1985 \\
1986\end{array}$ & 6.216 .772 & 4.132 .436 & $\begin{array}{l}3.161 .740 \\
3.276 .499 \\
2.763 .406\end{array}$ & 0,53 \\
\hline
\end{tabular}

Fonte: IBGE - Censo Agropecuário e PNAD

(1) buscou-se a relação (B)/(A) nos anos mais próximos dessas duas fontes para o grupo de mulheres.

As informações da PNAD sobre a mão-de-obra empregada no setor agropecuário das regiões Norte e centro- Oeste - este último apenas na década de 70 - não são adequadas, pois se referem apenas aos trabalhadores residentes nas áreas urbanas, não sendo levantados os residentes na zona rural.

Tendo isso em conta, refizemos os cálculos 
anteriores, excluindo essas duas regiões(6).

Ao trabalharmos somente com os dados das regiões Nordeste, Sudeste e sul (excluindo as regiões Norte e Centro-oeste), verificamos que há maior aproximação dos dados nas duas fontes: $C A$ e PNAD. Pode-se observar (tabelas 4,5 e 6) que esse fato ocorre genericamente, tanto no total de pessoas ocupadas na agropecuária, como parcialmente, na quantidade de homens, mulheres e crianças; - que não exclui, mas apenas minimiza as divergências anteriormente analisadas.

Tabela 4. Evolução do total de pessoas ocupadas na agropecuária das regiões: Nordeste, sudeste e Sul, $1975-86$.

\begin{tabular}{lccc}
\hline $\begin{array}{c}\text { Censo Agropecuário } \\
\text { pessoas ocupadas } \\
\text { total (A) }\end{array}$ & $\begin{array}{c}\text { PNAD } \\
\text { pessoas ocupadas } \\
\text { total (B) }\end{array}$ & $\begin{array}{c}\text { Relação1 } \\
(\mathrm{B}) /(\mathrm{A})\end{array}$ \\
\hline 1975 & 17.716 .119 & 14.117 .224 & 0,80 \\
\hline 1976 & & 14.148 .337 & 0,78 \\
\hline 1979 & 18.037 .194 & 12.358 .477 & 0,69 \\
1980 & & 13.923 .850 & 0,72 \\
\hline 1984 & & 14.111 .908 & \\
1985 & 19.670 .137 & 13.291 .466 & \\
\hline
\end{tabular}

Fonte: IBGE - Censo Agropecuário e PNAD

(1) buscou-se a relação (B)/(A) nos anos mais próximos dessas duas fontes.

(6) Encontra-se no APÊNDICE 1 - tabelas 1.1 a 1.4 - a análise discriminada para cada uma das regiões: Nordeste, Sudeste e Sul. 
Tabela 5. Evolução do total de homens na agropecuária das regiões: Nordeste, sudeste e sul, 1975-86.

\begin{tabular}{lccc}
\hline ano & $\begin{array}{c}\text { Censo Agropecuário } \\
\text { homens maiores } \\
\text { de } 14 \text { anos }(\mathrm{A})\end{array}$ & $\begin{array}{c}\text { PNAD } \\
\text { homens maiores } \\
\text { de anos }(\mathrm{B})\end{array}$ & $\begin{array}{c}\text { Relaçãol } \\
(\mathrm{B}) /(\mathrm{A})\end{array}$ \\
\hline 1975 & 9.113 .763 & 11.066 .758 & 1,21 \\
\hline 1976 & 10.443 .208 & 10.764 .502 & 1,03 \\
\hline 1979 & & 9.603 .551 & 0,92 \\
1980 & & 10.821 .928 & 0.97 \\
\hline 1981 & 11.256 .107 & 10.905 .704 & \\
\hline 1985 & & 10.589 .614 & \\
\hline
\end{tabular}

Fonte: IBGE - Censo Agropecuário e PNAD

(1) buscou-se a relação (B)/(A) nos anos mais próximos dessas duas fontes.

Tabela 6. Evolução do total de mulheres e crianças das regiões: Nordeste, Sudeste e Sul, 1975-86.

\begin{tabular}{|c|c|c|c|c|}
\hline \multirow{2}{*}{ ano } & \multicolumn{2}{|c|}{ Censo Agropecuário } & PNAD & \multirow{2}{*}{$\begin{array}{l}\text { Relação } \\
(\mathrm{B}) /(\mathrm{A})\end{array}$} \\
\hline & $\begin{array}{l}\text { mulheres maiores } \\
\text { de } 14 \text { anos (A) }\end{array}$ & $\begin{array}{c}\text { menores } \\
\text { de } 14 \text { anos }\end{array}$ & $\begin{array}{c}\text { mulheres maiores } \\
\text { de } 10 \text { anos (B) }\end{array}$ & \\
\hline $\begin{array}{l}1975 \\
1976\end{array}$ & 4.886 .827 & 3.715 .529 & 3.050 .466 & 0,62 \\
\hline $\begin{array}{l}1979 \\
1980 \\
1981\end{array}$ & 4.629 .634 & 2.964 .352 & $\begin{array}{l}3.383 .835 \\
2.754 .926\end{array}$ & $\begin{array}{l}0,73 \\
0,60\end{array}$ \\
\hline $\begin{array}{l}1984 \\
1985 \\
1986\end{array}$ & 5.259 .247 & 3.154 .778 & $\begin{array}{l}3.101 .922 \\
3.206 .204 \\
2.701 .852\end{array}$ & 0,61 \\
\hline
\end{tabular}

Fonte: IBGE - Censo Agropecuário e PNAD

(1) buscou-se a relação (B)/(A) nos anos mais próximos dessas duas fontes para o grupo de mulheres. 
o nosso interesse é verificar se os dados sobre a composição da mão-de-obra, segundo o sexo e a idade, mostrariam a mesma tendência de comportamento nas duas fontes (CA e PNAD), 0 que explicaria parte das discrepâncias entre os trabalhos de MARTINE (1987), MUELLER (1987), GRAZIANO DA SILVA (1987) e AGUIRRE e BACHA (1989a). Porém, os dados da PNAD estão disponiveis apenas para a categoria empregados, e tão somente quanto ao sexo.

Diante dessa limitação, realizamos apenas a análise da categoria empregados.

Verifica-se, ao se confrontar as tabelas 7 e 1 , que a divergência entre as duas fontes de informações é amenizada quando se compara tão somente os dados dentro da categoria empregados do CA e da PNAD.

Tabela 7. Evolução do total de empregados na agropecuária, segundo os Censos Agropecuários e as PNADs Brasil, 1975-86.

\begin{tabular}{lccc}
\hline ano & $\begin{array}{c}\text { Censo Agropecuário } \\
\text { empregados } \\
\text { total (A) }\end{array}$ & $\begin{array}{c}\text { PNAD } \\
\text { empregados } \\
\text { total (B) }\end{array}$ & $\begin{array}{c}\text { Relaçãol } \\
(\mathrm{B}) /(\mathrm{A})\end{array}$ \\
\hline 1975 & 3.249 .962 & 4.640 .155 & 1,43 \\
\hline 1976 & 4.938 .534 & 4.821 .979 & 0,98 \\
1979 & & 4.874 .250 & 0,99 \\
1980 & 4.959 .097 & 5.800 .704 & 1,17 \\
\hline 1981 & & 5.796 .585 & \\
\hline 1985 & & 5.621 .051 & \\
\hline
\end{tabular}

Fonte: IBGE - Censo Agropecuário e PNAD

(1) buscou-se a relação (B)/(A) nos anos mais próximos dessas duas fontes. 
A divergência entre os dados do censo Agropecuário e da PNAD diminuiu, especialmente na quantidade de mulheres, muito embora tenha aumentado a diferença no número de homens (confrontar as tabelas 8 e 9 com 2 e 3) (7).

Observa-se também que a quantidade de empregados levantada pela PNAD - tanto na análise global, como nas análises isoladas dos grupos homens e mulheres - é superior à levantada pelo CA.

Essas divergências podem ser em parte explicadas pelas diferenças metodológicas no levantamento dos dados dessas duas fontes:

No que se refere aos empregados, cabe-nos ressaltar que as duas fontes incluem nesta categoria os empregados permanentes e temporários (ou volantes) (8).

No entanto, divergem, primeiramente, quanto a inclusão ou não dos membros da familia que ajudem os empregados na execução da sua tarefa. O CA inclui os membros da família do empregado e a PNAD não os inclui como empregados (eles são incluídos como não remunerados).

$\mathrm{Na}$ análise acima, $\circ \mathrm{CA}$ inclui os menores de 10 anos, enquanto que a PNAD só inclui como pessoas ocupadas aquelas acima de 10 anos.

Finalmente, diferem no fato de que, a PNAD engloba nesta categoria o parceiro empregado e os membros da familia que o auxiliavam na atividade. O CA divulga separadamente a categoria parceiro empregado.

(7) Encontra-se no APENDICE 1 - tabelas 1.5 e 1.6 - a análise com os dados originais sem distribuição dos menores de 14 anos nos grupos de homens e de mulheres.

(8) Os dados do CA sobre empregados permanentes e temporários se encontram divulgados separadamente, por isso, englobamos ambos como "empregados", tal como os dados da PNAD. 
Tabela 8. Evolução do total de homens na categoria empregados na agropecuária, segundo os Censos Agropecuários e as PNADs - Brasil, 1975-86.

\begin{tabular}{lccc}
\hline ano & $\begin{array}{c}\text { Censo Agropecuário } \\
\text { homens } \\
\text { totali (A) }\end{array}$ & $\begin{array}{c}\text { PNAD } \\
\text { homens maiores } \\
\text { de } 10 \text { anos (B) }\end{array}$ & $\begin{array}{c}\text { Relação2 } \\
(B) /(A)\end{array}$ \\
\hline 1975 & 2.811 .591 & 4.008 .686 & 1,43 \\
\hline 1976 & 4.291 .762 & 4.129 .130 & 0,96 \\
1979 & & 4.206 .380 & 0,98 \\
1980 & 4.280 .039 & 5.005 .775 & 1,16 \\
1981 & & 4.970 .808 & \\
1984 & 4.902 .645 &
\end{tabular}

Fonte: IBGE - Censo Agropecuário e PNAD

(1) distribuiu-se os menores de 14 anos do CA por sexo (grupo de homens e de mulheres), admitindo-se a mesma proporção de homens e de mulheres maiores de 14 anos desta categoria (empregados).

(2) buscou-se a relação (B)/(A) nos anos mais próximos dessas duas fontes.

Tabela 9. Evolução do total de mulheres na categoria empregados na agropecuária, segundo os Censos Agropecuários e as PNADs - Brasil, 1975-86.

\begin{tabular}{lccc}
\hline ano & $\begin{array}{c}\text { Censo Agropecuário } \\
\text { mulheres } \\
\text { totali (A) }\end{array}$ & $\begin{array}{c}\text { PNAD } \\
\text { mulheres maiores } \\
\text { de } 10 \text { anos }(B)\end{array}$ & $\begin{array}{c}\text { Relação } \\
(B) /(A)\end{array}$ \\
\hline 1975 & 438.371 & 631.469 & 1,44 \\
\hline 1976 & 646.772 & 692.849 & 1,07 \\
1979 & & 667.870 & 1,03 \\
1980 & & 794.929 & 1,22 \\
1981 & 679.058 & 825.777 & \\
\hline 1984 & & 718.406 & \\
1986 & & & \\
\hline
\end{tabular}

Fonte: IBGE - Censo Agropecuário e PNAD (1) e (2) idem tabela 8 
Elaboramos também, para a categoria empregados, a análise restrita ao conjunto das regiões Nordeste, Sudeste e Sul, excluindo as regiões Norte e Centro-Oeste, por razões já citadas. Os resultados podem ser contemplados nas tabelas 10,11 e 12 a seguir (9).

Tabela 10. Evolução do total de empregados na agropecuária das regiões: Nordeste, Sudeste e Sul, 1975-86.

\begin{tabular}{lccc}
\hline ano & $\begin{array}{c}\text { Censo Agropecuário } \\
\text { empregados } \\
\text { total (A) }\end{array}$ & $\begin{array}{c}\text { PNAD } \\
\text { empregados } \\
\text { total (B) }\end{array}$ & $\begin{array}{c}\text { Relação } \\
(\mathrm{B}) /(\mathrm{A})\end{array}$ \\
\hline 1975 & 2.898 .518 & 4.543 .877 & 1,57 \\
\hline 1976 & 4.340 .143 & 4.709 .641 & 1,09 \\
1979 & & 4.472 .347 & 1,03 \\
1980 & 4.322 .409 & 5.329 .421 & 1,23 \\
1981 & & 5.316 .775 & \\
\hline 1985 & & 5.119 .339 & \\
\hline
\end{tabular}

Fonte: IBGE - Censo Agropecuário e PNAD

(1) buscou-se a relação (B)/(A) nos anos mais próximos dessas duas fontes.

Não encontramos para a categoria empregados a mesma tendência que a análise anterior (página 33). Pelo contrário, ao excluirmos os dados das regiões Norte e Centro-oeste aumentou a divergência entre os dados da PNAD e do CA para a categoria empregados, tanto na análise global, como na análise isolada do grupo de homens e de mulheres.

(9) Encontra-se no APENDICE 1 - tabelas 1.7 a 1.10 - a análise discriminada para cada uma das regiões: Nordeste, Sudeste e SuI. 
Tabela 11. Evolução do total de homens na categoria empregados na agropecuária das regiões: Nordeste, sudeste e sul, 1975-86.

\begin{tabular}{lccc}
\hline ano & $\begin{array}{c}\text { Censo Agropecuário } \\
\text { homens } \\
\text { total1 (A) }\end{array}$ & $\begin{array}{c}\text { PNAD } \\
\text { homens maiores } \\
\text { de } 10 \text { anos (B) }\end{array}$ & $\begin{array}{c}\text { Relação2 } \\
(\mathrm{B}) /(\mathrm{A})\end{array}$ \\
\hline 1975 & 2.495 .302 & 3.915 .929 & 1,57 \\
\hline 1976 & 3.766 .281 & 4.021 .763 & 1,07 \\
1979 & & 3.817 .597 & 1,01 \\
1980 & 3.715 .043 & 4.553 .314 & 1,21 \\
1984 & & 4.509 .316 & \\
1985 & & 4.421 .299 & \\
\hline
\end{tabular}

Fonte: IBGE - Censo Agropecuário e PNAD

(1) distribuiu-se os menores de 14 anos do $C A$ por sexo (grupo de homens e de mulheres), admitindo-se a mesma proporção de homens e de mulheres maiores de 14 anos desta categoria (empregados).

(2) buscou-se a relação (B)/(A) nos anos mais próximos dessas duas fontes.

Tabela 12. Evolução do total de mulheres na categoria empregados na agropecuária das regiões: Nordeste, sudeste e sul, 1975-86.

\begin{tabular}{lccc}
\hline ano & $\begin{array}{c}\text { Censo Agropecuário } \\
\text { mulheres } \\
\text { totali (A) }\end{array}$ & $\begin{array}{c}\text { PNAD } \\
\text { mulheres maiores } \\
\text { de anos }(\mathrm{B})\end{array}$ & $\begin{array}{c}\text { Relaçãoz } \\
(\mathrm{B}) /(\mathrm{A})\end{array}$ \\
\hline 1975 & 403.216 & 627.948 & 1,56 \\
\hline 1976 & & 687.878 & 1,20 \\
1979 & 573.862 & 654.750 & 1,14 \\
1980 & & 776.107 & 1,33 \\
1981 & 607.366 & 807.459 & \\
1985 & & 698.040 & \\
\hline 1986 & & &
\end{tabular}

Fonte: IBGE - Censo Agropecuário e PNAD

(1) e (2) idem tabela 11 
Para uma possivel explicação desse fato, faz-se necessária uma análise isolada dos dados sobre empregados parceiros, empregados permanentes e empregados temporários nas regiões Nordeste, sudeste e sul. Porém, os dados das PNADs, embora levantados separadamente, são divulgados globalmente, o que nos impede avançar nesse estudo.

Muito embora as divergências entre as duas fontes de dados se amenizem - quando se compara somente o grupo de homens (tabela 2), quando se exclui as regiões Norte e centro-oeste (tabelas 4 e 5), e também quando analisamos apenas a categoria dos empregados (tabela 7) -, em nenhum dos casos conseguimos que as relações dos dados da PNAD/dados do CA ficassem próximas de 1 (um).

A partir dessa constatação, prova-se a 1 . hipótese de nossa dissertação e passamos a estudar separadamente os dados levantados pela PNAD e pelo censo Agropecuário a respeito das pessoas ocupadas no setor agrícola.

Analisamos, no terceiro capitulo, a evolução e a composição da mão-de-obra na agricultura segundo os dados levantados pelas PNADs. Nosso intuito é constatar se o resultado encontrado por AGUIRRE e BACHA (1989a) para o Brasil como um todo se verifica para os estados da Federação.

No quarto capitulo analisamos os dados dos censos Agropecuários sobre 0 total de pessoas ocupadas. Verificamos com mais informações (decomposição da mão-de-obra por categoria, por faixa etária e por sexo; produtividade do trabalho e evolução dos salários rural e urbano) se o aumento das pessoas ocupadas no setor agricola brasileiro, na primeira metade da década de 80, foi uma 
volta à agricultura de subsistência, gerando subemprego e subocupação no campo (conforme as conclusões dos trabalhos de MUELLER, 1987; GRAZIANO DA SILVA, 1987 e MARTINE, 1987).

Para isso, descrevemos, a seguir, a metodologia a ser utilizada.

\title{
2.2. Metodologia utilizada para o estudo da evolução e composição da mão-de-obra rural
}

\begin{abstract}
Analisamos através dos dados das PNADs a tendência recente (1976-89) do emprego rural - evolução do total de pessoas ocupadas e composição da mão-de-obra - a nível de Brasil e grandes regiões, decompondo os dados por estados para as regiões Nordeste, sudeste e sul (não serão decompostos para as regiões Norte e Centro-Oeste devido à inadequação dos dados para a área rural destas regiões). Isto não foi realizado no trabalho de AGUIRRE e BACHA (1989a).

Serão calculadas as médias da composição relativa do pessoal ocupado para 4 (quatro) períodos ao longo da série estudada. Este procedimento tem 0 intuito de identificar a existência de diferentes padrões de evolução - conforme o que ocorreu na economia em geral - nos subperiodos assim caracterizados: 1976/79 - crescimento econômico e inflação moderada; 1981/83 - recessão e ajustamento externo; 1984/86 - retomada do crescimento econômico; 1987/89 - crise inflacionária.
\end{abstract}

No capítulo 4 , com os dados dos censos Agropecuários, realizamos a análise das pessoas ocupadas no Brasil, nas macrorregiões e nos estados, no período 1980 - 
-85. Tomamos os estados que mais contribuiram para o aumento da mão-de-obra rural neste período e verificamos em que (quais) categoria(s) esse aumento ocorreu, decompondo a mão-de-obra nas seguintes categorias: Responsável e Membros não Remunerados da Família, Empregado Permanente, Empregado Temporário, Parceiro e outra condição.

Posteriormente, é realizada uma análise por faixa etária, naquela(s) categoria(s) que apresenta(m) maior crescimento de pessoas ocupadas, verificando como isso se refletiu nos grupos: menores de 14 anos, homens maiores de 14 anos e mulheres maiores de 14 anos. Procura-se, com isso, verificar qual grupo teve maior crescimento de ocupação.

\subsection{Metodologia para cálculo da produtividade e análise dos salários}

A análise tão somente dos dados referentes à evolução e composição da mão-de-obra rural não basta para averiguar se 0 incremento das pessoas ocupadas no setor agropecuário brasileiro, no primeiro qüinqüênio da década de 80, significou na sua maioria um crescimento do subemprego e da subocupação no campo.

Desta forma, estudamos o comportamento da produtividade do trabalho na agropecuária e o comportamento dos salários rural e urbano. A análise abrange o Brasil como um todo e os estados que mais contribuiram com o aumento das pessoas naquele período.

Se a produtividade do trabalho em 1985 aumentar em relação à 1980, as conclusões dos trabalhos de GRAzIANO DA SILVA (1987), MUELLER (1987) e MARTINE (1987) - que sugeriram um aumento da subocupação ou do subemprego na 
agricultura brasileira naquele qüinqüênio - estarão comprometidas.

A análise da produtividade abrange os seguintes períodos: $1970-75,1975-80$ e 1980-85.

A ocorrência de uma deteriorização do salário relativo (salário na agricultura/salário mínimo e salário na agricultura/salário de servente) e da produtividade do trabalho na agricultura, no primeiro qüinqüênio da década de 80 , pode indicar que o incremento da mão-de-obra rural, observado naquele período, tenha gerado subemprego e subocupação no setor agrícola.

\subsubsection{Modelos que quantificam as relações entre uso de mão-de-obra, produtividade e produção}

Apresentamos nesse item as várias metodologias já utilizadas para o cálculo da produtividade agrícola no Brasil e ressaltamos a que será utilizada por nós.

A maioria dos trabalhos analisados sobre este tema seguem uma metodologia básica, semelhante à dos trabalhos clássicos sobre desenvolvimento da agricultura(10). Os autores desses últimos procuraram analisar a evolução da produção agrícola em função do aumento (ou diminuição) dos índices de produtividade parcial dos fatores terra e mão-de-obra.

o seguinte modelo matemático tem sido empregado neste tipo de análise:

$$
Y=(Y / A) \cdot(A / N) \cdot N
$$

em que: $\quad Y=$ produção agrícola 


$$
\begin{aligned}
Y / A & =\text { produtividade da terra } \\
A / N & =\text { relação área cultivada por homem } \\
N= & \text { quantidade de mão-de-obra ocupada na produção } \\
& \text { agrícola }
\end{aligned}
$$

Tomando-se o logaritmo neperiano da expressão (1), e derivando a expressão resultante em relação ao tempo, tem-se a seguinte expressão válida para variações infinitesimais:

$$
(\Delta Y) / Y=[\Delta(Y / A)] /(Y / A)+[\Delta(A / N)] /(A / N)+(\Delta N) / N
$$

Através dessa expressão (2) é possível decompor o crescimento da produção agrícola $[\Delta(Y) / Y]$ em três componentes básicos: taxa de crescimento da produtividade da terra $\{[\Delta(Y / A)] /(Y / A)\}$, taxa de crescimento da relação área/homem $\{[\Delta(A / N)] /(A / N)\}$ e taxa de crescimento da mão-de-obra empregada na agricultura $[(\Delta N) / N]$.

Outra forma de analisar a equação (1) é a de transferir o fator mão-de-obra $(N)$ para o primeiro membro da equação, como segue:

$$
Y / N=Y / A \cdot A / N
$$

obtendo assim, as fontes de crescimento da produtividade da mão-de-obra $(Y / N)$.

$$
[\Delta(Y / N)] /(Y / N)=[\Delta(Y / A)] /(Y / A)+[\Delta(A / N)] /(A / N)
$$

$$
\text { Ou seja, a soma das taxas de crescimento da }
$$
relação área/homem e da produtividade da terra fornece a taxa de crescimento da produtividade da mão-de-obra. 
DELFIM NETO et alii (1969) realizaram essa análise decompondo as taxas de crescimento da produção agricola - a nível de Brasil, regiões Nordeste e centro-sul (exceto são Paulo) e estado de são Paulo -, para o período 1950-60, nos três componentes acima referidos (equação 2).

BARROS, PASTORE e RIZZIERE (1977) também avaliaram as fontes de crescimento da produção agrícola, ampliando para o período 1940-70 o estudo já realizado por DELFIM NETO et alii (1969).

Para avaliação da evolução da produção agrícola, BARROS, PASTORE e RIZZIERE (1977) construíam indices de quantum por grupos de produtos e por regiões do País. Os indices foram construídos utilizando-se dados de SEP/FIBGE (para São Paulo a fonte foi dupla: até 1947 foi o SEP e nos anos posteriores a fonte foi o IEA).

os índices de produção foram construídos com o critério de Laspeyres, com base móvel e encadeados. Assim, a introdução de novos produtos é capturada corretamente na evolução do quantum produzido.

os dados sobre área cultivada e pessoal ocupado foram retirados dos censos Agropecuários.

- trabalho de ARAÚJo et alii (1986) fez novas considerações em relação aos dados, embora tenha realizado a decomposição do crescimento da produção agricola - para o Brasil e suas macrorregiões na década de 70 - sob o mesmo prisma (fator terra) que os dois estudos anteriores.

Nesse estudo, utiliza-se os dados da PEA agrícola (pessoas economicamente ativas no setor agropecuário) descrevendo suas limitações. Para os dados de produção agrícola, utilizou-se o indice de valor da produção: 


$\frac{\sum_{j} q_{i j} \cdot p_{i j}}{\sum_{j} q_{0 j} \cdot p_{0 j}}$

onde: $j=1,2,3, \ldots, 15$ : representa os 15 produtos mais importantes em termos de valor da produção agrícola;

$q_{0 j}$ e $q_{i j}$ : são, respectivamente, as produções do bem j no ano base (1970) e no ano i (1980);

$p_{o j} e p_{i j}$ : são, respectivamente, os preços reais (deflacionados pelo IGP/DI, tomando 1980 como sendo a base 100) do produto $j$ no ano base e no ano $i$.

o modelo matemático utilizado foi o seguinte:

$$
\mathrm{VPA}=P \cdot Y=(P \cdot Y) / A \cdot(A / N) \cdot N
$$

onde: VPA é o valor da produção agrícola.

Tomando o logaritmo neperiano da expressão (5), e derivando a expressão resultante em relação ao tempo, tem-se a seguinte expressão válida para variações infinitesimais:

$$
\begin{aligned}
(\Delta V P A) / V P A= & (\Delta P) / P+[\Delta(Y / A)] /(Y / A)+[\Delta(A / N)] /(A / N)+ \\
& +(\Delta N) / N
\end{aligned}
$$

ARAÚJo et alii (1986, p.5) ressaltam que "uma vez determinadas as taxas de crescimento do valor da produção, do valor da produtividade parcial da terra, da relação área/homem e da quantidade de homens, há que se adicionar (ou subtrair) a influência do efeito-preço nas taxas de crescimento do valor da produção e do valor da produtividade da terra para estimar as taxas de crescimento 
físico dessas variáveis."

GASQUES e VILLA VERDE (1990) analisaram OS condicionantes da produção agrícola, no período 1981-88, decompondo $\circ$ produto real nos seguintes componentes: variação do produto por área (produtividade da terra), variação da relação área/homem e variação da quantidade de mão-de-obra rural (emprego rural).

os autores seguiram a metodologia utilizada pelo IBGE para o cálculo do produto real, que toma como base o vetor de preços do Censo Agropecuário de 1980. Com estes preços do censo e dispondo das informações anuais de produção física foi calculado o valor bruto da produção, cuja variação anual indica a taxa de crescimento do produto real. Os produtos considerados nos cálculos foram: algodão herbáceo, amendoim em casca, arroz, batata-inglesa, cacau, café, cana-de-açúcar, cebola, feijão, fumo, laranja, mamona, mandioca, milho, soja, trigo e algodão arbóreo(11).

Para mensurar o produto, GASQUES e VILLA VERDE consideraram no cálculo apenas a produção de lavouras, que foi expressa em cruzeiros aos preços do censo de 1980. A produtividade da terra, por ser uma medida de um conjunto heterogêneo de produtos, foi expressa em valor. A relação área/homem e a variação do emprego foram expressas em número de hectares por pessoa e número de pessoas ocupadas por ano.

AGUIRRE e BACHA (1989b) partiram da posição de que o aumento da produtividade do trabalho age no sentido de aumentar a produção, de modo que a decomposição do aumento do produto, sob o prisma do trabalho, pode ser

(11) Ver VALENTE, E.; SILVA, J.A. e SILVA, L.F. (1988) - Ensaios sobre o Produto Real da Agropecuária, V.1 n.9, setembro de 1988 . 
assim considerado: (12)

$$
\begin{gathered}
V=P \cdot(Q / N) \cdot(N / A) \cdot A \\
\text { sendo } V=P \cdot Q
\end{gathered}
$$

onde: $V=$ valor do produto agropecuário

$P=$ preço

$Q=$ quantidade física do produto agropecuário

$A=$ área

$N=$ quantidade de mão-de-obra

Tomando o logaritmo neperiano da expressão (7), e derivando a expressão resultante em relação ao tempo, tem-se a seguinte expressão válida para variações infinitesimais:

$$
(\Delta V) / V=(\Delta P) / P+[\Delta(Q / N)] /(Q / N)+[\Delta(N / A)] /(N / A)+(\Delta A) / A
$$

Para aplicar a expressão (8) na agropecuária brasileira, AGUIRRE e BACHA (1989b) definiram as variáveis como sendo:

$V=$ produto interno bruto da agropecuária a custo de fatores, deflacionado pelo deflator implícito do produto nacional (base $1977=100$ );

$P=$ índice de preços recebidos pela agropecuária, deflacionado pelo deflator implícito do produto nacional (ambos com base 1977 = 100);

$Q=$ produto físico da agropecuária;

$N=$ total de mão-de-obra ocupada na agropecuária segundo os censos Agropecuários los dados de 1985 são da sinopse preliminar);

(12) Essa identidade difere da normalmente utilizada na literatura sobre fontes de crescimento do produto agropecuário (como nos trabalhos de DELFIM NETO et alii, 1969; BARROS, PASTORE e RIZZIERE, 1977) por utilizar o valor do produto agropecuário (V) e não o produto físico; além de decompor o produto sob o prisma do trabalho e não do fator terra. 
$A=$ área total explorada, definida como a soma da área utilizada com lavouras (permanentes, temporárias e em descanso para a lavoura), com pastagens (naturais e plantadas) e com matas e florestas plantadas.

Os trabalhos até então mencionados calculam o valor bruto da produtividade da terra e do trabalho, sem descontar os insumos utilizados na produção agrícola. Porém, os trabalhos de HOFFMANN et alii (1985) e HOFFMANN e JAMAS (1990) consideram esse fato e recorrem ao conceito de valor agregado.

- Valor Agregado (VA) foi definido pelos autores em análise como a diferença entre o valor da produção (VB) e o valor de todos os insumos utilizados $(\mathrm{CI}=$ consumo intermediário) e a amortização das instalações e dos equipamentos utilizados no processo de produção (Am).

$$
V A=V B-C I-A m
$$

Ao valor da produção agropecuária que aparece publicado nos censos Agropecuários foi acrescentada uma parcela referente à variação do estoque, representada apenas pela variação dos rebanhos bovino e suíno, dada a impossibilidade de obter a variação do valor das culturas permanentes e matas. O valor da produção de animais publicado nos censos refere-se apenas ao valor de animais abatidos e vendidos, não levando em conta a variação do estoque animal.

$$
\mathrm{VB}=\mathrm{VB}_{\text {censo }}+\operatorname{variação~do~estoque~animal~}
$$

- valor da variação de rebanho em cada ano foi definido como a variação do número de animais (nascidos - 
vitimados - abatidos - vendidos + comprados) multiplicada pelo preço médio de compra.

- número de animais e os preços foram obtidos a partir dos Censos Agropecuários. Para o ano de 1970 foi necessário estimar o número de animais comprados e o valor da compra de animais, já que não se encontravam disponíveis no Censo. Essa estimativa foi feita a partir da proporção do número dos animais comprados em relação a "vendidos e abatidos" em 1975, pela qual se multiplicou o número de animais "vendidos e abatidos" em 1970, obtendo-se assim uma estimativa do número dos animais comprados em 1970. O mesmo se fez para estimar o valor da compra de animais em 1970.

Ao utilizar o preço médio de compra para valorar a variação do rebanho seguiu-se o mesmo procedimento da Fundação Getúlio Vargas no cálculo das Contas Nacionais.

O Consumo Intermediário (CI), por sua vez, foi calculado a partir dos dados de despesas dos estabelecimentos (exceto salários, quota-parte da produção entregue a parceiros, arrendamento de terras, serviços de empreitada, juros e despesas bancárias). Além dessas despesas, foram acrescentados ao consumo intermediário os gastos com compras de animais (bovinos, suinos, caprinos, ovinos, galinhas(13) e outras aves), o que se justifica porque o valor da produção animal que consta nos censos refere-se ao valor das vendas e abate, sem descontar portanto o valor das compras efetuadas dentro do próprio setor. Estas compras e vendas intra-setoriais não passam de simples transferências - não representando portanto acréscimo de valor - cujos valores monetários devem-se cancelar mutuamente.

(13) Nos trabalhos mencionados (HOFFMANN et alii, 1985 e HOFFMANN e JAMAS, 1990) está implícito no termo "galinhas" também os galos, os frangos, as frangas e os pintos (pois os dados censitários os apresentarn englobados). 
HOFFMANN e JAMAS (1990) ressaltam que ao se calcular o valor agregado não se descontou a amortização de instalações e equipamentos; consequentemente as medidas de produtividade obtidas tendem a favorecer as regiões mais capitalizadas, onde o valor dessas instalações e equipamentos é relativamente maior.

Para calcular os valores reais (da produção e do valor agregado), HOFFMANN et alii (1985) utilizaram como deflator um índice de preços de Pasche obtido a partir dos dados de quantidade e valor da produção das principais culturas (entre 8 e 12 , conforme a região) e produtos animais dos censos Agropecuários, com base em 1970. Em outro trabalho, HOFFMANN e JAMAS (1990) utilizaram o indice geral de preços - disponibilidade interna da Fundação Getúlio vargas.

Utiliza-se como unidade da produtividade do trabalho a relação valor agregado por equivalente-homem.

- número de equivalentes-homem (EH) é uma tentativa de medir a força de trabalho empregada, levando em consideração que uma criança ou uma mulher adulta não-assalariada corresponde a menos força de trabalho do que um homem adulto(14).

(14) De acordo com a metodologia proposta por GRAZIANO DA SILVA e KAGEYAMA (1983b) a transformaç̃o do número de pessoas ocupadas em equivalente-homem empregados segue o seguinte critério:

1 - não-assalariados empregados (parceiros e outra condicão):

1 mulher $=0,66 \mathrm{EH}$

1 criança $=0,5 \mathrm{EH}$

2 - não empregados (responsável e membros não remunerados dá família):

I mulher $=0,6 \mathrm{EH}$

1 criança $=0,4 \mathrm{EH}$

3 - empregados assalariados (permanentes e temporários):

1 mulher $=1 \mathrm{EH}$

I criança $=0,5 \mathrm{EH}$

OBS.: admite-se para a categoria "outra condiçă a mesma proporção de menores e maiores de 14 anos existente na categoria "parceiros". 
Os dados básicos são obtidos dos censos Agropecuários.

Utiliza-se o número médio de empregados temporários ao longo do ano e inclui-se uma estimativa da mão-de-obra contratada por empreitada(15).

HOFFMANN e JAMAS (1990) realizaram o estudo de produtividade do trabalho na agricultura para as 332 microrregiões homogêneas das regiões Nordeste, sudeste, sul e Centro-oeste do Brasil, tanto para o ano de 1975 como para 0 ano de 1980 .

Para calcular a produtividade do trabalho agrícola utilizamos a metodologia de HOFFMANN et alii (1985) e de HOFFMANN e JAMAS (1990), com as seguintes modificações e considerações:

1 - calculamos o valor agregado pela diferença entre o valor da produção e o consumo intermediário:

$\mathrm{VA}=\mathrm{VB}-\mathrm{CI}$

Não deduzimos a amortização (ou depreciação) porque não existe uma metodologia definida para o seu cálculo (no que se refere ao método de depreciação e à

(15) Conforme a metodologia proposta por GRAZIANO DA SILVA e KAGEYAMA (1983b):

1- una estimativa do número médio de trabalhadores temporários pode ser obtida pela média aritmética do número máximo de trabalhadores temporários empregados mês a mês. Para uma posterior conversão em equivalentes-homem, a divisão em homens e mulheres maiores de 14 anos e de menores de 14 anos, foi obtida aplicando-se a mesma proporção desses elementos existente no número de empregados temporários registrados como parte das pessoas ocupadas em 31 de dezembro (conforme página 239 do trabalho acima citado).

2- na estimativa do pessoal ocupado em empreitada preferiu-se utilizar uma estimativa do número total de diárias pagas, dividindo-se o montante global de serviços com empreitada registrados no Censo pelo salário médio (Cr\$/dia) do trabalhador eventual, segundo as séries fornecidas pelo Centro de Estudos Agrários da FGV. O número assim obtido deve ser dividido por 300, obtendo-se como resultado final uma estimativa do número de equivalentes-homem envolvidos em trabalho de empreitada no ano do censo. 
estimativa da vida útil dos diferentes bens declarados pelos estabelecimentos agrícolas)(15).

- cálculo do valor agregado bruto segue uma tendência mundial pois "na prática, internacionalmente, é muito dificil calcular os agregados Irquidos." (Novo Sistema de Contas Nacionais, 1988, p.49).

2 - calculamos os gastos com compra de animais tendo em conta os seguintes grupos: bovinos, suínos, caprinos, ovinos, galinhas, galos, frangos(as) e pintos. Em 1985, em vez de descontarmos os gastos com compra de pintos de 1 dia, deduzimos o valor da despesa com ovos fertilizados e com pintos de 1 dia. Portanto, difere de HOFFMANN et alii (1985) e HOFFMANN e JAMAS (1990) ao excluir "outras aves" (uma vez que os gastos com compra de "outras aves" não se encontram disponiveis no censo de 1970 e não há possibilidade de ser estimado) .

3 - os valores obtidos a partir do censo de 1970, 1975 e 1980 são colocados em "mil cruzados" de 1985 , utilizando o Indice Geral de Preços (IGPdisponibilidade interna) da FGV. Tendo por base 1977, esse índice era:

Índice Geral de Preços

\begin{tabular}{rr}
\hline ano & \multicolumn{1}{c}{ IGP-DI } \\
\hline 1970 & 18,5953 \\
1975 & 49,6333 \\
1980 & 427,5000 \\
1985 & 46587,5000 \\
\hline
\end{tabular}

Fonte: Indices Econômicos - Suplemento Especial - Conjuntura Econômica, Vol. $33, \mathrm{n}^{2} 11, \mathrm{FGV}$.

(16) Fizemos um teste utilizando o método Linear de depreciação. Tomamos os valores dos bens divulgados nos Censos Agropecuáxios (instalações e outras benfeitorias, veículos e outros meios de transporte, máquinas e instrumentos agrários). Ao variarmos o critério sobre a vida útil dos bens, verificamos que os resultados mudaram de tendência, possibilitando assim diferentes conclusões. 
4 - no cálculo do número de equivalentes-homem a única modificação que realizamos foi quanto a estimativa de menores e de maiores de 14 anos da categoria "outra condição" para os anos de 1975, 1980 e 1985; uma vez que nesses anos censitários, a categoria não está subdividida em grupos por idade, mas apenas por sexo.

Ao invés de se admitir para a categoria "outra condição" a mesma proporção de menores e maiores de 14 anos existente na categoria parceiros (conforme a sugestão de GRAZIANO DA SILVA e KAGEYAMA, 1983b), pareceu-nos mais exato determinar o total de menores de 14 anos da categoria "outra condição" subtraindo do total de menores de 14 anos dado pelo censo lobtido pela diferença entre o total de pessoas ocupadas e o total de homens e de mulheres maiores de 14 anos) os menores de 14 anos nas demais categorias (Responsável e Membros não Remunerados da Família, Empregado Permanente, Empregado Temporário e Parceiro). Posteriormente, admitindo a mesma proporção de homens e de mulheres registrados no total da categoria "outra condição", calculamos o número de homens e de mulheres maiores de 14 anos (excluído o grupo de menores de 14 anos anteriormente determinado).

Antes de prosseguirmos, pareceu-nos conveniente explicar os motivos pelos quais optamos pelo cálculo do valor agregado seguindo a metodologia de HOFFMANN et aIii (1985) e de HOFFMANN e JAMAS (1990) em vez de utilizarmos os dados do PIB $_{\text {cf }}$ (produto interno bruto a custo de fatores) das Contas Nacionais.

Como pode ser visto na tabela 13, o valor agregado dos estabelecimentos agrícolas (calculado no 
apêndice 3 desse trabalho) é diferente do valor do PIB cf do setor agrícola, especialmente nos últimos anos analisados $(1980$ e 1985).

observa-se que os valores do PIB $_{\text {cf }}$ (calculados pelas Contas Nacionais), ao longo do periodo analisado, são superiores àqueles calculados através do conceito de valor Agregado.

As diretrizes metodológicas - utilizadas na realização de cada um dos cálculos - explicam, em grande parte, as divergências.

Tabela 13. Valor agregado dos estabelecimentos agrícolas versus $\mathrm{PIB}_{\text {cf }}$ do setor agrícolal (valores reais expressos em Cz\$1000 de 1985) - Brasil, 1970-85

\begin{tabular}{lcc}
\hline ano & PIB $_{C f}$ & Valor Agregado \\
\hline 1970 & $50.500 .085,37$ & $48.775 .816,99$ \\
1975 & $100.777 .371,74$ & $92.110 .280,30$ \\
1980 & $134.270 .187,92$ & $113.860 .688,68$ \\
1985 & $149.288 .902,00$ & $135.937 .878,00$ \\
\hline
\end{tabular}

Fonte: Anuário Estatístico do Brasil/92 e valores calculados a partir dos dados dos censos Agropecuários. (1) inclui os serviços de intermediação financeira.

Ao revermos a metodologia do Novo sistema de Contas Nacionais (NSCN, 1988) verificamos que:

1 - na classificação adotada em 1980, a atividade agropecuária incluiu os estabelecimentos agrícolas investigados no censo agropecuário, sendo feita também uma estimativa da produção das hortas domésticas de moradores em unidades rurais (NSCN, 1988, p. 54). No presente trabalho não foi estimada a produção de hortas domésticas porque no censo Agropecuário não são 
consideradas como ocupadas as pessoas que se dedicam à essa atividade.

2 - a produção de animais vivos, parte dos produtos da pecuária, é dada pelo somatório, para todos os estabelecimentos agrícolas, de: vendas - compras + abate no estabelecimento mais variação do rebanho (NSCN, 1988, p. 61). Ao se deduzirem as compras feitas pela atividade agropecuária evita-se contar como produção a simples mudança de propriedade dos animais. Para equinos, asininos $e$ muares não foi considerado $\circ$ abate. Este procedimento é o mesmo que se adotou nos trabalhos de HOFFMANN et alii e de HOFFMANN e JAMAS.

3 - no caso de galináceos, as compras de pintos de 1 dia não foram deduzidas, consideradas como uma etapa especifica do processo de criação de aves (NSCN, 1988, p. 61). No presente estudo, deduzimos as compras de pintos de 1 dia, uma vez que estão englobadas no valor total da produção.

4 - a avaliação da produção de bovinos vivos não se baseou unicamente nos dados do Censo Agropecuário, uma vez que revelaram inconsistências em relação ao consumo e exportação de carne estimados e também em relação ao cálculo da variação do rebanho. Depois de vários estudos, foram utilizados os dados da Pesquisa Mensal de Abate para determinação do número de animais abatidos (NSCN, 1988, p. 61). Em nosso trabalho, a avaliação da produção de bovinos vivos baseou-se unicamente nos dados do CA, apesar dessa recomendação.

5 - para alguns produtos, como carvão vegetal, lenha, hortaliças e outros, onde a produção fora dos 
estabelecimentos agropecuários lobtenção em terras devolutas ou hortas domésticas) é relevante, a produção foi estimada a partir do total do consumo (NSCN, 1988, p. 61).

Essa estimativa não foi realizada no presente trabalho. Uma vez que temos o número de pessoas ocupadas nos estabelecimentos agropecuários, nosso interesse passa a ser a produção obtida pela mão-de-obra rural nestes estabelecimentos. Não temos o número de pessoas ocupadas na produção de carvão vegetal, lenha, hortaliças e outros produtos fora dos estabelecimentos.

portanto, nesse trabalho calculamos o valor agregado dos estabelecimentos agropecuários e não do setor agrícola como o faz a metodologia de cálculo do PIB deste setor.

6 - no PIB do setor agrícola estão incluídos o valor da produção de pescado e dos produtos da caça.

- pessoal ocupado divulgado no censo Agropecuário não inclui a caça e a pesca. Dessa forma, não foram computados esses valores no total da produção dos estabelecimentos agropecuários dados pelo CA.

7 - o cálculo do consumo intermediário inclui tanto insumos adquiridos como produzidos no próprio estabelecimento. Aos dados fornecidos pelo censo Agropecuário, foram acrescentadas estimativas para consumo de produção própria de produtos agrícolas processados na indústria rural, da lenha utilizada na produção de carvão vegetal, de ovos para incubação e de forragens (NSCN, 1988, p. 68).

Dessa forma, o valor mais elevado do PIB $_{c f}$ em relação ao valor agregado é, em parte, explicado pela 
inclusão da atividade extrativa animal (caça e pesca) e da produção fora dos estabelecimentos agropecuários, além da imputação dos serviços de intermediação financeira.

Tendo em conta as divergências acima, pareceu-nos mais adequado utilizar a metodologia de HOFFMANN et alii (1985) e de HOFFMANN e JAMAS (1990), mesmo porque podemos trabalhar dentro da mesma fonte de dados (tanto no que se refere às informações que serão utilizadas no cálculo do valor agregado, como àquelas sobre as pessoas ocupadas).

\subsubsection{Procedimentos adotados para a análise dos salários rural e urbano}

Analisamos o comportamento do salário rural (do empregado temporário e do empregado permanente), do salário mínimo (vigente no país nas diferentes épocas) e do salário de servente da construção civil, no período 1977-87, nos estados que mais contribuíram para o incremento das pessoas ocupadas na agricultura brasileira, segundo os dados dos Censos Agropecuários, no primeiro qüinqüênio da década de 80 .

A ocorrência de uma deterioração do salário relativo (salário na agricultura/salário mínimo e salário na agricultura/salário de servente), no período 1980-85, pode indicar que o aumento da mão-de-obra - observado nos dados do Censo Agropecuário naquele período - seja uma volta à agricultura de subsistência, gerando subocupação e subemprego no campo - conclusões dos trabalhos de MUELLER (1987), GRAZIANO DA SILVA (1987) e MARTINE (1987).

Para analisarmos a evolução do salário rural, nas categorias empregado permanente e empregado temporário, 
calculamos a média aritmética do $1^{\circledR}$ e do $2^{\circ}$ semestre dos dados fornecidos pelo centro de Estudos Agrícolas da Fundação Getúlio Vargas (CEA - IBRE - FGV).

Para a construção civil, na ocupação de servente, calculamos a média anual dos salários através dos dados mensais levantados pelo Sistema Nacional de Pesquisa de Custos e Indices da construção civil (SINAPI - IBGE). Calculamos a média conforme a disponibilidade dos dados divulgados no Anuário Estatístico do Brasil:

1- nos períodos 1977-80 e 1983-86 tomamos a média dos 12 meses; exceto:

a) calculamos para o Brasil em 1985 a média mensal das 10 capitais divulgadas:

b) em 1986, tomou-se a média de junho e dezembro para o Brasil (média mensal das 26 capitais divulgadas) e para os estados de Rondônia e Paraíba;

2 - nos anos de 1981 e 1982 calculamos a média para os meses divulgados: março, junho, setembro e dezembro;

3- em 1987 tomamos a média de junho e dezembro para todos os estados e para o Brasil (para este calculamos a média das 26 capitais do País).

Os dados sobre salário mínimo nominal são os
fornecidos pelo Boletim do DIEESE (Departamento Intersindical de Estatistica e Estudos Sócios-Econômicos).

Calculamos a média anual do salário mínimo nominal para cada estado em análise, tendo em consideração os seguintes aspectos:

1 - no período de 1977-82 tínhamos diferentes salários para as regiões Nordeste; Centro-Oeste e Norte; sul e Sudeste;

2 - no período 1983 até abril de 1984 temos os mesmos salários para as regiões Norte, Nordeste e Centro- 
Oeste, e outros para as regiões sul e sudeste;

3 - a partir de maio de 1984 o salário vigente é o mesmo para todo o território nacional.

Os salários nominais são deflacionados pelo IGP (disponibilidade interna) da Fundação Getúlio Vargas, tomando março de 1986 como sendo a base 100 .

Indice Geral de Preços

\begin{tabular}{lr}
\hline ano & IGP -DI \\
\hline 1977 & 0,0890 \\
1978 & 0,1240 \\
1979 & 0,1910 \\
1980 & 0,3820 \\
1981 & 0,8020 \\
1982 & 1,5680 \\
1983 & 3,9906 \\
1984 & 12,7940 \\
1985 & 41,6490 \\
1986 & 100,9000 \\
1987 & 327,7400 \\
\hline
\end{tabular}

Fonte: Conjuntura Econômica - Instituto Brasileiro de Economia - Dez/86, Vol. $40, \mathrm{n}^{2} 12, \mathrm{FGV}$.

Vários estudos têm mostrado a perda de salário real que vem ocorrendo no Brasil, especialmente na década de 80, devido à recessão econômica que vem solapando o País. Como nosso objetivo é comparar a evolução dos diferentes salários, usaremos índices de salário real (tendo por base o ano de 1980), a fim de verificar em que categoria de emprego ocorreu maior decréscimo do salário real. Também calculamos o salário relativo (salário na agricultura/salário mínimo e salário na agricultura/salário de servente). 


\title{
3. A EVOLUÇÃO DA MÃO-DE-OBRA NA AGRICULTURA SEGUNDO AS PNADS
}

\begin{abstract}
A análise dos dados das PNADs no que se refere à composição das pessoas ocupadas no setor agrícola brasileiro, ao longo do período 1976-89, para o Brasil como um todo (conforme a tabela 14), mostrou uma queda na participação relativa da categoria não remunerados, concomitantemente ao acréscimo relativo da categoria empregados (conforme já verificaram AGUIRRE e BACHA, 1989a, considerando o período 1976 a 1987).
\end{abstract}

Tabela 14. Média da participação relativa do pessoal ocupado na agricultura, segundo cada categoria BRASIL, $1976-1989$

\begin{tabular}{lrrrr}
\hline categoria & $1976-79$ & $1981-83$ & $1984-86$ & $1987-89$ \\
\hline & & & & \\
empregados & 33,67 & 36,92 & 38,55 & 38,68 \\
conta própria & 31,31 & 30,46 & 30,57 & 30,91 \\
empregadores & 3,17 & 3,39 & 3,39 & 3,62 \\
não remunerados & 31,86 & 29,22 & 27,49 & 26,79 \\
sem declaração & 0,00 & 0,00 & 0,00 & 0,00 \\
\hline TOTAL & 100,00 & 100,00 & 100,00 & 100,00 \\
\hline
\end{tabular}

Fonte: IBGE - Pesquisa Nacional por Amostra de Domicilios 
Através da tabela 15 verificamos que apenas as regiões Nordeste (de maior expressão, devido ao valor absoluto das pessoas ocupadas nestas duas categorias) e Centro-oeste mostraram o mesmo resultado para o período 1976-89. A região Norte que apresentara essa tendência no período 1984-86, já não volta a apresentá-la no período subsequente (1987-89).

$\mathrm{Na}$ região sul (conforme a tabela 15) ocorre decréscimo relativo de não remunerados e acréscimo relativo de conta-próprias, ao longo de todo o período 1976-89, enquanto se mantém estável a participação relativa dos empregados.

É interessante notar a queda relativa de empregados e conta-próprias a favor dos não remunerados na região sudeste, no período 1981-83.

A análise por estado (veja as tabelas 16, 17 e 18) da composição das pessoas ocupadas na agropecuária das regiões Nordeste, Sudeste e sul, mostrou a tendência acima mencionada - de aumento de importância relativa da categoria empregados e de perda de importância relativa da categoria não remunerados - apenas nos estados da Bahia, Maranhão, Paraíba, Minas Gerais, Espírito Santo, São Paulo (exceto o $1^{2}$ período), Santa catarina e Rio Grande do Sul. - estado do ceará passou a exibir essa tendência somente no último período analisado (1987-89).

Nota-se a diversidade de resultados para os estados da região Nordeste, não apresentando uma tendência comum entre os estados de uma mesma região.

Os estados do sul apresentam uma mesma tendência: redução da participação relativa da categoria dos não remunerados e acréscimo relativo dos conta-próprias. 
Tabela 15. Média da participação relativa do pessoal ocupado na agricultura, segundo a região e a categoria - BRASIL, 1976-1989

\begin{tabular}{|c|c|c|c|c|}
\hline categoria & $1976-79$ & $1981-83$ & $1984-86$ & $1987-89$ \\
\hline \multicolumn{5}{|l|}{ NORTE 1} \\
\hline empregados & & 35,50 & 39,46 & 35,27 \\
\hline conta própria & & 46,63 & 43,76 & 44,37 \\
\hline empregadores & & 3,15 & 4,23 & 5,46 \\
\hline não remunerados & & 14,72 & 12,54 & 14,90 \\
\hline sem declaração & & 0,00 & 0,00 & 0,00 \\
\hline SUBTOTAL & & 100,00 & 100,00 & 100,00 \\
\hline \multicolumn{5}{|l|}{ NORDESTE } \\
\hline empregados & 28,16 & 33,30 & 35,32 & 35,83 \\
\hline conta própria & 38,67 & 38,36 & 36,66 & 36,34 \\
\hline empregadores & 2,05 & 2,26 & 2,24 & 2,35 \\
\hline não remunerados & 31,12 & 26,08 & 25,78 & 25,49 \\
\hline sem declaração & 0,00 & 0,00 & 0,00 & 0,00 \\
\hline SUBTOTAL & 100,00 & 100,00 & 100,00 & 100,00 \\
\hline \multicolumn{5}{|l|}{ SUDESTE } \\
\hline empregados & 58,11 & 55,88 & 57,81 & 57,22 \\
\hline conta própria & 20,58 & 18,30 & 17,89 & 18,95 \\
\hline empregadores & 4,71 & 5,13 & 5,75 & 5,97 \\
\hline não remunerados & 16,61 & 20,69 & 18,55 & 17,87 \\
\hline sem declaração & 0,00 & 0,00 & 0,00 & 0,00 \\
\hline SUBTOTAL & 100,00 & 100,00 & 100,00 & 100,00 \\
\hline \multicolumn{5}{|l|}{ SUL } \\
\hline empregados & 21,58 & 21,01 & 21,60 & 21,41 \\
\hline conta própria & 28,49 & 30,10 & 31,78 & 33,56 \\
\hline empregadores & 3,23 & 2,60 & 2,36 & 2,43 \\
\hline não remunerados & 46,70 & 46,28 & 44,27 & 42,61 \\
\hline sem declaração & 0,00 & 0,00 & 0,00 & 0,00 \\
\hline SUBTOTAL & 100,00 & 100,00 & 100,00 & 100,00 \\
\hline \multicolumn{5}{|l|}{ CENTRO-OESTE } \\
\hline empregados & & 44,48 & 46,25 & 47,46 \\
\hline conta própria & & 30,66 & 32,03 & 28,88 \\
\hline empregadores & & 6,49 & 5,80 & 7,10 \\
\hline não remunerados & & 18,37 & 15,91 & 16,56 \\
\hline sem declaração & & 0,00 & 0,00 & 0,00 \\
\hline SUBTOTAL & & 100,00 & 100,00 & 100,00 \\
\hline
\end{tabular}

Fonte: IBGE - Pesquisa Nacional por Amostra de Domicílios (1) apenas as pessoas residentes em área urbana. 
Tabela 16. Média da participação relativa do pessoal ocupado na agricultura, segundo o estado e a categoria - NORDESTE, 1976-1989

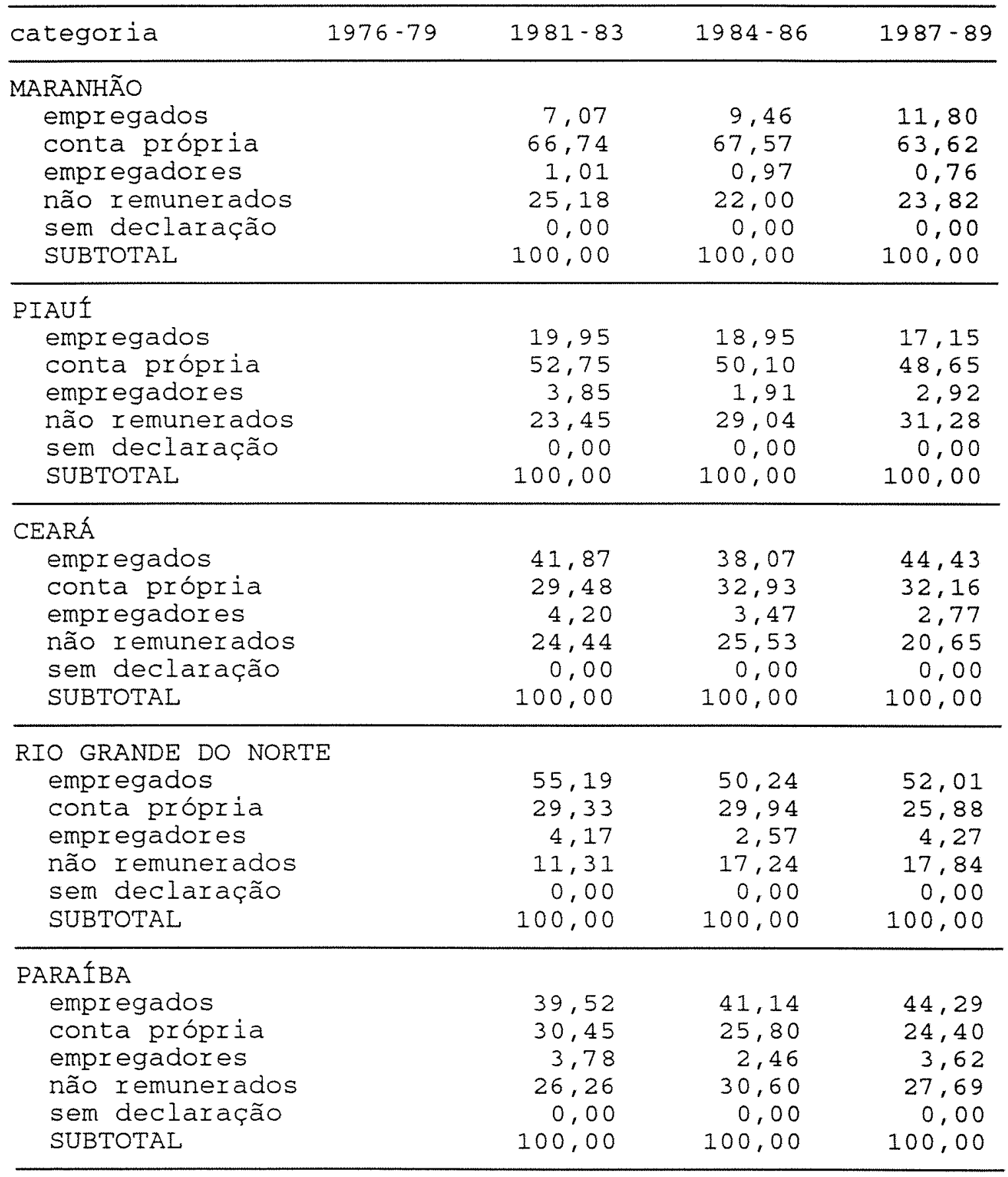

Fonte: IBGE - Pesquisa Nacional por Amostra de Domicilios Nota: continua 
Cont. Tabela 16. Média da participação relativa do pessoal ocupado na agricultura, segundo o estado e a categoria - NORDESTE, 1976-1989

\begin{tabular}{|c|c|c|c|c|}
\hline categoria & $1976-79$ & $1981-83$ & $1984-86$ & $1987-89$ \\
\hline \multicolumn{5}{|l|}{ PERNAMBUCO } \\
\hline empregados & & 51,08 & 48,19 & 48,33 \\
\hline conta própria & & 22,12 & 23,59 & 24,39 \\
\hline empregadores & & 2,49 & 2,73 & 2,69 \\
\hline não remunerados & & 24,31 & 25,49 & 24,59 \\
\hline sem declaração & & 0,00 & 0,00 & 0,00 \\
\hline SUBTOTAL & & 100,00 & 100,00 & 100,00 \\
\hline \multicolumn{5}{|l|}{ ALAGOAS } \\
\hline empregados & & & 52,48 & 45,00 \\
\hline conta própria & & & 22,80 & 25,05 \\
\hline empregadores & & & 1,31 & 1,56 \\
\hline não remunerados & & & 23,41 & 28,39 \\
\hline sem declaração & & & 0,00 & 0,00 \\
\hline SUBTOTAL & & & 100,00 & 100,00 \\
\hline \multicolumn{5}{|l|}{ SERGIPE } \\
\hline empregados & & & 38,49 & 39,15 \\
\hline conta própria & & & 31,58 & 34,78 \\
\hline empregadores & & & 1,85 & 1,64 \\
\hline não remunerados & & & 28,08 & 24,43 \\
\hline sem declaração & & & 0,00 & 0,00 \\
\hline SUBTOTAL & & & 100,00 & 100,00 \\
\hline \multicolumn{5}{|l|}{ BAHIA } \\
\hline empregados & & 33,06 & 39,02 & 38,92 \\
\hline conta própria & & 36,60 & 31,09 & 31,31 \\
\hline empregadores & & 2,16 & 2,37 & 2,46 \\
\hline não remunerados & & 28,18 & 27,52 & 27,31 \\
\hline sem declaração & & 0,00 & 0,00 & 0,00 \\
\hline SUBTOTAL & & 100,00 & 100,00 & 100,00 \\
\hline
\end{tabular}

Fonte: IBGE - Pesquisa Nacional por Amostra de Domicilios Nota: o cálculo da "Média" da Participação Relativa para os estados do Maranhão, Piaul, Rio Grande do Norte e Paraíba, no "período" 1981-83, fez-se somente sobre o ano 1983 (os dados apenas estão disponíveis a partir desta data). 
Tabela 17. Média da participação relativa do pessoal ocupado na agricultura, segundo o estado e a categoria - SUDESTE, 1976-1989

\begin{tabular}{|c|c|c|c|c|}
\hline categoria & $1976-79$ & $1981-83$ & $1984-86$ & $1987-89$ \\
\hline \multicolumn{5}{|l|}{ MINAS GERAIS } \\
\hline empregados & & 52,78 & 54,00 & 53,18 \\
\hline conta própria & & 22,85 & 22,50 & 22,96 \\
\hline empregadores & & 5,28 & 6,19 & 6,13 \\
\hline não remunerado & & 19,08 & 17,31 & 17,73 \\
\hline sem declaração & & 0,00 & 0,00 & 0,00 \\
\hline SUBTOTAL & & 100,00 & 100,00 & 100,00 \\
\hline \multicolumn{5}{|l|}{ ESPIRITO SANTO } \\
\hline empregados & & 46,85 & 49,47 & 48,86 \\
\hline conta própria & & 10,99 & 11,97 & 12,67 \\
\hline empregadores & & 3,95 & 4,23 & 5.17 \\
\hline não remunerado & & 38,21 & 34,33 & 33,30 \\
\hline sem declaração & & 0,00 & 0,00 & 0,00 \\
\hline SUBTOTAL & & 100,00 & 100,00 & 100,00 \\
\hline \multicolumn{5}{|l|}{ RIO DE JANEIRO } \\
\hline empregados & 67,05 & 63,41 & 70,13 & 65,08 \\
\hline conta própria & 20,55 & 18,37 & 16,51 & 19,95 \\
\hline empregadores & 4,27 & 6,81 & 5,79 & 6,42 \\
\hline não remunerado & 8,13 & 11,41 & 7.57 & 8,56 \\
\hline sem declaração & 0,00 & 0,00 & 0,00 & 0,00 \\
\hline SUBTOTAL & 100,00 & 100,00 & 100,00 & 100,00 \\
\hline \multicolumn{5}{|l|}{ SÃO PAULO } \\
\hline empregados & 69,15 & 61,94 & 64,13 & 65,13 \\
\hline conta própria & 12,28 & 12,89 & 12,54 & 14,20 \\
\hline empregadores & 4,95 & 5,03 & 5,52 & 5,89 \\
\hline não I emunerado & 13,61 & 20,13 & 17,81 & 14,78 \\
\hline sem declaração & 0,00 & 0,00 & 0,00 & 0,00 \\
\hline SUBTOTAL & 100,00 & 100,00 & 100,00 & 100,00 \\
\hline
\end{tabular}

Fonte: IBGE " Pesquisa Nacional por Amostra de Domicilios Nota: O cálculo da "Média" da Participação Relativa para o estado do Espírito Santo, no "período" 1981-83, fez-se somente sobre o ano 1983 (os dados apenas estão disponíveis a partir desta data). 


\begin{tabular}{|c|c|c|c|c|}
\hline categoria & $1976-79$ & $1981-83$ & $1984-86$ & $1987-89$ \\
\hline \multicolumn{5}{|l|}{ PARANÁ } \\
\hline empregados & & 29,63 & 29,59 & 28,92 \\
\hline conta própria & & 25,11 & 26,99 & 29,73 \\
\hline empregadores & & 3,17 & 2,84 & 2,59 \\
\hline não remunerados & & 42,09 & 40,58 & 38,76 \\
\hline sem declaração & & 0,00 & 0,00 & 0,00 \\
\hline SUBTOTAL & & 100,00 & 100,00 & 100,00 \\
\hline \multicolumn{5}{|l|}{ SANTA CATARINA } \\
\hline empregados & & 12,00 & 12,96 & 13,42 \\
\hline conta própria & & 31,96 & 33,86 & 34,09 \\
\hline empregadores & & 0,77 & 1,49 & 1,02 \\
\hline não remunerados & & 55,27 & 51,69 & 51,48 \\
\hline sem declaração & & 0,00 & 0,00 & 0,00 \\
\hline SUBTOTAL & & 100,00 & 100,00 & 100,00 \\
\hline \multicolumn{5}{|l|}{ RIO GRANDE DO SUL } \\
\hline empregados & & 15,77 & 17,00 & 17,06 \\
\hline conta própria & & 34,26 & 36,33 & 37,96 \\
\hline empregadores & & 2,55 & 2,28 & 3,09 \\
\hline não remunerados & & 47,42 & 44,38 & 41,89 \\
\hline sem declaração & & 0,00 & 0,00 & 0,00 \\
\hline SUBTOTAL & & 100,00 & 100,00 & 100,00 \\
\hline
\end{tabular}

Fonte: IBGE - Pesquisa Nacional por Amostra de Domicilios Nota: o cálculo da "Média" da Participação Relativa para o estado de Santa Catarina, no "período" 1981-83, fez-se somente sobre o ano 1983 (os dados apenas estão disponíveis a partir desta data). 
Observa-se nos estados de são paulo e do Rio de Janeiro, no período 1981-83, um decréscimo acentuado na participação relativa dos empregados, enquanto cresce relativamente a categoria dos não remunerados. Essa situação volta a se reverter nos períodos subsequentes, sendo que os conta-próprias aumentam sua participação relativa no último período analisado (1987-89) e os empregados não voltam ao nível de participação de 1976-79.

- que se pode concluir é que, com os dados disponíveis, não se evidencia de forma generalizada - nos estados brasileiros durante a década de 80 - a tendência de avanço dos empregados relativamente à redução dos não remunerados. Isto ocorre porque esses estados possuem padrões diferentes de desenvolvimento agrícola. Com isso, confirmamos nossa 2 hipótese. 


\title{
4. ANÁLISE DOS DADOS SOBRE A MÃO-DE-OBRA SEGUNDO OS CENSOS AGROPECUÁRIOS
}

\begin{abstract}
Apresentamos, neste capítulo, os resultados encontrados sobre a evolução e composição da mão-de-obra rural na década de 80 , de acordo com os dados até então disponíveis para o censo Agropecuário (item 4.1); as análises sobre a evolução da produtividade do trabalho na agricultura (item 4.2) e sobre a evolução dos salários rural e urbano (item 4.3).
\end{abstract}

4.1. A evolução e a composição da mão-de-obra rural

A análise dos dados do Censo Agropecuário mostrou que, se no qüinqüênio 1975-80 ○ número de pessoas ocupadas na agropecuária cresceu apenas $4 \%$, no qüinqüênio subsequente a expansão foi de $11 \frac{0}{6}$ (veja a tabela 1, p. 30). Em termos absolutos, o incremento do pessoal ocupado, que no período 1975-80 foi de pouco mais de 818 mil pessoas, atingiu mais de 2,3 milhões de pessoas entre 1980 e 85 .

observamos através da tabela 19 que as regiões que mais concorrem para o aumento da mão-de-obra rural, no qüinqüênio 1980-85, foram: Nordeste (50\%), Norte (30\%) e Sudeste $(19,5 \%)$. 
Tabela 19. Variação das pessoas ocupadas na agropecuária no período 1980-85, segundo os Censos Agropecuários - Brasil e Regiões.

\begin{tabular}{|c|c|c|}
\hline \multirow{2}{*}{ Região } & \multicolumn{2}{|c|}{ Variação } \\
\hline & Absoluta & Relativa \\
\hline Norte & 714.435 & $30,02 \%$ \\
\hline Nordeste & 1.190 .523 & $50,03 \%$ \\
\hline Sudeste & 463.371 & 19,47 \% \\
\hline Sul & 101.669 & 4,27 के \\
\hline Centro-oeste & -90.519 & $-3,808$ \\
\hline BRASIL & 2.379 .473 & 100,00 z \\
\hline
\end{tabular}

A análise a nível de estado (veja a tabela 20) mostrou que praticamente $70 \%$ desse crescimento se concentrou em seis estados brasileiros(17).

Tabela 20. Variação das pessoas ocupadas na agropecuária no periodo 1980-85, nos estados que mais contribuíram para o aumento da mão-de-obra.

\begin{tabular}{|c|c|c|}
\hline \multirow{2}{*}{ Estado } & \multicolumn{2}{|c|}{ Variação } \\
\hline & Absoluta & Relativa \\
\hline Rondônia & 150.541 & $6,3 \%$ \\
\hline Pará & 201.561 & 8,5 \% \\
\hline Ceará & 221.216 & $9,3 \%$ \\
\hline Paraíba & 119.183 & 5,0 \% \\
\hline Bahia & 561.235 & $23,6 \%$ \\
\hline Minas Gerais & 403.093 & 16,9 \% \\
\hline Total (1) & 1.656 .829 & 69,68 \\
\hline
\end{tabular}

Fonte: IBGE - Censo Agropecuário do Brasil de 1980 e 1985. (1) Iefere-se ao total dos seis estados que mais contribuíram para $\circ$ aumento das pessoas ocupadas na agropecuária brasileira, no qüinqüênio 80-85.

(17) Encontra-se no APENDICE 2 - tabela 2.1 a análise para todos os estados brasileiros. 
Ao decompormos a mão-de-obra nas diversas categorias assinaladas pelo censo Agropecuário (conforme a tabela 21), para os estados que mais contribuiram para o aumento das pessoas ocupadas no setor agricola brasileiro, no perlodo 1980-85, verificamos que a categoria Responsável e Membros não Remunerados da Família foi a que mais absorveu esta mão-de-obra, respondendo - no Brasil como um todo - por $85,5 \%$ do acréscimo total das pessoas no setor (conforme a tabela 22).

Tabela 21. Variação das pessoas ocupadas entre 1980 e 1985 , segundo a categoria, na agropecuária brasileira $e$ nos estados que mais contribuiram para o aumento da mão-de-obra.

\begin{tabular}{lcccccc}
\hline & \multicolumn{5}{c}{ Pessoal Ocupado (variação absoluta) } \\
\cline { 2 - 7 } Estado & Total & $\begin{array}{c}\text { Respon- } \\
\text { sável }\end{array}$ & $\begin{array}{c}\text { Empreg. } \\
\text { Perman. }\end{array}$ & $\begin{array}{c}\text { Empreg. } \\
\text { Tempor. }\end{array}$ & Parceiro & $\begin{array}{c}\text { Outra } \\
\text { Condição }\end{array}$ \\
\hline Rondônia & 150541 & 140844 & 838 & 8276 & -647 & 1230 \\
\hline Pará & 201561 & 204945 & -2200 & -3582 & -420 & 2818 \\
\hline Ceará & 221216 & 267922 & -47761 & -2392 & -27643 & 31090 \\
\hline Paraíba & 119183 & 139455 & -7039 & -46686 & 11576 & 21877 \\
\hline Bahia & 561235 & 417480 & 40152 & 81997 & -2223 & 23829 \\
\hline M.Gerais & 403093 & 216236 & 34202 & 95374 & -2920 & 60201 \\
\hline Total(1) & 1656829 & 1386882 & 18192 & 132987 & -22277 & 141045 \\
\hline BRAsIL & 2379473 & 2035008 & 26116 & 93794 & -22830 & 247385 \\
\hline Fonte: IBGE - Censo Agropecuário do Brasil & de 1980 & 1985
\end{tabular}

(1) idem nota tabela 20.

Desta forma, nosso interesse, neste momento, passa a ser a análise do que ocorreu com a mão-de-obra nesta categoria. 
A análise por faixa etária (veja a tabela 22), para o Brasil como um todo, mostrou que da contribuição de 85,5 pontos percentuais da categoria Responsável e Membros não Remunerados da Família no acréscimo da mão-de-obra rural, 40,3 pontos percentuais ocorreu devido ao aumento de homens maiores de 14 anos; 28,7 pontos percentuais ocorreu devido ao aumento de mulheres maiores de 14 anos e apenas 16,6 pontos percentuais ocorreu devido ao aumento de menores de 14 anos.

Tabela 22. Contribuição da categoria Responsável no acréscimo total das pessoas ocupadas no País no qüinqüênio $1980-85$ e decomposição dessa contribuição por idade e sexo.

\begin{tabular}{lcccc}
\hline \multirow{2}{*}{ Estados } & \multicolumn{2}{c}{ Responsável e Membros não Remunerados (8) } \\
\cline { 2 - 5 } & Total(1) & $\begin{array}{c}\text { Homens } \\
\text { maiores de } \\
\text { I4 anos }\end{array}$ & $\begin{array}{c}\text { Mulheres } \\
\text { miores de } \\
14 \text { anos }\end{array}$ & $\begin{array}{c}\text { Menores } \\
\text { de } \\
14 \text { anos }\end{array}$ \\
\hline Rondônia & 5,9 & 2,5 & 1,6 & 1,8 \\
\hline Pará & 8,6 & 2,4 & 1,9 & 4,4 \\
\hline Ceará & 11,3 & 5,2 & 3,6 & 2,5 \\
\hline Paraíba & 5,9 & 2,5 & 2,1 & 1,3 \\
\hline Bahia & 17,5 & 6,7 & 5,0 & 5,8 \\
\hline Minas Gerais & 9,1 & 4,9 & 3,0 & 1,1 \\
\hline Total(2) & 58,3 & 24,2 & 17,2 & 16,9 \\
\hline Brasil & 85,5 & 40,3 & 28,7 & 16,6 \\
\hline
\end{tabular}

Fonte: IBGE - Censo Agropecuário do Brasil de 1980 e 1985. (1) obtida a partir da tabela 21 pela divisão da coluna "Responsável" (de cada estado, do total desses estados e do País como um todo) por 2.379.473

(2) idem nota tabela 20 . 
No que se refere aos seis estados em questão, verificamos que a categoria Responsável e Membros não Remunerados da Familia responde por $58,3 \%$ do acréscimo de mão-de-obra rural, sendo que, deste acréscimo, 24,2 pontos percentuais ocorre devido ao aumento de homens maiores de 14 anos; 17,2 pontos percentuais ocorre devido ao aumento de mulheres maiores de 14 anos e 16,9 pontos percentuais ocorre devido ao aumento de menores de 14 anos.

Os dados da tabela 22 indicam um maior crescimento relativo de "homens maiores de 14 anos" sobre "mulheres maiores de 14 anos" e "menores de 14 anos" em todos os estados analisados (exceto o Pará) e para o Brasil como um todo; mostrando que não foi predominante a participação de menores de 14 anos e de mulheres no aumento de pessoas ocupadas na agricultura, no período 1980-85.

\subsection{Evolução da produtividade do trabalho na agricultura brasileira}

Calculamos a produtividade do trabalho no setor agropecuário - a nível de Brasil e dos estados que mais contribuíram para o aumento da mão-de-obra rural no primeiro qüinqüênio da década dos oitenta - utilizando o conceito de valor agregado por equivalente-homem, conforme a metodologia descrita no item 2.3 .1 do segundo capítulo, e empregando os dados dos Censos Agropecuários.

A análise dos dados de produtividade da mão-de-obra agrícola, para o Brasil como um todo, nos anos de 1970, 1975, 1980 e 1985 estão compilados na tabela 23:(18)

(18) Encontram-se no APENDICE 3 - tabelas 3.1 a 3.82 - todos os cálculos que conduziram aos resultados de valor agregado por equivalente-homem para o Brasil e os seis estados em análise. 
Tabela 23. Valor agregado (Cz\$ 1000 de 1985) por equivalente-homem no BRASIL - 1970, 1975, 1980 e 1985.

\begin{tabular}{cccccc}
\hline \multirow{2}{*}{ ano } & \multicolumn{2}{c}{ Produtividade do trabalho } & & \multicolumn{2}{c}{ VA/EH } \\
\cline { 2 - 3 } & $\begin{array}{c}\text { média } \\
(\mathrm{VA} / \mathrm{EH})\end{array}$ & $\begin{array}{c}\text { marginal } \\
(\Delta \mathrm{VA} / \Delta \mathrm{EH})\end{array}$ & & $\begin{array}{c}\text { variação } \\
(\text { q })\end{array}$ & $\begin{array}{c}\text { taxas } \\
(8 \text { ao ano })\end{array}$ \\
\hline 1970 & 3,235 & 19,26 & & 64,3 & 10,44 \\
1975 & 5,316 & 14,80 & & 13,9 & 2,65 \\
1980 & 6,058 & 8,63 & & 5,3 & 1,04 \\
\hline
\end{tabular}

Fonte: valores calculados a partir dos dados dos censos Agropecuários (IBGE)

Podemos observar na tabela 23 que a produtividade média do trabalho (VA/EH) cresce nos períodos 1970-75, 1975-80 e 1980-85, muito embora se verifique um decréscimo no seu ritmo de crescimento (apenas $1,04 \%$ ao ano de 1980 a 1985, contra 2,65\% ao ano de 1975 a 1980 e $10,44 \%$ ao ano de 1970 a 1975).

Porém, isso é coerente com a desaceleração no emprego de capital no setor agrícola na primeira metade da década dos oitenta (conforme tabela 24).

Ressaltamos, ainda, que a produtividade marginal $(\Delta \mathrm{VA} / \Delta \mathrm{EH})$ do fator trabalho - apesar de decrescente - é positiva, o que implica num acréscimo no produto total quando se emprega uma unidade a mais de trabalho.

A análise dos seis estados que mais contriburram para o aumento das pessoas ocupadas na agricultura brasileira, no período 1980-85, diverge em alguns aspectos (conforme tabelas 25 a 30 ). 
Tabela 24. Taxas médias qüinqüênais de crescimento do número de tratores e do consumo aparente de fertilizantes e de defensivos agrícolas BRASIL, 1970 a 1985 .

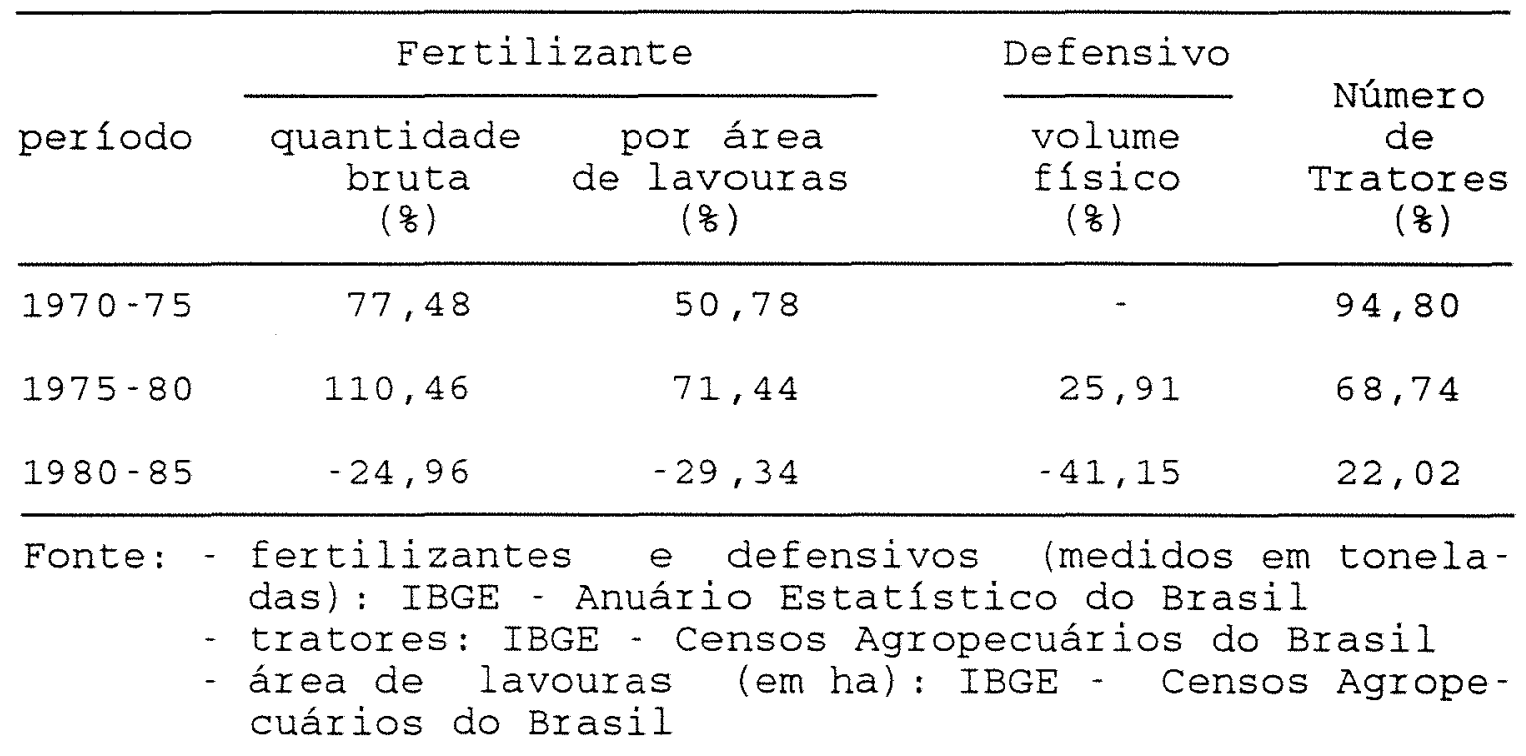

Tabela 25. Valor agregado (Cz\$ 1000 de 1985) por equivalente-homem em RONDÔNIA - 1970, 1975, 1980 e 1985.

\begin{tabular}{|c|c|c|c|c|}
\hline \multirow{2}{*}{ ano } & \multicolumn{2}{|c|}{ Produtividade do trabalho } & \multicolumn{2}{|c|}{$\mathrm{VA} / \mathrm{EH}$} \\
\hline & $\begin{array}{c}\text { média } \\
(\mathrm{VA} / \mathrm{EH})\end{array}$ & $\begin{array}{r}\text { marginal } \\
(\triangle \mathrm{VA} / \Delta \mathrm{EH})\end{array}$ & $\begin{array}{c}\operatorname{variação~} \\
\left(\frac{8}{8}\right)\end{array}$ & $\begin{array}{c}\text { taxas } \\
\left(\begin{array}{c}\text { ta a ano })\end{array}\right.\end{array}$ \\
\hline 1970 & 5,304 & & & \\
\hline 1975 & 3159 & 2,60 & $-40,4$ & $-9,85$ \\
\hline 1980 & 3,310 & 3,50 & 4,7 & 0,94 \\
\hline 1985 & 3,847 & 4,53 & 16,2 & 3,05 \\
\hline
\end{tabular}

Fonte: valores calculados a partir dos dados dos censos Agropecuários (IBGE)

Verifica-se que o ceará (tabela 27) é o único estado em que a produtividade média do trabalho decresce no 
último período (1980-85). No entanto, nos estados de Rondônia, da Paraíba e de Minas Gerais (tabelas 25, 28 e 30, Iespectivamente), não somente a produtividade média cresce no período 1980-85, como também se observa acréscimo no seu ritmo de crescimento.

Tabela 26. Valor agregado (Cz\$1000 de 1985) por equivalente-homem no PARÁ - 1970, 1975, 1980 e 1985.

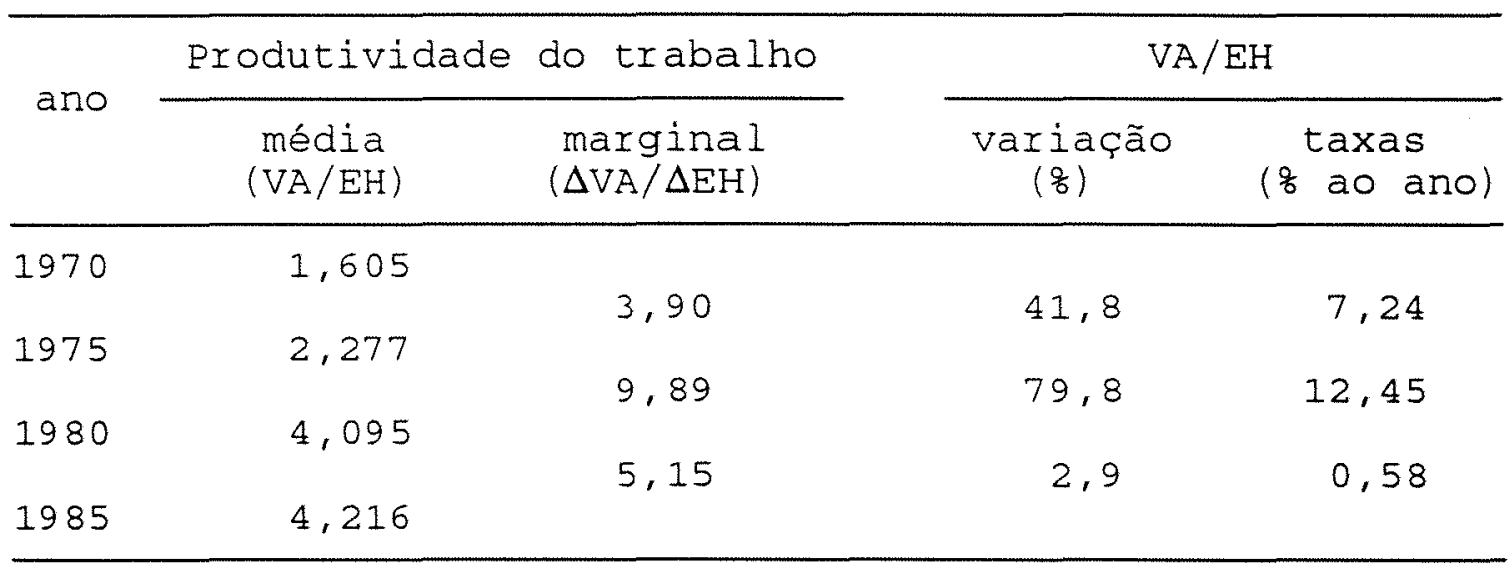

Fonte: valores calculados a partir dos dados dos censos Agropecuários (IBGE)

Tabela 27. Valor agregado (Cz\$ 1000 de 1985) por equivalente-homem no CEARÁ - 1970, 1975, 1980 e 1985.

\begin{tabular}{|c|c|c|c|c|}
\hline \multirow{2}{*}{ ano } & \multicolumn{2}{|c|}{ Produtividade do trabalho } & \multicolumn{2}{|c|}{$\mathrm{VA} / \mathrm{EH}$} \\
\hline & $\begin{array}{l}\text { média } \\
\text { (VA/EH) }\end{array}$ & $\begin{array}{c}\operatorname{marginal} \\
(\Delta \mathrm{VA} / \Delta \mathrm{EH})\end{array}$ & $\begin{array}{l}\operatorname{variação~} \\
\left(\frac{q}{8}\right)\end{array}$ & $\begin{array}{c}\text { taxas } \\
\left(\begin{array}{c}8 \\
\text { ao ano }\end{array}\right.\end{array}$ \\
\hline 1970 & 1,105 & & & \\
\hline 1975 & 2,057 & 19,91 & 86,2 & 13,24 \\
\hline 1980 & 2,485 & 11,89 & 20,8 & 3,85 \\
\hline 1985 & 2,444 & 2,29 & $-1,6$ & $-0,33$ \\
\hline
\end{tabular}

Fonte: valores calculados a partir dos dados dos censos Agropecuários (IBGE) 
Tabela 28. Valor agregado (Cz\$ 1000 de 1985) por equivalente-homem na PARAIBA - 1970, 1975, 1980 e 1985.

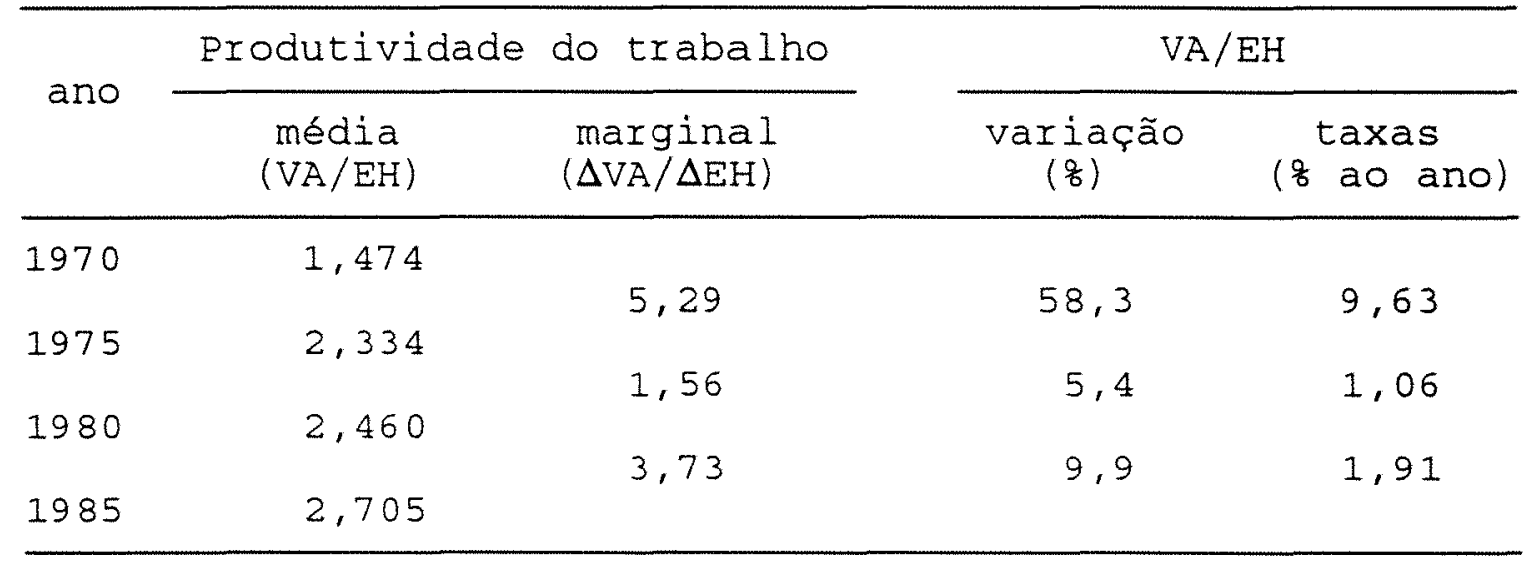

Fonte: valores calculados a partir dos dados dos censos Agropecuários (IBGE)

Tabela 29. Valor agregado (Cz\$1000 de 1985) por equivalente-homem na BAHIA - 1970, 1975, 1980 e 1985.

\begin{tabular}{|c|c|c|c|c|c|}
\hline \multirow{2}{*}{ ano } & \multicolumn{2}{|c|}{ Produtividade do trabalho } & \multicolumn{3}{|c|}{$\mathrm{VA} / \mathrm{EH}$} \\
\hline & $\begin{array}{l}\text { média } \\
(\mathrm{VA} / \mathrm{EH})\end{array}$ & $\begin{array}{r}\text { marginal } \\
(\Delta V A / \Delta E H)\end{array}$ & $\begin{array}{c}\text { variação } \\
\left(\frac{q}{z}\right)\end{array}$ & & $\begin{array}{l}\text { axas } \\
\text { ao ano) }\end{array}$ \\
\hline 1970 & 2,007 & & & & \\
\hline 1975 & 3,016 & 9,64 & 50,2 & & 8,48 \\
\hline 1980 & 3,721 & 8,98 & 23,3 & & 4,29 \\
\hline 1985 & 4,065 & 5,49 & 9,2 & & 1,78 \\
\hline
\end{tabular}


Tabela 30. Valor agregado (Cz\$1000 de 1985) por equivalente-homem em MINAS GERAIS - 1970, 1975, 1980 e 1985 .

\begin{tabular}{|c|c|c|c|c|}
\hline \multirow{2}{*}{ ano } & \multicolumn{2}{|c|}{ Produtividade do trabalho } & \multicolumn{2}{|c|}{$\mathrm{VA} / \mathrm{EH}$} \\
\hline & $\begin{array}{l}\text { média } \\
\text { (VA/EH) }\end{array}$ & $\begin{array}{c}\text { marginal } \\
(\Delta \mathrm{VA} / \Delta \mathrm{EH})\end{array}$ & $\begin{array}{c}\operatorname{variação~} \\
\left(\frac{q}{8}\right)\end{array}$ & $\begin{array}{c}\text { taxas } \\
\left(\begin{array}{l}\text { g ao ano })\end{array}\right.\end{array}$ \\
\hline 1970 & 3,527 & & & \\
\hline 1975 & 5,815 & 38,31 & 64,8 & 10,52 \\
\hline 1980 & 6,564 & 11,95 & 12,8 & 2,45 \\
\hline 1985 & 7.771 & 13,46 & 18,4 & 3,43 \\
\hline
\end{tabular}

Fonte: valores calculados a partir dos dados dos censos Agropecuários (IBGE)

Em uma avaliação global das tabelas 25 a 30 temos que Pará e Bahia apresentaram a mesma tendência - aumento da produtividade média do trabalho com decréscimo no seu ritmo de crescimento - que o Brasil como um todo, especialmente no perído 1980-85. O estado do ceará é o único em que se observou diminuição da produtividade média. os demais estados (Rondônia, Paraíba e Minas Gerais) aumentaram a taxa de crescimento da produtividade média do trabalho.

Sendo esses os seis estados que mais contribuíram para o incremento da mão-de-obra rural no primeiro qüinqüênio da década de 80 , de acordo com os censos Agropecuários, é notável que eles - exceto Pará e ceará tenham apresentado taxas de crescimento da produtividade do trabalho superior à do Brasil como um todo (vide dados compilados na tabela 31); o que também indica não serem eles os responsáveis pela baixa taxa de crescimento da produtividade média do trabalho no Brasil como um todo. 
Tabela 31. Variação e taxas médias anuais de crescimento da produtividade média do trabalho (VA/EH), BRASIL e ESTADOS - 1970 a 1985.

\begin{tabular}{|c|c|c|c|c|}
\hline \multirow{2}{*}{ estados } & \multicolumn{2}{|c|}{ variação (q) } & \multicolumn{2}{|c|}{ taxas (z ao ano) } \\
\hline & $75-80$ & $80-85$ & $75-80$ & $80-85$ \\
\hline Rondônia & 4,78 & 16,22 & 0,94 & 3,05 \\
\hline Pará & 79,83 & 2,95 & 12,45 & 0,58 \\
\hline Ceará & 20,82 & $-1,65$ & 3,85 & $-0,33$ \\
\hline Paraíba & 5,41 & 9,95 & 1,06 & 1,91 \\
\hline Bahia & 23,39 & 9,24 & 4,29 & 1,78 \\
\hline M.Gerais & 12,87 & 18,39 & 2,45 & 3,43 \\
\hline BRASIL & 13,95 & 5,31 & 2,65 & 1,04 \\
\hline
\end{tabular}

Fonte: valores calculados a partir dos dados dos censos Agropecuários (IBGE)

Não encontramos, a nível de estados, dados disponiveis sobre o consumo fisico de fertilizantes e de defensivos agrícolas, por isso, restringimo-nos à análise de tratores em cada estado.

Observamos (tabela 32) uma queda generalizada na taxa de crescimento de tratores para os seis estados em análise no período 1980-85 em relação ao período anterior, como já havíamos verificado para o Brasil como um todo (tabela 24).

Apenas Rondônia apresenta uma taxa de crescimento do número de tratores superior à do Brasil como um todo, porém, o número de tratores neste estado é pequeno.

Verifica-se taxas negativas de crescimento do número de tratores nos estados do Pará e da Paraíba. Esses dois estados mais o ceará são os que apresentam taxas de 
crescimento do número de tratores bastante inferiores à taxa observada no total brasileiro.

Bahia e Minas Gerais tiveram uma taxa de crescimento do número de tratores bem próxima à do Brasil como um todo.

Tabela 32. Taxas médias qüinqüênais de crescimento do número de tratores nos estabelecimentos recenseados - BRASIL E ESTADOS - 1970 a 1985.

\begin{tabular}{lccc}
\hline \multirow{2}{*}{ estados } & \multicolumn{2}{c}{ taxas de crescimento de tratores $(\%)$} \\
\cline { 2 - 4 } & $1970-75$ & $1975-80$ & $1980-85$ \\
\hline Rondônia & 30,77 & 738,24 & 58,42 \\
Pará & 54,01 & 232,22 & $-41,60$ \\
Ceará & 93,32 & 173,50 & 8,17 \\
Paraíba & 72,26 & 119,56 & $-7,24$ \\
Bahia & 136,24 & 207,44 & 19,51 \\
M.Gerais & 122,69 & 117,89 & 22,24 \\
Brasil & 94,80 & 68,74 & 22,02 \\
\hline
\end{tabular}

Fonte: IBGE - Censos Agropecuários

A análise acima sobre o comportamento da produtividade do trabalho agrícola no período de 1980 a 1985 não corrobora a afirmação de que o aumento do emprego nesse período se caracterizou por ser baseado em subemprego e subocupação. 


\subsection{Evolução dos salários rural e urbano}

Realizamos neste item o estudo de diversos Índices de salário, especificamente, do salário rural (do empregado temporário e do empregado permanente), do salário mínimo e do salário de servente da construção civil.

o período analisado é 1977-87, especialmente o primeiro qüinqüênio da década dos oitenta.

A análise se restringe ao Brasil como um todo e àqueles estados que mais contribuiram para o incremento das pessoas ocupadas na agricultura brasileira, no primeiro qüinqüênio da década de 80 , segundo os dados dos censos Agropecuários.

As tabelas 33 a 39 a seguir mostram os resultados obtidos(19).

Tabela 33. Indice do salário médio real(1) - Brasil, 1977 a 1987 .

\begin{tabular}{lrrrr}
\hline \multirow{5}{c}{ Indice } \\
\cline { 2 - 5 } ano & Servente & Mínimo & Permanente & Temporário \\
\hline 1977 & 105,27 & 78,87 & 96,47 & 96,47 \\
1978 & 107,18 & 79,87 & 101,28 & 94,45 \\
1979 & 104,27 & 99,36 & 103,74 & 97,42 \\
1980 & 100,00 & 100,00 & 100,00 & 100,00 \\
1981 & 109,08 & 68,04 & 100,49 & 96,49 \\
1982 & 114,40 & 71,07 & 102,96 & 90,05 \\
1983 & 88,56 & 61,09 & 90,51 & 79,76 \\
1984 & 75,96 & 55,93 & 84,90 & 75,16 \\
1985 & 80,46 & 58,95 & 96,45 & 87,94 \\
1986 & 94,29 & 58,17 & 88,60 & 101,60 \\
1987 & 95,06 & 46,73 & 78,67 & 85,37 \\
\hline
\end{tabular}

Fonte: SINAPI (IBGE), CEA (IBRE-FGV) e DIEESE

(1) deflacionado pelo IGP-DI (base: março/86=100)

(19) Encontram-se no APENDICE 4 tabelas 4.1 a 4.7 - os dados sobre salário médio nominal utilizados nos cálculos deste item. 
Tabela 34. Indice do salário médio real(1) - Rondônia, 1977 a 1987

\begin{tabular}{lrrrr}
\hline \multirow{5}{*}{ ano } & \multicolumn{5}{c}{ Indice } \\
\cline { 2 - 5 } & Servente & Minimo & Permanente & Temporário \\
\hline 1977 & 106,88 & 77,77 & - & - \\
1978 & 120,81 & 78,79 & 101,19 & 85,05 \\
1979 & 97,73 & 98,60 & 105,25 & 92,46 \\
1980 & 100,00 & 100,00 & 100,00 & 100,00 \\
1981 & 116,74 & 68,16 & 103,79 & 79,51 \\
1982 & 107,00 & 71,41 & 103,93 & 83,92 \\
1983 & 89,05 & 61,06 & 95,00 & 85,17 \\
1984 & 67,65 & 57,97 & 88,36 & 68,81 \\
1985 & - & 61,60 & 100,21 & 77,66 \\
1986 & 66,07 & 60,79 & 115,40 & 110,40 \\
1987 & 68,27 & 48,83 & 83,20 & 78,26 \\
\hline
\end{tabular}

Fonte: SINAPI (IBGE), CEA (IBRE-FGV) e DIEESE

(1) deflacionado pelo IGP-DI (base: março/86=100)

Tabela 35. Índice do salário médio real(1) - Pará, 1977 a 1987 .

\begin{tabular}{lrrrr}
\hline \multicolumn{5}{c}{ indice } \\
\cline { 2 - 5 } ano & Servente & Minimo & Permanente & Temporário \\
\hline 1977 & 99,35 & 77,77 & 87,07 & 82,70 \\
1978 & 98,52 & 78,79 & 99,92 & 95,73 \\
1979 & 104,84 & 98,60 & 97,65 & 89,83 \\
1980 & 100,00 & 100,00 & 100,00 & 100,00 \\
1981 & 114,97 & 68,16 & 102,44 & 90,01 \\
1982 & 120,34 & 71,41 & 96,74 & 87,13 \\
1983 & 116,27 & 61,06 & 82,60 & 82,80 \\
1984 & 95,57 & 57,97 & 90,65 & 80,48 \\
1985 & 94,02 & 61,60 & 99,87 & 86,97 \\
1986 & 97,32 & 60,79 & 88,03 & 114,21 \\
1987 & 122,41 & 48,83 & 80,95 & 83,76 \\
\hline
\end{tabular}

Fonte: SINAPI (IBGE), CEA (IBRE-FGV) e DIEESE

(1) deflacionado pelo IGP-DI (base: $\operatorname{mar} c 0 / 86=100$ ) 
Tabela 36. Indice do salário médio real(1) - Ceará, 1977 a 1987 .

\begin{tabular}{lcrrr}
\hline \multirow{5}{c}{ Indice } \\
\cline { 2 - 5 } ano & Servente & Mínimo & Permanente & Temporário \\
\hline 1977 & 105,45 & 75,93 & 93,26 & 98,46 \\
1978 & 102,35 & 76,93 & 91,98 & 95,10 \\
1979 & 104,70 & 97,63 & 102,59 & 96,52 \\
1980 & 100,00 & 100,00 & 100,00 & 100,00 \\
1981 & 113,09 & 69,17 & 94,98 & 99,82 \\
1982 & 115,20 & 74,42 & 94,43 & 90,56 \\
1983 & 101,00 & 65,80 & 75,89 & 75,91 \\
1984 & 93,14 & 62,47 & 77,93 & 78,41 \\
1985 & 116,44 & 66,39 & 85,35 & 83,60 \\
1986 & 100,14 & 65,52 & 93,26 & 106,07 \\
1987 & 111,51 & 52,62 & 78,18 & 76,18 \\
\hline
\end{tabular}

Fonte: SINAPI (IBGE), CEA (IBRE-FGV) e DIEESE

(1) deflacionado pelo IGP-DI (base: março/86=100)

Tabela 37. Indice do salário médio real(1) - Paraíba, 1977 a 1987 .

\begin{tabular}{lrrrr}
\hline \multirow{5}{c}{ Indice } \\
\cline { 2 - 5 } ano & Servente & Mínimo & Permanente & Temporário \\
\hline 1977 & 106,76 & 75,93 & 86,26 & 96,09 \\
1978 & 110,91 & 76,93 & 97,54 & 94,87 \\
1979 & 106,75 & 97,63 & 101,14 & 97,58 \\
1980 & 100,00 & 100,00 & 100,00 & 100,00 \\
1981 & 95,46 & 69,17 & 93,44 & 94,44 \\
1982 & 120,56 & 74,42 & 88,02 & 83,20 \\
1983 & 99,07 & 65,80 & 81,24 & 77,28 \\
1984 & 100,46 & 62,47 & 75,20 & 73,71 \\
1985 & - & 66,39 & 80,76 & 77,01 \\
1986 & 121,62 & 65,52 & 93,29 & 92,77 \\
1987 & 134,74 & 52,62 & 74,64 & 73,43 \\
\hline
\end{tabular}

Fonte: SINAPI (IBGE), CEA (IBRE-FGV) e DIEESE

(1) deflacionado pelo IGP-DI (base: março/86=100) 
Tabela 38. Indice do salário médio real(1) - Bahia, 1977 a 1987 .

\begin{tabular}{lrrrr}
\hline \multirow{5}{c}{ Indice } \\
\cline { 2 - 5 } ano & Servente & Mínimo & Permanente & Temporário \\
\hline 1977 & 99,58 & 75,93 & 103,24 & 90,06 \\
1978 & 110,01 & 76,93 & 113,79 & 96,77 \\
1979 & 102,14 & 97,63 & 122,36 & 104,90 \\
1980 & 100,00 & 100,00 & 100,00 & 100,00 \\
1981 & 95,14 & 69,17 & 99,88 & 91,97 \\
1982 & 96,19 & 74,42 & 99,22 & 74,56 \\
1983 & 72,59 & 65,80 & 89,93 & 70,29 \\
1984 & 71,96 & 62,47 & 94,54 & 70,02 \\
1985 & 76,33 & 66,39 & 108,22 & 82,90 \\
1986 & 81,38 & 65,52 & 94,44 & 89,51 \\
1987 & 87,66 & 52,62 & 83,61 & 70,79 \\
\hline
\end{tabular}

Fonte: SINAPI (IBGE), CEA (IBRE-FGV) e DIEESE

(1) deflacionado pelo IGP-DI (base: $\operatorname{mar} c$ $/ 86=100$ )

Tabela 39. Indice do salário médio real(1) - Minas Gerais, 1977 a 1987 .

\begin{tabular}{lcccr}
\hline \multirow{5}{c}{ indice } \\
\cline { 2 - 5 } ano & Servente & Mínimo & Permanente & Temporário \\
\hline 1977 & 109,06 & 82,03 & 100,38 & 97,83 \\
1978 & 107,91 & 83,02 & 100,69 & 94,99 \\
1979 & 104,92 & 101,33 & 107,02 & 100,86 \\
1980 & 100,00 & 100,00 & 100,00 & 100,00 \\
1981 & 104,19 & 67,06 & 95,36 & 93,61 \\
1982 & 107,82 & 68,21 & 94,62 & 83,06 \\
1983 & 82,19 & 57,49 & 85,78 & 73,19 \\
1984 & 67,70 & 49,20 & 79,36 & 70,78 \\
1985 & 72,01 & 51,03 & 89,86 & 87,13 \\
1986 & 89,87 & 50,36 & 85,55 & 103,14 \\
1987 & 81,48 & 40,45 & 81,07 & 90,13 \\
\hline
\end{tabular}

Fonte: SINAPI (IBGE), CEA (IBRE-FGV) e DIEESE

(1) deflacionado pelo IGP-DI (base: março/86=100) 
Verifica-se para o período 1980-85 que os índices de salário médio das categorias empregado permanente, empregado temporário e servente da construção civil foram superiores ao índice de salário mínimo médio (veja as tabelas 33 a 39 ).

o salário dos empregados permanentes sofre menor perda real que o salário dos empregados temporários no período $1980-85$.

O Plano Cruzado (1986) pode ter beneficiado o salário rural, que recuperou parte das perdas anteriores, especialmente para a categoria empregados temporários.

A ocorrência de uma deterioração do salário relativo (salário na agricultura/salário mínimo e salário na agricultura/salário de servente), no período 1980-85, pode indicar que o aumento da mão-de-obra - observado nos dados do Censo Agropecuário naquele periodo - seja uma volta à agricultura de subsistência, gerando subocupação e subemprego no campo - conclusões dos trabalhos de MUELLER (1987), GRAZIANO DA SILVA (1987) e MARTINE (1987).

Verifica-se, para o Brasil como um todo, que o salário relativo (salário da agricultura/salário mínimo e salário da agricultura/salário servente) não se deteriora no período 1980-85 (veja a tabela 40).

Também não observamos nos estados analisados uma diminuição da relação salário rural/salário mínimo e salário rural/salário servente, no período 1980-85 (exceto os estados do Ceará e do Pará - tabelas 41 a 46).

- estado do ceará (conforme a tabela 43) apresenta a relação entre salários (rural/mínimo) abaixo de 1 (um), mas mesmo assim se nota, a partir de 1981, uma melhora do salário agrícola sobre o salário mínimo. 
Tabela 40. Salário relativo: agricultura/mínimo e agricultura/servente - Brasil, 1977 a 1987.

\begin{tabular}{lcccc}
\hline \multirow{5}{*}{ ano } & \multicolumn{5}{c}{ salário relativo } \\
\cline { 2 - 5 } & $\begin{array}{c}\text { perm./ } \\
\text { /mínimo }\end{array}$ & $\begin{array}{c}\text { temp./mínimo } \\
\text { /merm./ } \\
\text { /servente }\end{array}$ & $\begin{array}{c}\text { temp./ } \\
\text { /servente }\end{array}$ \\
\hline 1977 & 1,05 & 1,06 & 1,06 & 1,08 \\
1978 & 1,09 & 1,03 & 1,10 & 1,04 \\
1979 & 0,89 & 0,85 & 1,15 & 1,10 \\
1980 & 0,86 & 0,87 & 1,16 & 1,18 \\
1981 & 1,27 & 1,23 & 1,07 & 1,04 \\
1982 & 1,24 & 1,10 & 1,04 & 0,93 \\
1983 & 1,27 & 1,14 & 1,19 & 1,06 \\
1984 & 1,30 & 1,17 & 1,30 & 1,17 \\
1985 & 1,40 & 1,30 & 1,39 & 1,29 \\
1986 & 1,30 & 1,52 & 1,09 & 1,27 \\
1987 & 1,44 & 1,59 & 0,96 & 1,06 \\
\hline
\end{tabular}

Fonte: CEA (IBRE-FGV), SINAPI (IBGE) e DIEESE

nota: multiplicou-se o salário diário dos empregados temporários por 25 (dias) e o salário-hora dos serventes por 25 (dias) e 8 (horas).

Tabela 41. Salário relativo: agricultura/mínimo e agricultura/servente - Rondônia, 1977 a 1987.

\begin{tabular}{lcccc}
\hline \multirow{5}{*}{ ano } & \multicolumn{5}{c}{ salário relativo } \\
\cline { 2 - 5 } & $\begin{array}{c}\text { perm./ } \\
\text { /mínimo }\end{array}$ & $\begin{array}{c}\text { temp./ } / \text { mínimo } \\
\text { perm./ } \\
\text { /servente }\end{array}$ & $\begin{array}{c}\text { temp./ } \\
\text { /servente }\end{array}$ \\
\hline 1977 & - & - & - & - \\
1978 & 1,47 & 1,75 & 0,90 & 1,08 \\
1979 & 1,22 & 1,52 & 1,16 & 1,44 \\
1980 & 1,15 & 1,62 & 1,08 & 1,53 \\
1981 & 1,75 & 1,89 & 0,96 & 1,04 \\
1982 & 1,67 & 1,91 & 1,05 & 1,20 \\
1983 & 1,78 & 2,27 & 1,15 & 1,46 \\
1984 & 1,75 & 1,93 & 1,41 & 1,55 \\
1985 & 1,87 & 2,05 & - & - \\
1986 & 2,18 & 2,95 & 1,88 & 2,55 \\
1987 & 1,95 & 2,60 & 1,31 & 1,75 \\
\hline
\end{tabular}

Fonte: CEA (IBRE-FGV), SINAPI (IBGE) e DIEESE nota: idem tabela 39 
Tabela 42. Salário relativo: agricultura/mínimo e agricultura/servente - Pará, 1977 a 1987.

\begin{tabular}{lcccc}
\hline \multirow{4}{*}{ ano } & \multicolumn{5}{c}{ salário relativo } \\
\cline { 2 - 5 } & $\begin{array}{c}\text { perm./́nimo } \\
\text { /míniorm./ }\end{array}$ & $\begin{array}{c}\text { temp./mimo } \\
\text { /mínervente }\end{array}$ & $\begin{array}{c}\text { temp./ } \\
\text { /servente }\end{array}$ \\
\hline 1977 & 1,02 & 0,98 & 1,36 & 1,31 \\
1978 & 1,15 & 1,12 & 1,58 & 1,53 \\
1979 & 0,90 & 0,84 & 1,45 & 1,35 \\
1980 & 0,91 & 0,92 & 1,55 & 1,58 \\
1981 & 1,37 & 1,22 & 1,38 & 1,23 \\
1982 & 1,23 & 1,13 & 1,25 & 1,14 \\
1983 & 1,23 & 1,25 & 1,10 & 1,12 \\
1984 & 1,42 & 1,28 & 1,47 & 1,33 \\
1985 & 1,47 & 1,30 & 1,65 & 1,46 \\
1986 & 1,32 & 1,73 & 1,41 & 1,85 \\
1987 & 1,51 & 1,58 & 1,03 & 1,08 \\
\hline
\end{tabular}

Fonte: CEA (IBRE-FGV), SINAPI (IBGE) e DIEESE nota: idem tabela 39

Tabela 43. Salário relativo: agricultura/mínimo e agricultura/servente - Ceará, 1977 a 1987.

\begin{tabular}{lcccc}
\hline \multirow{4}{*}{ ano } & \multicolumn{4}{c}{ salário relativo } \\
\cline { 2 - 5 } & $\begin{array}{c}\text { perm./ } \\
\text { /mínimo }\end{array}$ & $\begin{array}{c}\text { temp./ } \\
\text { /mínimo }\end{array}$ & $\begin{array}{c}\text { perm./ } \\
\text { /servente }\end{array}$ & $\begin{array}{c}\text { temp./ } \\
\text { /servente }\end{array}$ \\
\hline 1977 & 0,85 & 0,84 & 1,12 & 1,11 \\
1978 & 0,83 & 0,80 & 1,14 & 1,10 \\
1979 & 0,73 & 0,64 & 1,24 & 1,09 \\
1980 & 0,69 & 0,65 & 1,27 & 1,19 \\
1981 & 0,95 & 0,93 & 1,06 & 1,05 \\
1982 & 0,88 & 0,79 & 1,04 & 0,93 \\
1983 & 0,80 & 0,75 & 0,95 & 0,89 \\
1984 & 0,86 & 0,81 & 1,06 & 1,00 \\
1985 & 0,89 & 0,81 & 0,93 & 0,85 \\
1986 & 0,98 & 1,05 & 1,18 & 1,26 \\
1987 & 1,03 & 0,94 & 0,89 & 0,81 \\
\hline
\end{tabular}

Fonte: CEA (IBRE-FGV), SINAPI (IBGE) e DIEESE nota: idem tabela 39 
Tabela 44. Salário relativo: agricultura/minimo e agricultura/servente - Paraíba, 1977 a 1987.

\begin{tabular}{lcccc}
\hline \multirow{5}{*}{ ano } & \multicolumn{5}{c}{ salário relativo } \\
\cline { 2 - 5 } & $\begin{array}{c}\text { perm./ } \\
\text { /mínimo }\end{array}$ & $\begin{array}{c}\text { temp./ } / \text { mínimo } \\
\text { perm./ } \\
\text { /servente }\end{array}$ & $\begin{array}{c}\text { temp./ } \\
\text { /servente }\end{array}$ \\
\hline 1977 & 0,80 & 1,03 & 1,07 & 1,37 \\
1978 & 0,90 & 1,00 & 1,17 & 1,30 \\
1979 & 0,73 & 0,81 & 1,26 & 1,39 \\
1980 & 0,71 & 0,81 & 1,33 & 1,52 \\
1981 & 0,96 & 1,11 & 1,30 & 1,51 \\
1982 & 0,84 & 0,91 & 0,97 & 1,05 \\
1983 & 0,87 & 0,95 & 1,09 & 1,19 \\
1984 & 0,85 & 0,96 & 0,99 & 1,12 \\
1985 & 0,86 & 0,94 & - & - \\
1986 & 1,01 & 1,15 & 1,02 & 1,16 \\
1987 & 1,00 & 1,13 & 0,74 & 0,83 \\
\hline
\end{tabular}

Fonte: CEA (IBRE-FGV), SINAPI (IBGE) e DIEESE

nota: idem tabela 39

Tabela 45. Salário relativo: agricultura/mínimo e agricultura/servente - Bahia, 1977 a 1987.

\begin{tabular}{|c|c|c|c|c|}
\hline \multirow{2}{*}{ ano } & \multicolumn{4}{|c|}{ salário relativo } \\
\hline & perm./ & temp./ & $\begin{array}{l}\text { perm./ } \\
\text { / servente }\end{array}$ & $\begin{array}{l}\text { temp./ } \\
\text { /servente }\end{array}$ \\
\hline 1977 & 1,11 & 1,16 & 1,22 & 1,27 \\
\hline 1978 & 1,21 & 1,23 & 1,22 & 1,24 \\
\hline 1979 & 1,03 & 1,05 & 1,41 & 1,44 \\
\hline 1980 & 0,82 & 0,97 & 1,18 & 1,41 \\
\hline 1981 & 1,18 & 1,30 & 1,24 & 1,36 \\
\hline 1982 & 1,09 & 0,98 & 1,22 & 1,09 \\
\hline 1983 & 1,12 & 1,04 & 1,46 & 1,36 \\
\hline 1984 & 1,24 & 1,09 & 1,55 & 1,37 \\
\hline 1985 & 1,33 & 1,22 & 1,67 & 1,53 \\
\hline 1986 & 1,18 & 1.33 & 1,37 & 1,55 \\
\hline 1987 & 1,30 & 1,31 & 1,13 & 1,14 \\
\hline
\end{tabular}

Fonte: CEA (IBRE-FGV), SINAPI (IBGE) e DIEESE nota: idem tabela 39 
Tabela 46. Salário relativo: agricultura/mínimo e agricultura/servente - Minas Gerais, 1977 a 1987.

\begin{tabular}{lcccc}
\hline \multirow{4}{*}{ ano } & \multicolumn{4}{c}{ salário relativo } \\
\cline { 2 - 5 } & $\begin{array}{c}\text { perm./ } \\
\text { /mínimo }\end{array}$ & $\begin{array}{c}\text { temp./minimo } \\
\text { /mim./ } \\
\text { /servente }\end{array}$ & $\begin{array}{c}\text { temp./ } \\
\text { /servente }\end{array}$ \\
\hline 1977 & 0,94 & 0,89 & 1,12 & 1,06 \\
1978 & 0,93 & 0,86 & 1,13 & 1,04 \\
1979 & 0,81 & 0,75 & 1,24 & 1,14 \\
1980 & 0,77 & 0,75 & 1,22 & 1,19 \\
1981 & 1,09 & 1,05 & 1,11 & 1,06 \\
1982 & 1,07 & 0,91 & 1,07 & 0,91 \\
1983 & 1,15 & 0,95 & 1,27 & 1,06 \\
1984 & 1,24 & 1,08 & 1,40 & 1,22 \\
1985 & 1,35 & 1,28 & 1,52 & 1,43 \\
1986 & 1,31 & 1,53 & 1,16 & 1,36 \\
1987 & 1,54 & 1,67 & 1,21 & 1,31 \\
\hline
\end{tabular}

Fonte: CEA (IBRE-FGV), SINAPI (IBGE) e DIEESE nota: idem tabela 39 


\section{CONCLUSÃO}

Nosso objetivo neste estudo foi analisar a evolução do mercado de trabalho na agricultura brasileira na década de 80, analisando especialmente as divergências constatadas nas conclusões dos autores que analisaram os dados censitários no período 1980-85 (MUELLER, 1987 ; GRAZIANO DA SILVA, 1987 e MARTINE, 1987) e dos autores que analisaram as PNADs (AGUIRRE e BACHA, 1989a,b).

Inicialmente, realizamos uma discussão sobre as duas fontes de informações: Censo Agropecuário e PNAD. Dessa discussão constatou-se que as divergências entre as duas fontes de dados se amenizam quando se compara somente - grupo de homens, quando se exclui as regiões Norte e Centro-Oeste, e também quando se analisa apenas a categoria dos empregados. Os dados da PNAD e do Censo Agropecuário são elaborados com metodologias diferentes, o que requer certa cautela ao compará-los.

A partir dessa constatação, passou-se a estudar separadamente os dados levantados pela PNAD e pelo censo Agropecuário a respeito das pessoas ocupadas no setor agrícola.

A análise da evolução e da composição da mão-de-obra na agricultura segundo os dados levantados pelas PNADs, no período 1976-89, mostrou - para o Brasil como um todo - a queda na participação relativa da categoria não remunerados e acréscimo relativo da categoria empregados (conforme já verificara AGUIRRE e BACHA, 1989a, 
considerando o período 1976-87).

A nível de macrorregiões, a análise constatou 0 mesmo resultado para o período 1976-89 apenas nas regiões Nordeste (de maior expressão, devido ao valor absoluto das pessoas ocupadas nestas duas categorias) e Centro-oeste. A região Norte, que apresentara essa tendência no perído 1984-86, já não volta a apresentá-la no período subsequente $(1987-89)$.

A análise, por estado, da composição das pessoas ocupadas na agropecuária das regiões Nordeste, Sudeste e Sul - utilizando os dados da PNAD - mostrou a mesma tendência apenas nos estados da Bahia, Maranhão, Paraíba, Minas Gerais, Espirito Santo, São paulo (exceto o $1^{\text {a }}$ período), Santa Catarina e Rio Grande do Sul. O estado do Ceará passou a exibir essa tendência somente no último período analisado (1987-89).

Portanto, o que se pode concluir é que, com os dados disponíveis, não se evidencia de forma generalizada nos estados brasileiros durante a década de 80 - a tendência de avanço dos empregados relativamente à redução dos não remunerados. Isso ocorre porque esses estados possuem padrões diferentes de desenvolvimento agrícola.

A análise dos dados dos censos Agropecuários sobre a evolução da mão-de-obra rural mostrou um incremento significativo de pessoas ocupadas no setor agropecuário, no período 1980-85: mais de 2,3 milhões de pessoas, contra pouco mais de $818 \mathrm{mil}$ pessoas no período 1975-80 (como haviam constatados os trabalhos de MARTINE, 1987; MUELLER, 1987 e GRAZIANO DA SILVA, 1987).

As regiões que mais concorreram para o aumento da mão-de-obra rural, no qüinqüênio 1980-85, foram: Nordeste $(50 \%)$, Norte $(30 \%)$ e sudeste $(19,5 \%)$. Sendo que praticamente $70 \%$ desse aumento concentrou-se em seis 
estados brasileiros: Rondônia, Pará, Ceará, Paraĺba, Bahia e Minas Gerais.

Procuramos verificar se 0 aumento das pessoas ocupadas na agricultura brasileira na primeira metade da década de 80 foi uma volta à agricultura de subsistência, gerando subemprego e subocupação no campo (conforme as conclusões dos trabalhos de MUELLER, 1987; GRAZIANO DA SILVA, 1987 e MARTINE, 1987). Para tanto, utilizamos outras informações, tais como: decomposição da mão-de-obra rural por categoria, faixa etária e sexo; produtividade do trabalho e evolução dos salários rural e urbano.

A decomposição da mão-de-obra, nas diversas categorias assinaladas pelo censo Agropecuário, mostrou que a categoria Responsável e Membros não Remunerados da Familia foi a que mais absorveu o incremento de mão-de-obra, tanto no Brasil como um todo como nos seis estados em análise.

A análise por faixa etária e por sexo dessa categoria (Responsável e Membros não Remunerados da Familia), indicou maior crescimento relativo de "homens maiores de 14 anos" sobre "mulheres maiores de 14 anos" e "menores de 14 anos" em todos os estados analisados (exceto - Pará) e para o Brasil como um todo; mostrando que não foi predominante a participação de menores de 14 anos e de mulheres no aumento de pessoas ocupadas na agricultura, no período $1980-85$.

No estudo realizado sobre a evolução da produtividade do trabalho na agricultura, para o Brasil como um todo, observou-se que a produtividade média (VA/EH) cresceu nos períodos 1970-75, 1975-80 e 1980-85, muito embora a taxas decrescentes (apenas 1,04\% ao ano de 1980 a 1985, contra $2,65 \%$ ao ano de 1975 a 1980 e $10,44 \%$ ao ano de 
1970 a 1975). Porém, isso é coerente com a desaceleração no emprego de capital ocorrida no setor agricola na primeira metade da década dos oitenta. E ainda, apesar de decrescente, a produtividade marginal ( $\triangle \mathrm{VA} / \Delta \mathrm{EH}$ ) do fator trabalho é positiva, o que implica num acréscimo no produto total para cada unidade adicional de trabalho.

os estados do Pará e da Bahia apresentaram a mesma tendência - aumento da produtividade média do trabalho com decréscimo no seu ritmo de crescimento - que o Brasil como um todo, especialmente no período 1980-85. O estado do ceará foi o único em que se observa a diminuição da produtividade média. Os demais estados (Rondônia, Paraíba e Minas Gerais), aumentaram a taxa de crescimento da produtividade média do trabalho.

A análise da evolução dos índices de salário médio, para o período 1980-85, à nível de Brasil e dos seis estados analisados, mostrou a superioridade desses índices para as categorias empregado permanente, empregado temporário e servente da construção civil em relação ao indice do salário mínimo médio.

- salário médio dos empregados permanentes apresentou menor perda real que o salário médio dos empregados temporários, no período 1980-85.

Verificou-se, para o Brasil como um todo, que o salário relativo (tanto o salário da agricultura/salário mínimo, como o salário da agricultura/salário servente) não se deteriorou. Não se observa também nos estados analisados - exceto ceará e pará - a diminuição da relação salário rural/salário mínimo e salário rural/salário servente no período $1980-85$.

Essas constatações sobre a composição da mão-de-obra rural, a evolução da produtividade do trabalho na agricultura e o comportamento do salário relativo 
(rural/minimo e rural/servente) não nos permitem afirmar que o aumento do emprego no campo no qüinqüênio 1980-85 foi um processo de subocupação.

Finalmente, cabe-nos ressaltar as limitações que essa dissertação apresenta.

Nosso trabalho procurou analisar o comportamento do mercado de trabalho rural na década de 80 tendo em vista a divergência de constatações existentes na literatura sobre esse tema.

o nosso interesse era verificar se os dados sobre a composição da mão-de-obra, segundo o sexo e a idade, mostrariam a mesma tendência de comportamento nas duas fontes ( $C A$ e PNAD), 0 que explicaria parte das discrepâncias entre os trabalhos de MARTINE (1987), MUELLER (1987), GRAZIANO DA SILVA (1987) e AGUIRRE e BACHA (1989a). Porém, a decomposição dos dados da PNAD por faixa etária e por sexo não se encontra disponivel - nas publicações desta fonte - para todas as categorias de ocupação. Os dados estão desagregados apenas para a categoria empregados, e tão somente quanto ao sexo.

Assim, novos estudos utilizando dados de fitas da PNAD e do censo Agropecuário poderão ser feitos buscando uma maior aproximação dos dados nas duas fontes. 


\section{BIBLIOGRAFIA}

AGUIRRE, Basilia M.B. (1987) Mercado de Trabalho Rural, Estado e Cooperativismo, Ensaios Econômicos n.67, Instituto de Pesquisa Econômica - IPE/USP -, São Paulo, 1987 .

AGUIRRE, Basilia M.B. (1989) "Perspectivas do Mercado de Trabalho Rural no Brasil" in Anais do XXVII Congresso Brasileiro de Economia e Sociologia Rural, vol. 2, pp. 190-209, Piracicaba/SP, 24 a 28 de julho de 1989.

AGUIRRE, Basilia M.B. e BACHA, Carlos J.C. (1989a) Mercado de Trabalho Rural e Suas Perspectivas, Relatório de Pesquisa do Banco Mundial, São Paulo, janeiro de 1989.

AGUIRRE, Basilia M.B. e BACHA, Carlos J.C. (1989b) "A Especialização da Mão-de-obra Rural no Brasil" in Anais do XXVII Congresso Brasileiro de Economia e Sociologia Rural, vol.1, pp. 572-584, Piracicaba/SP, 24 a 28 de julho de 1989 .

ARAÚJo, Paulo F.C. et alii (1986) "Mercado de Trabalho na Agricultura" in Boletim Agricultura da Fundação de Estudos Agrários Luiz de Queiróz, ano VI, $\mathrm{n}^{\mathrm{e}} 1 / 2, \mathrm{pp}$. 1-7, Piracicaba/SP, 1986.

BARROS, José R.M., PASTORE, A.C. e RIZZIERE, J. (1977) "A Evolução Recente da Agricultura Brasileira" in Estudos 
sobre a Modernização da Agriculturà Brasileira, IPE, São Paulo, 1977.

CACCIAMALI, Maria C. (1989) "Emprego no Brasil durante a Primeira Metade da Década de $80 "$ in SEDLACEK, G.L. e BARRos, R.P. Mercado de Trabalho e Distribuição de Renda: uma Coletânea, IPEA/INPES, Monografia n.35, pp. 155-178, Rio de Janeiro, 1989.

DELFIM NETO, A. et alii (1969) "Agricultura e Desenvolvimento Econômico no Brasil" in Estudos ANPES n.5, São Paulo, 1969.

DIAS, Guilherme L.S. (1989a) "O Ajustamento da Economia e o setor Agrícola" in $V$ seminário sobre problemas $e$ Perspectivas da Agricultura, ESALQ-USP, Departamento de Economia e Sociologia Rural, mimeo, Piracicaba/SP, 19 a 21 de setembro de 1989.

DIAS, Guilherme L.S. (1989b) "O Papel da Agricultura no Processo de Ajustamento - Nota Adicional" in Anais do XXVII Congresso Brasileiro de Economia e Sociologia Rural, vol.2, pp. 310-317, Piracicaba/SP, 24 a 28 de julho de 1989 .

FARIA, Vilmar (1986) "Mudanças na Ocupação do Emprego e na Estrutura das Ocupações" in BACHA, E. e KLEIN, H.S. (org.) A Transição Incompleta: Brasil desde 1945, pp. 75-109, Editora Paz e Terra, Rio de Janeiro, 1986.

FUNDAÇÃO GETÚLIO VARGAS, IBRE, centro de contas Nacionais (1984) Contas Nacionais do Brasil - Metodologia e Tabelas Estatísticas. Rio de Janeiro, 48p. 
FUNDAÇÃO GETÚLIO VARGAS, IBRE, centro de Estudos Agrícolas (1985) Agropecuária - Preços Médios de: arrendamento, vendas de terras, salários, empreitadas, transportes 1966 a 1988.

GASQUES, José G. e VILLA VERdE, Carlos M. (1990) "Crescimento da Agricultura Brasileira e Politica Agricola nos Anos Oitenta" in Anais do XXVIII Congresso Brasileiro de Economia e Sociologia Rural, vol.1, pp. 185-213, Florianópolis/sC, 22 a 27 de julho de 1990.

GASQUES, José G. e PAIVA, Adelina (1984) "Transformações na Agricultura: Processos de Produção e Emprego" in Seminário sobre Mercado de Trabalho e Emprego Rural no Brasil, mimeo, Piracicaba/SP, 11 e 12 de dezembro de 1984 .

GRAZIANO DA SILVA, José e KAGEYAMA, Angela A. (1982) "Como Mudou o Emprego no Campo" in Reforma Agrária 12(3): 67 -70 , mai/jun 1982 .

GRAZIANO DA SILVA, José e KAGEYAMA, Angela A. (1983a) "Pessoal Ocupado na Agricultura, 1970-80" in Reforma Agrária 13(01/02):40-42, jan/abr 1983.

GRAZIANO DA SILVA, José e KAGEYAMA, Angela A. (1983b) "Emprego e Relações de Trabalho na Agricultura Brasileira: uma Análise dos Dados Censitários de 1960 , 70 e 75" in Pesquisa e planejamento Econômico $13(1): 235-266$, abril de 1983 .

GRAZIANO DA SILVA, José (1987) "Pessoal Ocupado: alguns Resultados Preliminares do Censo Agropecuário de $1985^{\prime \prime}$ 
in IPEA Análise dos Dados do Censo Agropecuário de 1985, Edição Especial, pp. 42-62, Brasilia/DF, 1987.

GRAZIANO DA SILVA, José (1989) "Estimativas do Emprego Agrícola a Partir dos Coeficientes Técnicos por Produto - Brasil, 1984-87" in Anais do XXVII Congresso Brasileiro de Economia e Sociologia Rural, Piracicaba/SP, 24 a 28 de julho de 1989.

GRILICHES, S. (1963) "Sources of Measured Productivity Growth: United states Agriculture" in Journal of Political Economy, agosto, 1963.

GUIMARÃES, L.S.P., INNOCÊNCIO, N.R. e BRITO, S.R. (1984) "O Trabalhador Volante na Agricultura" in Revista Brasileira de Geografia $46(1): 5-78$, jan/mar, 1984.

HAYAMI, Y. e RUTTAN, V. (1971) Agricultural Development: an Internacional Perspective. The John Hopkins Press: Baltimore, 1971.

HOFFMANN, Rodolfo; CARVALHO, Abdias V.; KAGEYAMA, Angela; WIENDL, M. de Lourdes T.B.; QUEDA, Oriowaldo (1985) "Inovações Tecnológicas e Transformações Recentes na Agricultura Brasileira" in Relatório de Pesquisa FINEP-FEALQ/ESALQ/USP, pp.684-689, Piracicaba/SP, 1985.

HOFFMANN, Rodolfo e JAMAS, Antonio L. (1990) "A Produtividade da Terra e do Trabalho na Agricultura de 332 Microrregiões do Brasil" in Anais do XXVIII Congresso Brasileiro de Economia e Sociologia Rural, vol. 1, pp. 21-40, Florianópolis/SC, 22 a 27 de julho de 1990. 
HOMEM DE MELO, Fernando (1985) Prioridade Agrícola: Sucesso ou Fracasso?, Estudos Econômicos - FIPE, São Paulo, Pioneira, 1985 .

LOPES, Mauro de R. (1989) "Os Efeitos das Politicas Macroeconômicas sobre a Agricultura", Companhia de Financiamento da Produção, Coleção Análise e Pesquisa n.37, Brasilia/DF, julho de 1989.

MARTINE, George (1987) "A Evolução Recente da Estrutura de Produção Agropecuária: Algumas Notas Preliminares" in IPEA Análise dos Dados do Censo Agropecuário de 1985. Edição Especial, pp. 63-88, Brasilia/DF, 1987.

MARTINE, George e ARIAS, Alfonso R. (1987) "A Evolução do Emprego no Campo" in Revista Brasileira de Estudos de Popłlação 4(2):39-84, jul/dez 1987.

MUELlER, Charles C. (1987) "A Evolução Recente da - Agropecuária Brasileira segundo os Dados dos Censos Agropecuários" in IPEA Análise dos Dados do Censo Agropecuário de 1985, Edição Especial, pp. 11-41, Brasilia/DF, 1987 .

NOVO SISTEMA DE CONTAS NACIONAIS: metodologia e resultados provisórios, ano-base 1980. Textos para Discussão do IBGE, vol. 1, $\mathrm{n}^{2}$ 10, Rio de Janeiro, pp. 164, dezembro de 1988 .

REZENDE, Gervásio C. (1989a) "Controvérsias de Economia Agrícola: uma Revisão critical in Anais do XII Encontro Nacional de Economia, vol.4, pp. 1717-1752, Fortaleza, dezembro de 1989. 
REZENDE, Gervásio C. (1989b) "Agricultura e Ajuste Externo no Brasil: Novas Considerações" in Pesquisa e Planejamento Econômico 19(3):553-578, dezembro de 1989 .

VICENTE, Maria C.M. (1989) O Mercado de Mão-de-Obra Volante na Agricultura Paulista, $1974 / 75$ a $1986 / 87$, tese de mestrado, ESALQ-USP, Piracicaba/SP, 1989. 


\title{
$\begin{array}{lllllllll}A & P & \hat{E} & N & D & I & C & E & 1\end{array}$
}

\author{
Decomposição por idade e por sexo das \\ pessoas ocupadas na agropecuária, segundo \\ os Censos Agropecuários e as PNADs
}


Tabela 1.1 - Total das pessoas ocupadas na agropecuária, segundo os Censos Agropecuários e as PNADs Regiões: Nordeste, Sudeste e sul.

\begin{tabular}{|c|c|c|c|c|c|c|c|c|}
\hline \multirow{2}{*}{ ano } & \multicolumn{4}{|c|}{$\begin{array}{l}\text { Censo Agropecuário } \\
\text { total de pessoas ocupadas }\end{array}$} & \multicolumn{4}{|c|}{$\begin{array}{l}\text { P.N.A.D. } \\
\text { total de pessoas ocupadas }\end{array}$} \\
\hline & $\begin{array}{l}\text { Nordeste } \\
\text { (I) }\end{array}$ & $\begin{array}{l}\text { Sudeste } \\
\text { (2) }\end{array}$ & $\begin{array}{l}\text { Sul } \\
\text { (3) }\end{array}$ & $\begin{array}{c}\text { total } \\
(1+2+3)\end{array}$ & $\begin{array}{c}\text { Nordeste } \\
\text { (4) }\end{array}$ & $\begin{array}{l}\text { Sudeste } \\
\text { (5) }\end{array}$ & $\begin{array}{l}\text { Sul } \\
(6)\end{array}$ & $\begin{array}{c}\operatorname{total} \\
(4+5+6)\end{array}$ \\
\hline $\begin{array}{l}1975 \\
1976\end{array}$ & 8738763 & 4145513 & 4831843 & 17716119 & $\begin{array}{r}6568397 \\
(0,75)\end{array}$ & $\begin{array}{r}3503797 \\
(0,85)\end{array}$ & $\begin{array}{c}4045030 \\
(0,84)\end{array}$ & $\begin{array}{r}14117224 \\
(0,80)\end{array}$ \\
\hline 1979 & & 4 & & & $\begin{array}{r}6569403 \\
(0,70)\end{array}$ & $\begin{array}{c}3402711 \\
(0,79)\end{array}$ & $\begin{array}{c}4176223 \\
(0,95)\end{array}$ & $\begin{array}{r}14148337 \\
(0.78)\end{array}$ \\
\hline $\begin{array}{l}1980 \\
1981\end{array}$ & 9333172 & 4312211 & 4391811 & 18037194 & $\begin{array}{r}5366728 \\
(0,58)\end{array}$ & $\begin{array}{r}3517289 \\
(0,82)\end{array}$ & $\begin{array}{r}3474460 \\
(0,79)\end{array}$ & $\begin{array}{r}12358477 \\
(0,69)\end{array}$ \\
\hline 1984 & & & & & 6640346 & 3854856 & 3428648 & 13923850 \\
\hline 1985 & 10441667 & 4738188 & 4490282 & 19670137 & $\begin{array}{r}6790798 \\
(0,65)\end{array}$ & $\begin{array}{r}3798770 \\
(0,80)\end{array}$ & $\begin{array}{r}3522340 \\
(0.78)\end{array}$ & $\begin{array}{r}14111908 \\
(0,72)\end{array}$ \\
\hline 1986 & & & & & 6428996 & 3595258 & 3267212 & 13291466 \\
\hline
\end{tabular}

Fonte: IBGE - Censos Agropecuários e PNADs (Brasil). nota: os valores entre parenteses são resultados da relação PNAD/CA nos anos mais próximos dessas duas fontes. 
Tabela 1.2 - Total de homens ocupados na agropecuária, segundo os censos Agropecuários e as PNADs Regiões: Nordeste, Sudeste e sul.

\begin{tabular}{|c|c|c|c|c|c|c|c|c|}
\hline \multirow{2}{*}{ ano } & \multicolumn{4}{|c|}{$\begin{array}{l}\text { Censo Agropecuário } \\
\text { al de pessoas ocupadas }\end{array}$} & \multicolumn{4}{|c|}{$\begin{array}{l}\text { P.N.A.D. } \\
\text { total de pessoas ocupadas }\end{array}$} \\
\hline & $\begin{array}{l}\text { Nordeste } \\
\text { (1) }\end{array}$ & $\begin{array}{l}\text { Sudeste } \\
\text { (2) }\end{array}$ & $\begin{array}{l}\text { sul } \\
(3)\end{array}$ & $\begin{array}{c}\text { total } \\
(1+2+3)\end{array}$ & $\begin{array}{l}\text { Nordeste } \\
\text { (4) }\end{array}$ & $\begin{array}{l}\text { Sudeste } \\
\text { (5) }\end{array}$ & $\begin{array}{l}\text { Sul } \\
(6)\end{array}$ & $\begin{array}{c}\text { total } \\
(4+5+6)\end{array}$ \\
\hline 1975 & 4179968 & 2617690 & 2316105 & 9113763 & & & & \\
\hline 1976 & & & & & $\begin{array}{c}5136183 \\
(1,23)\end{array}$ & $\begin{array}{r}3022933 \\
(1,15)\end{array}$ & $\begin{array}{r}2907642 \\
(1,26)\end{array}$ & $\begin{array}{r}11066758 \\
(1,21)\end{array}$ \\
\hline 1979 & & & & & $\begin{array}{r}5015853 \\
(0,98)\end{array}$ & $\begin{array}{r}2816282 \\
(0.95)\end{array}$ & $\begin{array}{r}2932367 \\
(1,23)\end{array}$ & $\begin{array}{r}10764502 \\
(1,03)\end{array}$ \\
\hline 1980 & 5116990 & 2949910 & 2376308 & 10443208 & & & & \\
\hline 1981 & & & & & $\begin{array}{r}4230810 \\
(0,83)\end{array}$ & $\begin{array}{r}2948464 \\
(1,00)\end{array}$ & $\begin{array}{r}2424277 \\
(1,02)\end{array}$ & $\begin{array}{r}9603551 \\
(0.92)\end{array}$ \\
\hline 1984 & & & & & 5129297 & 3254938 & 2437693 & 10821928 \\
\hline 1985 & 5506722 & 3250761 & 2498624 & 11256107 & $\begin{array}{r}5187814 \\
(0.94)\end{array}$ & $\begin{array}{r}3210057 \\
(0,99)\end{array}$ & $\begin{array}{r}2507833 \\
(1,00)\end{array}$ & $\begin{array}{r}10905704 \\
(0,97)\end{array}$ \\
\hline 1986 & & & & & 5126429 & 3082569 & 2380616 & 10589614 \\
\hline
\end{tabular}

Fonte: IBGE - Censos Agropecuários e PNADs (Brasil). nota: os valores entre parenteses são resultados da relação PNAD/CA nos anos mais próximos dessas duas fontes. 
Tabela 1.3 - Total de mulheres ocupadas na agropecuária, segundo os Censos Agropecuários e as PNADs Regiões: Nordeste, Sudeste e sul.

\begin{tabular}{|c|c|c|c|c|c|c|c|c|}
\hline \multirow{2}{*}{ ano } & \multicolumn{4}{|c|}{$\begin{array}{l}\text { Censo Agropecuário } \\
\text { otal de pessoas ocupadas }\end{array}$} & \multicolumn{4}{|c|}{$\begin{array}{l}\text { P.N.A.D. } \\
\text { total de pessoas ocupadas }\end{array}$} \\
\hline & $\begin{array}{l}\text { Nordeste } \\
\text { (1) }\end{array}$ & $\begin{array}{l}\text { Sudeste } \\
\text { (2) }\end{array}$ & $\begin{array}{l}\text { Sul } \\
(3)\end{array}$ & $\begin{array}{c}\text { total } \\
(1+2+3)\end{array}$ & $\begin{array}{c}\text { Nordeste } \\
\text { (4) }\end{array}$ & $\begin{array}{l}\text { Sudeste } \\
\text { (5) }\end{array}$ & $\begin{array}{l}\text { Sul } \\
(6)\end{array}$ & $\begin{array}{l}\text { total } \\
(4+5+6)\end{array}$ \\
\hline 1975 & 2585986 & 883618 & 1417241 & 4886845 & & & & \\
\hline 1976 & & & & & $\begin{array}{r}1432214 \\
(0,55)\end{array}$ & $\begin{array}{l}480864 \\
(0,54)\end{array}$ & $\begin{array}{r}1137388 \\
(0,80)\end{array}$ & $\begin{array}{r}3050466 \\
(0.62)\end{array}$ \\
\hline 1979 & & & & & $\begin{array}{r}1553550 \\
(0,62)\end{array}$ & $\begin{array}{l}586429 \\
(0.69)\end{array}$ & $\begin{array}{r}1243856 \\
(0,97)\end{array}$ & $\begin{array}{r}3383835 \\
(0.73)\end{array}$ \\
\hline $\begin{array}{l}1980 \\
1981\end{array}$ & 2501700 & 849137 & 1278797 & 4629634 & $\begin{array}{r}1135918 \\
(0,45)\end{array}$ & $\begin{array}{l}568825 \\
(0,67)\end{array}$ & $\begin{array}{r}1050183 \\
(0,82)\end{array}$ & $\begin{array}{r}2754926 \\
(0.60)\end{array}$ \\
\hline 1984 & & & & & 1511049 & 599918 & 990955 & 3101922 \\
\hline 1985 & 2954056 & 960913 & 1344278 & 5259247 & $\begin{array}{c}1602984 \\
(0,54)\end{array}$ & $\begin{array}{l}588713 \\
(0,61)\end{array}$ & $\begin{array}{r}1014507 \\
(0,75)\end{array}$ & $\begin{array}{r}3203204 \\
(0,61)\end{array}$ \\
\hline 1986 & & & & & 1302567 & 512689 & 886596 & 2701852 \\
\hline
\end{tabular}

Fonte: IBGE - Censos Agropecuários e PNADs (Brasil). nota: os valores entre parenteses são resultados da relação PNAD/CA nos anos mais próximos dessas duas fontes.

Tabela 1.4 - Total de crianças na agropecuária - Regiões: Nordeste, Sudeste e Sul

\begin{tabular}{|c|c|c|c|c|}
\hline \multirow{2}{*}{$\begin{array}{l}\text { ano } \\
(1+2+3)\end{array}$} & \multicolumn{4}{|c|}{$\begin{array}{l}\text { Censo Agropecuário } \\
\text { total de pessoas ocupadas }\end{array}$} \\
\hline & $\begin{array}{c}\text { Nordeste } \\
\text { (I) }\end{array}$ & $\begin{array}{c}\text { Sudeste } \\
\text { (2) }\end{array}$ & $\begin{array}{l}\text { Sul } \\
(3)\end{array}$ & total \\
\hline 1975 & 1972827 & 644205 & 1098497 & 3715529 \\
\hline 1980 & 1714482 & 513164 & 736706 & 2964352 \\
\hline 1985 & 1980884 & 526514 & 647380 & 3154778 \\
\hline
\end{tabular}

Fonte: Censos Agropecuários do Brasil 
Tabela 1.5 - Evolução do total de empregados homens na agropecuária segundo os Censos Agropecuários e as PNADs - Brasil, 1975-86.

\begin{tabular}{lccc}
\hline Ano & $\begin{array}{c}\text { Censo Agropecuário } \\
\text { Homens maiores } \\
\text { de } 14 \text { anos }\end{array}$ & $\begin{array}{c}\text { PNAD } \\
\text { Homens maiores } \\
\text { de } 10 \text { anos }\end{array}$ & $\begin{array}{c}\text { Relação } \\
\text { PNAD/CA }\end{array}$ \\
\hline 1975 & 2.634 .692 & 4.008 .686 & 1,52 \\
\hline 1976 & 4.059 .210 & 4.129 .130 & 1,02 \\
\hline 1979 & & 4.206 .380 & 1,04 \\
\hline 1981 & 4.103 .994 & 5.005 .775 & 1,21 \\
1984 & & 4.970 .808 & \\
\hline 1986 & & 4.902 .645 & \\
\hline
\end{tabular}

Fonte: IBGE - Censo Agropecuário e PNAD

(1) buscou-se a relação PNAD/CA nos anos mais próximos dessas duas fontes.

Tabela 1.6 - Evolução do total de empregados mulheres e crianças segundo os Censos Agropecuários e as PNADs Brasil, 1975-86.

\begin{tabular}{|c|c|c|c|c|}
\hline \multirow[b]{2}{*}{ Ano } & \multicolumn{2}{|c|}{ Censo Agropecuário } & PNAD & \multirow{2}{*}{$\begin{array}{l}\text { Relação } \\
\text { PNAD/CA }\end{array}$} \\
\hline & $\begin{array}{c}\text { Mulheres maiores } \\
\text { de } 14 \text { anos }\end{array}$ & $\begin{array}{l}\text { Menores } \\
\text { de } 14 \text { anos }\end{array}$ & $\begin{array}{c}\text { Mulheres maiores } \\
\text { de } 10 \text { anos }\end{array}$ & \\
\hline $\begin{array}{l}1975 \\
1976\end{array}$ & 397.060 & 218.210 & 631.469 & 1,59 \\
\hline $\begin{array}{l}1979 \\
1980 \\
1981\end{array}$ & 596.396 & 282.928 & $\begin{array}{l}692.849 \\
667.870\end{array}$ & $\begin{array}{l}1,12 \\
1,16\end{array}$ \\
\hline $\begin{array}{l}1984 \\
1985 \\
1986\end{array}$ & 642.378 & 212.725 & $\begin{array}{l}794.929 \\
825.777 \\
718.406\end{array}$ & 1,29 \\
\hline
\end{tabular}

Fonte: IBGE - Censo Agropecuário e PNAD

(1) buscou-se a relação PNAD/CA nos anos mais próximos dessas duas fontes para o grupo de mulheres. 
Tabela 1.7 - Total de pessoas ocupadas na categoria empregados na agricultura, segundo os Censos Agropecuários e as PNADs - Regiões: Nordeste, Sudeste e sul

\begin{tabular}{|c|c|c|c|c|c|c|c|c|}
\hline \multirow{2}{*}{ ano } & \multicolumn{4}{|c|}{$\begin{array}{l}\text { Censo Agropecuário } \\
\text { al de pessoas ocupadas }\end{array}$} & \multicolumn{4}{|c|}{$\begin{array}{l}\text { P.N.A.D. } \\
\text { total de pessoas ocupadas }\end{array}$} \\
\hline & $\begin{array}{l}\text { Nordeste } \\
\text { (1) }\end{array}$ & $\begin{array}{l}\text { Sudeste } \\
\text { (2) }\end{array}$ & $\begin{array}{l}\text { sul } \\
\text { (3) }\end{array}$ & $\begin{array}{c}\text { total } \\
(1+2+3)\end{array}$ & $\begin{array}{c}\text { Nordeste } \\
\text { (4) }\end{array}$ & $\begin{array}{l}\text { Sudeste } \\
\text { (5) }\end{array}$ & $\begin{array}{l}\text { Sul } \\
(6)\end{array}$ & $\begin{array}{c}\text { total } \\
(4+5+6)\end{array}$ \\
\hline 1975 & 1048197 & 1284195 & 566126 & 2898518 & & & & \\
\hline 1976 & & & & & $\begin{array}{r}1818301 \\
(1,73)\end{array}$ & $\begin{array}{r}1920872 \\
(1,50)\end{array}$ & $\begin{array}{l}804704 \\
(1,42)\end{array}$ & $\begin{array}{r}4543877 \\
(1,57)\end{array}$ \\
\hline 1979 & & & & & $\begin{array}{r}1958835 \\
(0,99)\end{array}$ & $\begin{array}{r}1898702 \\
(1,15)\end{array}$ & $\begin{array}{l}852104 \\
(1,22)\end{array}$ & $\begin{array}{r}4709641 \\
(1,09)\end{array}$ \\
\hline $\begin{array}{l}1980 \\
1981\end{array}$ & 1984990 & 1657401 & 697752 & 4340143 & $\begin{array}{r}1818819 \\
(0,92)\end{array}$ & $\begin{array}{r}1924506 \\
(1,04)\end{array}$ & $\begin{array}{l}729022 \\
(1,04)\end{array}$ & $\begin{array}{r}4472347 \\
(1,03)\end{array}$ \\
\hline 1984 & & & & & 2337361 & 2247993 & 744067 & 5329421 \\
\hline 1985 & 1809002 & 1757926 & 755481 & 4322409 & $\begin{array}{r}2373068 \\
(1,31)\end{array}$ & $\begin{array}{r}2223396 \\
(1,26)\end{array}$ & $\begin{array}{l}720311 \\
(0,95)\end{array}$ & $\begin{array}{r}5316775 \\
(1,23)\end{array}$ \\
\hline 1986 & & & & & 2333180 & 2003436 & 782723 & 5119339 \\
\hline
\end{tabular}

Fonte: IBGE - Censos Agropecuários e PNADs (Brasil). nota: os valores entre parenteses são resultados da relação PNAD/CA nos anos mais próximos dessas duas fontes. 
Tabela 1.8 - Total de homens na categoria empregados, segundo os Censos Agropecuários e as PNADs Regiões: Nordeste, Sudeste e sul

\begin{tabular}{|c|c|c|c|c|c|c|c|c|}
\hline \multirow{2}{*}{ ano } & \multicolumn{4}{|c|}{$\begin{array}{l}\text { Censo Agropecuário } \\
\text { al de pessoas ocupad }\end{array}$} & \multicolumn{4}{|c|}{$\begin{array}{l}\text { P.N.A.D. } \\
\text { total de pessoas ocupadas }\end{array}$} \\
\hline & $\begin{array}{l}\text { Nordeste } \\
\text { (1) }\end{array}$ & $\begin{array}{l}\text { Sudeste } \\
\text { (2) }\end{array}$ & $\begin{array}{l}\text { Sul } \\
(3)\end{array}$ & $\begin{array}{l}\operatorname{tota} 1 \\
(1+2+3)\end{array}$ & $\begin{array}{l}\text { Nordeste } \\
\text { (4) }\end{array}$ & $\begin{array}{l}\text { Sudeste } \\
\text { (5) }\end{array}$ & $\begin{array}{l}\text { sul } \\
(6)\end{array}$ & $\begin{array}{l}\text { total } \\
(4+5+6)\end{array}$ \\
\hline 1975 & 837519 & 1042091 & 455946 & 2335556 & & & & \\
\hline 1976 & & & & & $\begin{array}{r}1553056 \\
(1,85)\end{array}$ & $\begin{array}{r}1678134 \\
(1.61)\end{array}$ & $\begin{array}{l}684739 \\
(1,50)\end{array}$ & $\begin{array}{r}3915929 \\
(1,68)\end{array}$ \\
\hline 1979 & & & & & $\begin{array}{r}1670262 \\
(1.02)\end{array}$ & $\begin{array}{r}1608895 \\
(1.18)\end{array}$ & $\begin{array}{l}742606 \\
(1,31)\end{array}$ & $\begin{array}{r}4021763 \\
(1,13)\end{array}$ \\
\hline 1980 & 1642124 & 1361284 & 566115 & 3569523 & & & & \\
\hline 1981 & & & & & $\begin{array}{c}1543605 \\
(0,94)\end{array}$ & $\begin{array}{r}1662721 \\
(1,22)\end{array}$ & $\begin{array}{l}611271 \\
(1,08)\end{array}$ & $\begin{array}{r}3817597 \\
(1.07)\end{array}$ \\
\hline 1984 & & & & & 1954155 & 1959274 & 639885 & 4553314 \\
\hline 1985 & 1468565 & 1474081 & 626020 & 3568666 & $\begin{array}{r}1958673 \\
(1,33)\end{array}$ & $\begin{array}{r}1925600 \\
(1,31)\end{array}$ & $\begin{array}{l}625043 \\
(1,00)\end{array}$ & $\begin{array}{r}4509316 \\
(1,26)\end{array}$ \\
\hline 1986 & & & & & 2001707 & 1752266 & 667326 & 4421299 \\
\hline
\end{tabular}

Fonte: IBGE - Censos Agropecuários e PNADs (Brasil). nota: os valores entre parenteses são resultados da relação PNAD/CA nos anos mais próximos dessas duas fontes. 
Tabela 1.9 - Total de mulheres na categoria empregados, segundo os Censos Agropecuários e as PNADs Regiões: Nordeste, sudeste e Sul

\begin{tabular}{|c|c|c|c|c|c|c|c|c|}
\hline \multirow{2}{*}{ ano } & \multicolumn{4}{|c|}{$\begin{array}{l}\text { Censo Agropecuário } \\
\text { total de pessoas ocupadas }\end{array}$} & \multicolumn{4}{|c|}{$\begin{array}{l}\text { P.N.A.D. } \\
\text { total de pessoas ocupadas }\end{array}$} \\
\hline & $\begin{array}{l}\text { Nordeste } \\
\text { (1) }\end{array}$ & $\begin{array}{l}\text { Sudeste } \\
\text { (2) }\end{array}$ & $\begin{array}{l}\text { Sul } \\
(3)\end{array}$ & $\begin{array}{c}\operatorname{total} \\
(1+2+3)\end{array}$ & $\begin{array}{l}\text { Nordeste } \\
\text { (4) }\end{array}$ & $\begin{array}{l}\text { Sudeste } \\
\text { (5) }\end{array}$ & $\begin{array}{l}\text { Sul } \\
(6)\end{array}$ & $\begin{array}{l}\text { total } \\
(4+5+6)\end{array}$ \\
\hline 1975 & 145078 & 150814 & 68819 & 364711 & & & & \\
\hline 1976 & & & & & $\begin{array}{l}265245 \\
(1,83)\end{array}$ & $\begin{array}{l}242738 \\
(1,61)\end{array}$ & $\begin{array}{l}119965 \\
(1,74)\end{array}$ & $\begin{array}{l}627948 \\
(1.72)\end{array}$ \\
\hline 1979 & & & & & $\begin{array}{l}288573 \\
\quad(1,22)\end{array}$ & $\begin{array}{r}289807 \\
(1,41)\end{array}$ & $\begin{array}{l}109498 \\
(1,23)\end{array}$ & $\begin{array}{l}687878 \\
(1,29)\end{array}$ \\
\hline $\begin{array}{l}1980 \\
1981\end{array}$ & 237416 & 205126 & 88842 & 531384 & $\begin{array}{l}275214 \\
(1,16)\end{array}$ & $\begin{array}{l}261785 \\
(1,28)\end{array}$ & $\begin{array}{l}117751 \\
(1.33)\end{array}$ & $\begin{array}{l}654750 \\
(1.23)\end{array}$ \\
\hline 1984 & & & & & 383206 & 288719 & 104182 & 776107 \\
\hline 1985 & 261424 & 212626 & 102400 & 576450 & $\begin{array}{l}414395 \\
(1,59)\end{array}$ & $\begin{array}{l}297796 \\
(1,40)\end{array}$ & $\begin{array}{l}95268 \\
(0,93)\end{array}$ & $\begin{array}{l}807459 \\
(1,40)\end{array}$ \\
\hline 1986 & & & & & 331473 & 251170 & 115397 & 698040 \\
\hline
\end{tabular}

Fonte: IBGE - censos Agropecuários e PNADs (Brasil). nota: os valores entre parenteses são resultados da relação PNAD/CA nos anos mais próximos dessas duas fontes.

Tabela 1.10 - Total de crianças na categoria empregados Regiões: Nordeste, Sudeste e sul

\begin{tabular}{ccccc}
\hline \multicolumn{5}{c}{$\begin{array}{c}\text { Censo Agropecuário } \\
\text { total de pessoas ocupadas }\end{array}$} \\
\cline { 2 - 5 } & $\begin{array}{c}\text { Nordeste } \\
(1)\end{array}$ & $\begin{array}{c}\text { Sudeste } \\
(2)\end{array}$ & $\begin{array}{c}\text { sul } \\
(3)\end{array}$ & $\begin{array}{c}\text { total } \\
(1+2+3)\end{array}$ \\
\hline 1975 & 65600 & 91290 & 41361 & 198251 \\
1980 & 105450 & 90991 & 42795 & 239236 \\
1985 & 79013 & 71219 & 27061 & 177293
\end{tabular}

Fonte: Censos Agropecuários do Brasil 


\title{
$\begin{array}{llllllll}\text { A } & P & \hat{E} & N & D & I & C & E\end{array}$
}

\author{
Variação das pessoas ocupadas na \\ agricultura entre 1980 e 1985 no Brasil, \\ nas macrorregiões e nos estados, segundo os \\ Censos Agropecuários e as PNADs
}


Tabela 2.1 - Variação por região e por estado pessoas ocupadas na agropecuária entre 1980 e 1985.

\begin{tabular}{|c|c|c|c|c|}
\hline \multirow{2}{*}{$\begin{array}{l}\text { Região/ } \\
\text { /Estado }\end{array}$} & \multicolumn{2}{|c|}{ Período } & \multirow{2}{*}{$\begin{array}{l}\text { Variação } \\
\text { Absoluta }\end{array}$} & \multirow{2}{*}{$\begin{array}{c}\text { Variação } \\
\text { Relativa } \\
\text { (q) }\end{array}$} \\
\hline & 1980 & 1985 & & \\
\hline BRASIL & 21163735 & 23543208 & 2379473 & 100,00 \\
\hline $\begin{array}{l}\text { NORTE } \\
\text { Rondônia } \\
\text { Acre } \\
\text { Amazonas } \\
\text { Roraima } \\
\text { Pará } \\
\text { Amapá } \\
\text { Tocantins }\end{array}$ & $\begin{array}{r}1781611 \\
176934 \\
95754 \\
460702 \\
16903 \\
1016795 \\
14523\end{array}$ & $\begin{array}{r}2496046 \\
327475 \\
116546 \\
550160 \\
21712 \\
1218356 \\
21492\end{array}$ & $\begin{array}{r}714435 \\
150541 \\
20792 \\
89458 \\
4809 \\
201561 \\
6969\end{array}$ & $\begin{array}{r}30,02 \\
6,33 \\
0,87 \\
3,76 \\
0,20 \\
8,47 \\
0,29\end{array}$ \\
\hline $\begin{array}{l}\text { NORDESTE } \\
\text { Maranhão } \\
\text { Piauí } \\
\text { Ceará } \\
\text { R.G. Norte } \\
\text { Paraíba } \\
\text { Pernambuco } \\
\text { Alagoas } \\
\text { Sergipe } \\
\text { Bahia }\end{array}$ & $\begin{array}{r}9333166 \\
1672502 \\
790326 \\
1069258 \\
432188 \\
648607 \\
1218871 \\
543524 \\
295055 \\
2662835\end{array}$ & $\begin{array}{r}10523689 \\
1688920 \\
822862 \\
1290474 \\
434128 \\
767790 \\
1313152 \\
631853 \\
350440 \\
3224070\end{array}$ & $\begin{array}{r}1190523 \\
16418 \\
32536 \\
221216 \\
1940 \\
119183 \\
94281 \\
88329 \\
55385 \\
561235\end{array}$ & $\begin{array}{r}50,03 \\
0,69 \\
1,37 \\
9,30 \\
0.08 \\
5,01 \\
3.96 \\
3,71 \\
2.33 \\
23.59\end{array}$ \\
\hline $\begin{array}{l}\text { SUDESTE } \\
\text { Minas Gerais } \\
\text { Esp. Santo } \\
\text { Rio Janeiro } \\
\text { São Paulo }\end{array}$ & $\begin{array}{r}4312211 \\
2284550 \\
349510 \\
301688 \\
1376463\end{array}$ & $\begin{array}{r}4775582 \\
2687643 \\
399681 \\
323324 \\
1364934\end{array}$ & $\begin{array}{r}463371 \\
403093 \\
50171 \\
21636 \\
-11529\end{array}$ & $\begin{array}{r}19,47 \\
16,94 \\
2,11 \\
0.91 \\
-0,48\end{array}$ \\
\hline $\begin{array}{l}\text { SUL } \\
\text { Paraná } \\
\text { S.Catarina } \\
\text { R.Grande sul }\end{array}$ & $\begin{array}{r}4391811 \\
1807826 \\
836755 \\
1747230\end{array}$ & $\begin{array}{r}4493480 \\
1851721 \\
890767 \\
1750992\end{array}$ & $\begin{array}{r}101669 \\
43895 \\
54012 \\
3762\end{array}$ & $\begin{array}{l}4,27 \\
1,84 \\
2,27 \\
0.16\end{array}$ \\
\hline $\begin{array}{l}\text { CENTRO-OESTE } \\
\text { MGrosso Sul } \\
\text { Mato Grosso } \\
\text { Goiás } \\
\text { D.Federal }\end{array}$ & $\begin{array}{r}1344930 \\
230983 \\
318570 \\
780749 \\
14628\end{array}$ & $\begin{array}{r}1254411 \\
254264 \\
364229 \\
618827 \\
17091\end{array}$ & $\begin{array}{r}-90519 \\
23281 \\
45659 \\
-161922 \\
2463\end{array}$ & $\begin{array}{r}-3.80 \\
0.98 \\
1.92 \\
-6.80 \\
0.10\end{array}$ \\
\hline
\end{tabular}

Fonte: Censos Agropecuários do Brasil - 1980 e 1985. Nota: 0 total das pessoas ocupadas no Brasil em 1980 apresentado pelo censo não corresponde com à somatória dos respectivos estados e macrorregiões. 


\section{A P}

Cálculo do valor agregado por
equivalente-homem




\section{1 - VALOR AGREGADO (VA)}

$\mathrm{VA}=\mathrm{VB}-\mathrm{CI}$

Tabela 3.1 - Valor agregado (Cz\$1000 de 1985) por equiva- Iente-homem no BRASIL - 1970, 1975, 1980 e 1985

\begin{tabular}{lccc}
\hline ano & $\begin{array}{c}\text { Valor agregado } \\
\text { real } \\
\text { (VAr) }\end{array}$ & $\begin{array}{c}\text { total de } \\
\mathrm{EH}\end{array}$ & VAr/EH \\
\hline 1970 & 48775816,99 & 15076647,23 & 3,24 \\
1975 & 92110280,30 & 17326932,31 & 5,32 \\
1980 & 113860688,68 & 18796605,31 & 6,06 \\
1985 & 137092854,00 & 21490070,00 & 6,38 \\
\hline
\end{tabular}

Fonte: IBGE - Censos Agropecuários (VAr) resultado das tabelas 3.8 a 3.14: Valor Agregado (VAr) - valores reais.

Tabela 3.2 - Valor agregado (Cz\$1000 de 1985) por equiva-lente-homem em RONDÔNIA - 1970,1975, 1980 e 1985

\begin{tabular}{lccc}
\hline ano & $\begin{array}{c}\text { valor agregado } \\
\text { real } \\
\text { (VAr) }\end{array}$ & $\begin{array}{c}\text { total de } \\
\mathrm{EH}\end{array}$ & VAr/EH \\
\hline 1970 & 85923,05 & 16199,56 & 5,30 \\
1975 & 248584,06 & 78691,13 & 3,16 \\
1980 & 472118,16 & 142630,94 & 3,31 \\
1985 & 978546,00 & 254360,44 & 3,85 \\
\hline
\end{tabular}

Fonte: IBGE - Censos Agropecuários

(VAI) resultado das tabelas 3.8 a 3.14: Valor Agregado (VAr) - valores reais. 
Tabela 3.3 - Valor agregado (Cz\$ 1000 de 1985) por equiva- lente-homem no PARÁ - 1970, 1975, 1980 e 1985

\begin{tabular}{lccc}
\hline ano & $\begin{array}{c}\text { valor agregado } \\
\text { real } \\
\text { (VAr) }\end{array}$ & $\begin{array}{c}\text { total de } \\
\mathrm{EH}\end{array}$ & VAr/EH \\
\hline 1970 & 687116,33 & 428022,02 & 1,61 \\
1975 & 1377234,12 & 604776,76 & 2,28 \\
1980 & 3254259,36 & 794658,34 & 4,10 \\
1985 & 3783695,00 & 897457,92 & 4,22 \\
\hline
\end{tabular}

Fonte: IBGE - Censos Agropecuários

(VAr) resultado das tabelas 3.8 a 3.14: Valor Agregado (VAr) - valores reais.

Tabela 3.4 - Valor agregado (Cz\$1000 de 1985) por equiva- Iente-homem no CEARÁ - 1970, 1975, 1980 e 1985

\begin{tabular}{lccc}
\hline ano & $\begin{array}{c}\text { valor agregado } \\
\text { real } \\
(\text { VAr })\end{array}$ & $\begin{array}{c}\text { total de } \\
\mathrm{EH}\end{array}$ & VAr/EH \\
\hline 1970 & 990517,70 & 896620,27 & 1,10 \\
1975 & 1942725,40 & 944450,29 & 2,06 \\
1980 & 2454054,37 & 987480,58 & 2,49 \\
1985 & 3063827,00 & 1253546,28 & 2,44 \\
\hline
\end{tabular}

Fonte: IBGE - Censos Agropecuários

(VAr) resultado das tabelas 3.8 a 3.14 : Valor Agregado (VAr) - valores reais. 
Tabela 3.5 - Valor agregado (Cz\$ 1000 de 1985) por equiva- lente-homem na PARAIBA - 1970, 1975, 1980 e 1985

\begin{tabular}{lccc}
\hline ano & $\begin{array}{c}\text { valor agregado } \\
\text { real } \\
\text { (VAr) }\end{array}$ & $\begin{array}{c}\text { total de } \\
\mathrm{EH}\end{array}$ & VAr/EH \\
\hline 1970 & 733996,21 & 498075,87 & 1,47 \\
1975 & 1500012,13 & 642765,86 & 2,33 \\
1980 & 1359784,40 & 552771,98 & 2,46 \\
1985 & 1853562,00 & 685326,30 & 2,70 \\
\hline
\end{tabular}

Fonte: IBGE - Censos Agropecuários

(VAr) resultado das tabelas 3.8 a 3.14: Valor Agregado (VAr) - valores reais.

Tabela 3.6 - Valor agregado (Cz\$ 1000 de 1985) por equiva- lente-homem na BAHIA - 1970, 1975, 1980 e 1985

\begin{tabular}{lccc}
\hline ano & $\begin{array}{c}\text { valor agregado } \\
\text { real } \\
(\text { VAr })\end{array}$ & $\begin{array}{c}\text { total de } \\
\mathrm{EH}\end{array}$ & VAr $/ \mathrm{EH}$ \\
\hline 1970 & 3282187,37 & 1635361,38 & 2,01 \\
1975 & 5682900,06 & 1884499,47 & 3,02 \\
1980 & 7953070,36 & 2137305,96 & 3,72 \\
1985 & 10783886,00 & 2652850,79 & 4,07 \\
\hline
\end{tabular}

Fonte: IBGE - Censos Agropecuários

(VAr) resultado das tabelas 3.8 a 3.14: Valor Agregado (VAr) - valores reais. 
Tabela 3.7 - Valor agregado (Cz\$1000 de 1985) por equiva- Iente-homem em MINAS GERAIS - 1970, 1975, 1980 e 1985

\begin{tabular}{lccc}
\hline ano & $\begin{array}{c}\text { valor agregado } \\
\text { real } \\
\text { (VAr) }\end{array}$ & $\begin{array}{c}\text { total de } \\
\text { EH }\end{array}$ & VAr/EH \\
\hline 1970 & 6360385,16 & 1803126,03 & 3,53 \\
1975 & 11224271,02 & 1930083,88 & 5,82 \\
1980 & 14429798,55 & 2198339,97 & 6,56 \\
1985 & 20712362,00 & 2665233,43 & 7,77 \\
\hline
\end{tabular}

Fonte: IBGE - Censos Agropecuários

(VAr) resultado das tabelas 3.8 a 3.14: Valor Agregado (VAr) - valores reais.

Tabela 3.8 - Valor agregado (VAI) - valores reais BRASIL - 1970, 1975, 1980 e 1985.

\begin{tabular}{cccc}
\hline ano & $\begin{array}{c}\text { Valor Agregado } \\
\text { nominal } \\
\text { (VAn) }\end{array}$ & $\begin{array}{c}\text { IGP }- \text { di } \\
(1977=100)\end{array}$ & $\begin{array}{c}\text { Valor Agregado } \\
\text { real } \\
\text { (VAr) }\end{array}$ \\
\hline 1970 & 19468762 & 18,5953 & 48775816,99 \\
1975 & 98132271 & 49,6333 & 92110280,30 \\
1980 & 1044817696 & 427,5000 & 113860688,68 \\
1985 & 137092854 & 46587,5000 & 137092854,00 \\
\hline
\end{tabular}

Fonte: IBGE - Censos Agropecuários

nota: os valores correntes de 1970 , 1975 e 1980 foram colocados em "mil cruzados" de 1985.

(VAn) resultado das tabelas 3.15 a 3.21: Valor Agregado (VAn) - valores nominais. 
Tabela 3.9 - Valor agregado (VAr) - valores reais RONDÔNIA - 1970, 1975, 1980 e 1985.

\begin{tabular}{lcrc}
\hline ano & $\begin{array}{c}\text { Valor Agregado } \\
\text { nominal } \\
\text { (VAn) }\end{array}$ & $\begin{array}{c}\text { IGP }- \text { di } \\
(1977=100)\end{array}$ & $\begin{array}{c}\text { Valor Agregado } \\
\text { real } \\
\text { (VAr) }\end{array}$ \\
\hline 1970 & 34296 & 18,5953 & 85923,05 \\
1975 & 264836 & 49,6333 & 248584,06 \\
1980 & 4332289 & 427,5000 & 472118,16 \\
1985 & 978546 & 46587,5000 & 978546,00 \\
\hline $\begin{array}{l}\text { Fonte: IBGE - Censos Agropecuários } \\
\text { nota: Os valores correntes de } 1970,\end{array}$ & 1975 & 1980 foram \\
$\begin{array}{l}\text { Colocados em "mil cruzados" de } 1985 . \\
\text { (VAn) idem tabela 3.8 }\end{array}$ &
\end{tabular}

Tabela 3.10 - Valor agregado (VAr) - valores reais PARÁ - 1970, 1975, 1980 e 1985.

\begin{tabular}{cccc}
\hline ano & $\begin{array}{c}\text { Valor Agregado } \\
\text { nominal } \\
\text { (VAn) }\end{array}$ & $\begin{array}{c}\text { IGP }- \text { di } \\
(1977=100)\end{array}$ & $\begin{array}{c}\text { Valor Agregado } \\
\text { real } \\
\text { (VAr) }\end{array}$ \\
\hline 1970 & 274261 & 18,5953 & 687116,33 \\
1975 & 1467275 & 49,6333 & 1377234,12 \\
1980 & 29861999 & 427,5000 & 3254259,36 \\
1985 & 3783695 & 46587,5000 & 3783695,00 \\
\hline
\end{tabular}

Fonte: IBGE - Censos Agropecuários

nota: os valores correntes de 1970,1975 e 1980 foram colocados 1975 e 1980 e, "mil cruzados" no ano de 1985.

(VAn) idem tabela 3.8 
Tabela 3.11 - Valor agregado (VAr) - valores reais CEARÁ - 1970, 1975, 1980 e 1985.

\begin{tabular}{cccc}
\hline ano & $\begin{array}{c}\text { Valor Agregado } \\
\text { nominal } \\
\text { (VAn) }\end{array}$ & $\begin{array}{c}\text { IGP }- \text { di } \\
(1977=100)\end{array}$ & $\begin{array}{c}\text { Valor Agregado } \\
\text { real } \\
\text { (VAr) }\end{array}$ \\
\hline 1970 & 395363 & 18,5953 & 990517,70 \\
1975 & 2069737 & 49,6333 & 1942725,40 \\
1980 & 22519093 & 427,5000 & 2454054,37 \\
1985 & 3063827 & 46587,5000 & 3063827,00 \\
\hline
\end{tabular}

Fonte: IBGE - Censos Agropecuários

nota: os valores correntes de 1970, 1975 e 1980 foram colocados em "mil cruzados" de 1985.

(VAn) idem tabela 3.8

Tabela 3.12 - Valor agregado (VAr) - valores reais PARAÍBA - 1970, 1975, 1980 e 1985.

\begin{tabular}{cccc}
\hline ano & $\begin{array}{c}\text { Valor Agregado } \\
\text { nominal } \\
\text { (VAn) }\end{array}$ & $\begin{array}{c}\text { IGP }- \text { di } \\
(1977=100)\end{array}$ & $\begin{array}{c}\text { Valor Agregado } \\
\text { real } \\
\text { (VAr) }\end{array}$ \\
\hline 1970 & 292973 & 18,5953 & 733996,21 \\
1975 & 1598080 & 49,6333 & 1500012,13 \\
1980 & 12477764 & 427,5000 & 1359784,40 \\
1985 & 1853562 & 46587,5000 & 1853562,00 \\
\hline
\end{tabular}

Fonte: IBGE - Censos Agropecuários

nota: os valores correntes de 1970, 1975 e 1980 foram colocados em "mil cruzados" de 1985.

(VAn) idem tabela 3.8 
Tabela 3.13 - Valor agregado (VAr) - valores reais BAHIA - 1970, 1975, 1980 e 1985.

\begin{tabular}{lccc}
\hline ano & $\begin{array}{c}\text { Valor Agregado } \\
\text { nominal } \\
\text { (VAn) }\end{array}$ & $\begin{array}{c}\text { IGP } \\
(1977=100)\end{array}$ & $\begin{array}{c}\text { Valor Agregado } \\
\text { Ieal } \\
\text { (VAr) }\end{array}$ \\
\hline 1970 & 1310078 & 18,5953 & 3282187,37 \\
1975 & 6054437 & 49,6333 & 5682900,06 \\
1980 & 72979610 & 427,5000 & 7953070,36 \\
1985 & 10783886 & 46587,5000 & 10783886,00 \\
\hline
\end{tabular}

Fonte: IBGE - Censos Agropecuários

nota: os valores correntes de 1970, 1975 e 1980 foram colocados em "mil cruzados" de 1985.

(VAn) idem tabela 3.8

Tabela 3.14 - Valor agregado (VAr) - valores reais MINAS GERAIS - 1970, 1975, 1980 e 1985.

\begin{tabular}{cccc}
\hline ano & $\begin{array}{c}\text { Valor Agregado } \\
\text { nominal } \\
\text { (VAn) }\end{array}$ & $\begin{array}{c}\text { IGP } \\
(1977=100)\end{array}$ & $\begin{array}{c}\text { Valor Agregado } \\
\text { real } \\
\text { (VAr) }\end{array}$ \\
\hline 1970 & 2538734 & 18,5953 & 6360385,16 \\
1975 & 11958092 & 49,6333 & 11224271,02 \\
1980 & 132411889 & 427,5000 & 14429798,55 \\
1985 & 20712362 & 46587,5000 & 20712362,00 \\
\hline
\end{tabular}

Fonte: IBGE - Censos Agropecuários

nota: os valores correntes de 1970,1975 e 1980 foram colocados em "mil cruzados" de 1985.

(VAn) idem tabela 3.8 
Tabela 3.15 - Valor agregado (VAn) - valores nominais BRASIL - 1970, 1975, 1980 e 1985.

\begin{tabular}{lccc}
\hline ano & $\begin{array}{c}\text { valor da produção } \\
\text { calculado } \\
\text { (VB) }\end{array}$ & $\begin{array}{c}\text { consumo } \\
\text { intermediário } \\
\text { (CI) }\end{array}$ & $\begin{array}{c}\text { valor } \\
\text { agregado } \\
\text { (VAn) }\end{array}$ \\
\hline 1970 & 26901398 & 7432636 & 19468762 \\
1975 & 149509977 & 51377706 & 98132271 \\
1980 & 1703025485 & 658207789 & 1044817696 \\
1985 & 208306402 & 71213548 & 137092854 \\
\hline
\end{tabular}

Fonte: IBGE - Censos Agropecuários do Brasil

nota: os valores estão expressos em "mil cruzeiros" nos anos de 1970, 1975 e 1980 e, "mil cruzados" no ano de 1985. (VB) resultado das tabelas 3.22 a 3.28 : Valor da produção Calculado (VB)

(CI) resultado das tabelas 3.62 a 3.68 : Consumo Intermadiário (CI)

$(\mathrm{VAn})=\mathrm{VB}-\mathrm{CI}$

Tabela 3.16 - Valor agregado (VAn) - valores nominais RONDÔNIA - 1970, 1975, 1980 e 1985.

\begin{tabular}{cccc}
\hline valor da produção & $\begin{array}{c}\text { valonsumo } \\
\text { calculado } \\
\text { (VB) }\end{array}$ & $\begin{array}{c}\text { consulor } \\
\text { intermediário } \\
\text { (CI) }\end{array}$ & $\begin{array}{c}\text { valor } \\
\text { agregado } \\
\text { (VAn) }\end{array}$ \\
\hline 1970 & 39138 & 4842 & 34296 \\
1975 & 367927 & 103091 & 264836 \\
1980 & 6448874 & 2116585 & 4332289 \\
1985 & 1286227 & 307681 & 978546 \\
\hline
\end{tabular}

Fonte: IBGE - Censos Agropecuários de Rondônia $(\mathrm{VAn})=\mathrm{VB}-\mathrm{CI}$

nota: idem 3.15 
Tabela 3.17 - Valor agregado (VAn) - valores nominais PARA - 1970, 1975, 1980 e 1985.

\begin{tabular}{lccc}
\hline ano & $\begin{array}{c}\text { valor da produção } \\
\text { calculado } \\
\text { (VB) }\end{array}$ & $\begin{array}{c}\text { consumo } \\
\text { intermediário } \\
\text { (CI) }\end{array}$ & $\begin{array}{c}\text { valor } \\
\text { agregado } \\
\text { (VAn) }\end{array}$ \\
\hline 1970 & 378586 & 104325 & 274261 \\
1975 & 2136773 & 669498 & 1467275 \\
1980 & 41257245 & 11395246 & 29861999 \\
1985 & 4951078 & 1167383 & 3783695 \\
\hline
\end{tabular}

Fonte: IBGE - Censos Agropecuários do Pará $(\mathrm{VAn})=\mathrm{VB}-\mathrm{CI}$

nota: idem 3.15

Tabela 3.18 - Valor agregado (VAn) - valores nominais CEARÁ - 1970, 1975, 1980 e 1985.

\begin{tabular}{lccc}
\hline ano & $\begin{array}{c}\text { valor da produçõo } \\
\text { calculado } \\
\text { (VB) }\end{array}$ & $\begin{array}{c}\text { consumo } \\
\text { intermediario } \\
\text { (CI) }\end{array}$ & $\begin{array}{c}\text { valor } \\
\text { agregado } \\
\text { (VAn) }\end{array}$ \\
\hline 1970 & 523422 & 128059 & 395363 \\
1975 & 2691208 & 621471 & 2069737 \\
1980 & 32695716 & 10176623 & 22519093 \\
1985 & 3945558 & 881731 & 3063827 \\
\hline
\end{tabular}

Fonte: IBGE - Censos Agropecuários do ceará $(\mathrm{VAn})=\mathrm{VB}-\mathrm{CI}$ nota: idem 3.15 
Tabela 3.19 - Valor agregado (VAn) - valores nominais PARAIBA - 1970, 1975, 1980 e 1985.

\begin{tabular}{lccc}
\hline ano & $\begin{array}{c}\text { valor da produção } \\
\text { calculado } \\
\text { (VB) }\end{array}$ & $\begin{array}{c}\text { consumo } \\
\text { intermediário } \\
\text { (CI) }\end{array}$ & $\begin{array}{c}\text { valor } \\
\text { agregado } \\
\text { (VAn) }\end{array}$ \\
\hline 1970 & 370851 & 77878 & 292973 \\
1975 & 2033456 & 435376 & 1598080 \\
1980 & 19057272 & 6579508 & 12477764 \\
1985 & 2479779 & 626217 & 1853562 \\
\hline
\end{tabular}

Fonte: IBGE - Censos Agropecuários da Paraíba $(V A n)=V B-C I$ nota: idem 3.15

Tabela 3.20 - Valor agregado (VAn) - valores nominais BAHIA - 1970, 1975, 1980 e 1985.

\begin{tabular}{lccc}
\hline ano & $\begin{array}{c}\text { valor da produção } \\
\text { calculado } \\
\text { (VB) }\end{array}$ & $\begin{array}{c}\text { consumo } \\
\text { intermediário } \\
\text { (CI) }\end{array}$ & $\begin{array}{c}\text { valor } \\
\text { agregado } \\
\text { (VAn) }\end{array}$ \\
\hline 1970 & 1663082 & 353004 & 1310078 \\
1975 & 8031471 & 1977034 & 6054437 \\
1980 & 98195522 & 25215912 & 72979610 \\
1985 & 13792260 & 3008374 & 10783886 \\
\hline
\end{tabular}

Fonte: IBGE - Censos Agropecuários da Bahia $(\mathrm{VAn})=\mathrm{VB}-\mathrm{CI}$ nota: idem 3.15 
Tabela 3.21 - Valor agregado (VAn) - valores nominais MINAS GERAIS - 1970, 1975, 1980 e 1985.

\begin{tabular}{lccc}
\hline ano & $\begin{array}{c}\text { valor da produção } \\
\text { calculado } \\
\text { (VB) }\end{array}$ & $\begin{array}{c}\text { consumo } \\
\text { intermediário } \\
\text { (CI) }\end{array}$ & $\begin{array}{c}\text { valor } \\
\text { agregado } \\
\text { (VAn) }\end{array}$ \\
\hline 1970 & 3421759 & 883025 & 2538734 \\
1975 & 18683806 & 6725714 & 11958092 \\
1980 & 222709755 & 90297866 & 132411889 \\
1985 & 30221410 & 9509048 & 20712362 \\
\hline
\end{tabular}

Fonte: IBGE - Censos Agropecuários de Minas Gerais $(\mathrm{VAn})=\mathrm{VB}-\mathrm{CI}$

nota: idem 3.15

\section{2 - VALOR DA PRODUÇÃO CALCULADO (VB)}

$\mathrm{VB}=\mathrm{VB}_{\text {censo }}+\operatorname{variação~do~rebanho~(estoque~animal)~}$

Tabela 3.22 - Valor da produção calculado (VB) ${ }^{1}$ - Brasil, $1970,1975,1980$ e 1985.

\begin{tabular}{cccc}
\hline ano & $\begin{array}{c}\text { valor da produção } \\
\text { total } \begin{array}{c}\text { variação do } \\
\text { (a) }\end{array}\end{array}$ & $\begin{array}{c}\text { venso } \\
\text { (b) }\end{array}$ & $\begin{array}{c}\text { valor da produção } \\
\text { calculado (VB) } \\
\text { (VB=a+b) }\end{array}$ \\
\hline 1970 & 24967914 & 1933484 & 26901398 \\
1975 & 139106514 & 10403463 & 149509977 \\
1980 & 1542298299 & 160727186 & 1703025485 \\
1985 & 196705538 & 11600864 & 208306402 \\
\hline
\end{tabular}

Fonte: IBGE - censos Agropecuários

(1) os valores estão expressos em "mil cruzeiros" nos anos de 1970, 1975 e 1980 e, "mil cruzados" no ano de 1985.

(b) Coluna "e" da tabela 3.29 a 3.42: Valor da Variação do Rebanho (somatória de bovino e suíno). 
Tabela 3.23 - Valor da produção calculado (VB) 1 - Rondônia, $1970,1975,1980$ e 1985.

\begin{tabular}{cccc}
\hline valor da produção & $\begin{array}{c}\text { variação do } \\
\text { total } \begin{array}{c}\text { valor da produção } \\
\text { (a) }\end{array}\end{array}$ & $\begin{array}{c}\text { valo } \\
\text { calculado } \\
(\mathrm{VB})\end{array}$ & $\begin{array}{c}\text { (VB) } \\
(\mathrm{bB})\end{array}$ \\
\hline 1970 & 37904 & 1234 & 39138 \\
1975 & 342994 & 24933 & 367927 \\
1980 & 5672968 & 775906 & 6448874 \\
1985 & 1088590 & 197637 & 1286227 \\
\hline
\end{tabular}

Fonte: IBGE - Censos Agropecuários

(1) idem tabela 3.22

(b) idem tabela 3.22

Tabela 3.24 - Valor da produção calculado (VB) ${ }^{1}$ - Pará, $1970,1975,1980$ e 1985 .

\begin{tabular}{cccc}
\hline ano & $\begin{array}{c}\text { valor da produção } \\
\text { total } \begin{array}{c}\text { variação do } \\
\text { (a) }\end{array}\end{array}$ & $\begin{array}{c}\text { valor da produção } \\
\text { rebanho } \\
\text { (b) }\end{array}$ & $\begin{array}{c}\text { valculado (VB) } \\
\text { (VB=a+b) }\end{array}$ \\
\hline 1970 & 347620 & 30966 & 378586 \\
1975 & 1918562 & 218211 & 2136773 \\
1980 & 36108070 & 5149175 & 41257245 \\
1985 & 4617987 & 333091 & 4951078 \\
\hline
\end{tabular}

Fonte: IBGE - Censos Agropecuários

(1) idem tabela 3.22

(b) idem tabela 3.22 
Tabela 3.25 - Valor da produção calculado (VB) 1 - Ceará, $1970,1975,1980$ e 1985.

\begin{tabular}{cccc}
\hline ano & $\begin{array}{c}\text { valor da produção } \\
\text { total }- \text { Censo } \\
(\mathrm{a})\end{array}$ & $\begin{array}{c}\text { variação do } \\
\text { rebanho } \\
\text { (b) }\end{array}$ & $\begin{array}{c}\text { valor da produção } \\
\text { calculado (VB) } \\
\text { (VB=a+b) }\end{array}$ \\
\hline 1970 & 484584 & 38838 & 523422 \\
1975 & 2440314 & 250894 & 2691208 \\
1980 & 29548039 & 3147677 & 32695716 \\
1985 & 3446790 & 498768 & 3945558 \\
\hline
\end{tabular}

Fonte: IBGE - Censos Agropecuários

(1) idem tabela 3.22

(b) idem tabela 3.22

Tabela 3.26 - Valor da produção calculado (VB) I - Paraíba, $1970,1975,1980$ e 1985.

\begin{tabular}{cccc}
\hline valor da produção & $\begin{array}{c}\text { variação do } \\
\text { total } \begin{array}{c}\text { valor da produção } \\
\text { (a) }\end{array}\end{array}$ & $\begin{array}{c}\text { valor } \\
\text { calculado (VB) } \\
\text { (VB=a+b) }\end{array}$ \\
\hline 1970 & 342533 & 28318 & 370851 \\
1975 & 1809893 & 223563 & 2033456 \\
1980 & 17806209 & 1251063 & 19057272 \\
1985 & 2169102 & 310677 & 2479779 \\
\hline
\end{tabular}

Fonte: IBGE - Censos Agropecuários

(1) idem tabela 3.22

(b) idem tabela 3.22 
Tabela 3.27 - Valor da produção calculado (VB) ${ }^{1}$ - Bahia, $1970,1975,1980$ e 1985.

\begin{tabular}{cccc}
\hline ano & $\begin{array}{c}\text { valor da produção } \\
\text { total censo } \\
(\mathrm{a})\end{array}$ & $\begin{array}{c}\text { variação do } \\
\text { rebanho } \\
(\mathrm{b})\end{array}$ & $\begin{array}{c}\text { valor da produção } \\
\text { calculado (VB) } \\
(\mathrm{VB}=\mathrm{a}+\mathrm{b})\end{array}$ \\
\hline 1970 & 1519564 & 143518 & 1663082 \\
1975 & 7003007 & 1028464 & 8031471 \\
1980 & 87810744 & 10384778 & 98195522 \\
1985 & 12885779 & 906481 & 13792260 \\
\hline
\end{tabular}

Fonte: IBGE - Censos Agropecuários

(1) idem tabela 3.22

(b) idem tabela 3.22

Tabela 3.28 - Valor da produção calculado (VB) ${ }^{1}$ - Minas Gerais, 1970, 1975, 1980 e 1985.

\begin{tabular}{cccc}
\hline ano & $\begin{array}{c}\text { valor da produção } \\
\text { total - Censo } \\
\text { (a) }\end{array}$ & $\begin{array}{c}\text { variação do } \\
\text { rebanho } \\
\text { (b) }\end{array}$ & $\begin{array}{c}\text { valor da produção } \\
\text { calculado (VB) } \\
\text { (VB=a+b) }\end{array}$ \\
\hline 1970 & 2998810 & 422949 & 3421759 \\
1975 & 17138868 & 1544938 & 18683806 \\
1980 & 197120401 & 25589354 & 222709755 \\
1985 & 28541015 & 1680395 & 30221410 \\
\hline
\end{tabular}

Fonte: IBGE - Censos Agropecuários

(1) idem tabela 3.22

(b) idem tabela 3.22 
Tabela 3.29 - Valor da variação do rebanho bovino', segundo os Censos Agropecuários - BRASIL- 1970, 1975, 1980 e 1985 .

\begin{tabular}{cccccc}
\hline ano & $\begin{array}{c}\text { número de } \\
\text { animais } \\
\text { comprados } \\
(\mathrm{a})\end{array}$ & $\begin{array}{c}\text { valor } \\
\text { da } \\
\text { compra } \\
(\mathrm{b})\end{array}$ & $\begin{array}{c}\text { preço } \\
\text { médio da } \\
\text { compra } \\
(\mathrm{c}=\mathrm{b} / \mathrm{a})\end{array}$ & $\begin{array}{c}\text { total } \\
(\mathrm{d})\end{array}$ & $\begin{array}{c}\text { valor da } \\
\text { variação } \\
\text { Rebanho } \\
(\mathrm{e}=\mathrm{d} . \mathrm{c})\end{array}$ \\
\hline 1970 & 5431608 & 1493526 & 0,27 & 6627934 & 1822478 \\
1975 & 9184251 & 9913588 & 1,08 & 8318185 & 8978746 \\
1980 & 12354560 & 148913703 & 12,05 & 12802124 & 154308344 \\
1985 & 13749736 & 12742107 & 0,93 & 11710040 & 10851887 \\
\hline
\end{tabular}

Fonte: IBGE - Censos Agropecuários do Brasil

(1) os valores estão expressos em "mil cruzeiros" nos anos de 1970,1975 e 1980 e, em "mil cruzados" no ano de 1985 .

(d) Coluna "e" das tabelas 3.43 a 3.56: Variação do Rebanho (em número de cabeças).

Tabela 3.30 - Valor da variação do rebanho suíno', segundo os Censos Agropecuários - BRASIL -1970, 1975, 1980 e 1985 .

\begin{tabular}{cccccc}
\hline ano & $\begin{array}{c}\text { número de } \\
\text { animais } \\
\text { comprados } \\
(\mathrm{a})\end{array}$ & $\begin{array}{c}\text { valor } \\
\text { da } \\
\text { compra } \\
(\mathrm{b})\end{array}$ & $\begin{array}{c}\text { preço } \\
\text { médio da } \\
\text { compra } \\
(\mathrm{c}=\mathrm{b} / \mathrm{a})\end{array}$ & $\begin{array}{c}\text { total } \\
(\mathrm{d})\end{array}$ & $\begin{array}{c}\text { valor da } \\
\text { variação } \\
\text { Rebanho } \\
(\mathrm{e}=\mathrm{d} . \mathrm{c})\end{array}$ \\
\hline 1970 & 1842628 & 101609 & 0,06 & 1970436 & 111006 \\
1975 & 2515615 & 527864 & 0,21 & 6789704 & 1424717 \\
1980 & 3123155 & 5636002 & 1,80 & 3556961 & 6418842 \\
1985 & 4701209 & 746666 & 0,16 & 4715758 & 748977 \\
\hline
\end{tabular}

Fonte: IBGE - Censos Agropecuários do Brasil

(1) idem tabela 3.29

(d) idem tabela 3.29 
Tabela 3.31 - Valor da variação do rebanho bovino1, segundo os Censos Agropecuários - RONDÔNIA - 1970, 1975,1980 e 1985 .

\begin{tabular}{cccccc}
\hline ano & $\begin{array}{c}\text { número de } \\
\text { animais } \\
\text { comprados } \\
(\mathrm{a})\end{array}$ & $\begin{array}{c}\text { valor } \\
\text { da } \\
\text { compra } \\
(\mathrm{b})\end{array}$ & $\begin{array}{c}\text { preço } \\
\text { médio da } \\
\text { compra } \\
(\mathrm{c}=\mathrm{b} / \mathrm{a})\end{array}$ & $\begin{array}{c}\text { total } \\
(\mathrm{d})\end{array}$ & $\begin{array}{c}\text { valor da } \\
\text { variação } \\
\text { Rebanho } \\
(\mathrm{e}=\mathrm{d} . \mathrm{c})\end{array}$ \\
\hline 1970 & 1664 & 636 & 0,38 & 3241 & 1239 \\
1975 & 8884 & 18742 & 2,11 & 8182 & 17261 \\
1980 & 36638 & 668524 & 18,25 & 39614 & 722826 \\
1985 & 113485 & 131774 & 1,16 & 156797 & 182066 \\
\hline
\end{tabular}

Fonte: IBGE - Censos Agropecuários de Rondônia

(1) idem tabela 3.29

(d) idem tabela 3.29

Tabela 3.32 - Valor da variação do rebanho suino1, segundo os Censos Agropecuários - RONDÔNIA - 1970, 1975,1980 e 1985 .

\begin{tabular}{|c|c|c|c|c|c|}
\hline ano & $\begin{array}{c}\text { número de } \\
\text { animais } \\
\text { comprados } \\
\text { (a) }\end{array}$ & $\begin{array}{l}\text { valor } \\
\text { da } \\
\text { compra } \\
\text { (b) }\end{array}$ & $\begin{array}{l}\text { preço } \\
\text { médio da } \\
\text { compra } \\
(\mathrm{c}=\mathrm{b} / \mathrm{a})\end{array}$ & $\begin{array}{c}\text { total } \\
\text { (d) }\end{array}$ & $\begin{array}{l}\text { valor da } \\
\text { variação } \\
\text { Rebanho } \\
(e=d . c)\end{array}$ \\
\hline 1970 & 729 & 35 & 0,05 & -103 & -5 \\
\hline 1975 & 6983 & 1826 & 0,26 & 29338 & 7672 \\
\hline 1980 & 34257 & 55704 & 1,63 & 32643 & 53080 \\
\hline 1985 & 45392 & 8207 & 0,18 & 86122 & 15571 \\
\hline
\end{tabular}

Fonte: IBGE - Censos Agropecuários de Rondônia

(1) idem tabela 3.29

(d) idem tabela 3.29 
Tabela 3.33 - Valor da variação do rebanho bovino1, segundo os Censos Agropecuários - PARÁ - 1970, 1975, 1980 e 1985 .

\begin{tabular}{cccccc}
\hline ano & $\begin{array}{c}\text { número de } \\
\text { animais } \\
\text { comprados } \\
(\mathrm{a})\end{array}$ & $\begin{array}{c}\text { valor } \\
\text { da } \\
\text { compra } \\
(\mathrm{b})\end{array}$ & $\begin{array}{c}\text { preço } \\
\text { médio da } \\
\text { compra } \\
(\mathrm{c}=\mathrm{b} / \mathrm{a})\end{array}$ & $\begin{array}{c}\text { total } \\
(\mathrm{d})\end{array}$ & $\begin{array}{c}\text { valor da } \\
\text { variação } \\
\text { Rebanho } \\
(\mathrm{e}=\mathrm{d} \cdot \mathrm{c})\end{array}$ \\
\hline 1970 & 69684 & 18799 & 0,27 & 103052 & 27800 \\
1975 & 107715 & 124989 & 1,16 & 162062 & 188051 \\
1980 & 163225 & 2184547 & 13,38 & 363690 & 4867501 \\
1985 & 235687 & 263807 & 1,12 & 264699 & 296280 \\
\hline
\end{tabular}

Fonte: IBGE - Censos Agropecuários do Pará

(1) idem tabela 3.29

(d) idem tabela 3.29

Tabela 3.34 - Valor da variação do rebanho suíno', segundo os Censos Agropecuários - PARÁ - 1970, 1975, 1980 e 1985 .

\begin{tabular}{cccccc}
\hline ano & $\begin{array}{c}\text { número de } \\
\text { animais } \\
\text { comprados } \\
(\mathrm{a})\end{array}$ & $\begin{array}{c}\text { valor } \\
\text { da } \\
\text { compra } \\
(\mathrm{b})\end{array}$ & $\begin{array}{c}\text { preço } \\
\text { médio da } \\
\text { compra } \\
(\mathrm{c}=\mathrm{b} / \mathrm{a})\end{array}$ & $\begin{array}{c}\text { total } \\
(\mathrm{d})\end{array}$ & $\begin{array}{c}\text { valor da } \\
\text { variação } \\
\text { Rebanho } \\
(\mathrm{e}=\mathrm{d} . \mathrm{c})\end{array}$ \\
\hline 1970 & 9999 & 350 & 0,04 & 90440 & 3166 \\
1975 & 14116 & 2094 & 0,15 & 203314 & 30160 \\
1980 & 29851 & 51644 & 1,73 & 162812 & 281674 \\
1985 & 57645 & 8761 & 0,15 & 242204 & 36811 \\
\hline
\end{tabular}

Fonte: IBGE - Censos Agropecuários do Pará

(I) idem tabela 3.29

(d) idem tabela 3.29 
Tabela 3.35 - Valor da variação do rebanho bovino', segundo os Censos Agropecuários - CEARÁ - 1970, 1975, 1980 e 1985 .

\begin{tabular}{cccccc}
\hline ano & $\begin{array}{c}\text { número de } \\
\text { animais } \\
\text { comprados } \\
(\mathrm{a})\end{array}$ & $\begin{array}{c}\text { valor } \\
\text { da } \\
\text { compra } \\
(\mathrm{b})\end{array}$ & $\begin{array}{c}\text { preço } \\
\text { médio da } \\
\text { compra } \\
(\mathrm{c}=\mathrm{b} / \mathrm{a})\end{array}$ & $\begin{array}{c}\text { total } \\
(\mathrm{d})\end{array}$ & $\begin{array}{c}\text { valor da } \\
\text { variação } \\
\text { Rebanho } \\
(\mathrm{e}=\mathrm{d} . \mathrm{c})\end{array}$ \\
\hline 1970 & 108525 & 27817 & 0,26 & 142899 & 36628 \\
1975 & 105490 & 134343 & 1,27 & 178296 & 227062 \\
1980 & 176507 & 2037649 & 11,54 & 256030 & 2955686 \\
1985 & 178407 & 229544 & 1,29 & 358510 & 461270 \\
\hline
\end{tabular}

Fonte: IBGE - Censos Agropecuários do Ceará

(1) idem tabela 3.29

(d) idem tabela 3.29

Tabela 3.36 - Valor da variação do rebanho suíno1, segundo os Censos Agropecuários - CEARÁ - 1970, 1975, 1980 e 1985 .

\begin{tabular}{cccccc}
\hline ano & $\begin{array}{c}\text { número de } \\
\text { animais } \\
\text { comprados } \\
(\mathrm{a})\end{array}$ & $\begin{array}{c}\text { valor } \\
\text { da } \\
\text { compra } \\
(\mathrm{b})\end{array}$ & $\begin{array}{c}\text { preço } \\
\text { médio da } \\
\text { compra } \\
(\mathrm{c}=\mathrm{b} / \mathrm{a})\end{array}$ & $\begin{array}{c}\text { total } \\
(\mathrm{d})\end{array}$ & $\begin{array}{c}\text { valor da } \\
\text { variação } \\
\text { Rebanho } \\
(\mathrm{e}=\mathrm{d} . \mathrm{c})\end{array}$ \\
\hline 1970 & 29025 & 639 & 0,02 & 100393 & 2210 \\
1975 & 67296 & 6025 & 0,09 & 266194 & 23832 \\
1980 & 68771 & 91044 & 1,32 & 145022 & 191991 \\
1985 & 119168 & 12113 & 0,10 & 368907 & 37498 \\
\hline
\end{tabular}

Fonte: IBGE - Censos Agropecuários do ceará

(1) idem tabela 3.29

(d) idem tabela 3.29 
Tabela 3.37 - Valor da variação do rebanho bovinor, segundo os Censos Agropecuários - PARAIBA - 1970, 1975,1980 e 1985 .

\begin{tabular}{cccccc}
\hline ano & $\begin{array}{c}\text { número de } \\
\text { animais } \\
\text { comprados } \\
(\mathrm{a})\end{array}$ & $\begin{array}{c}\text { valor } \\
\text { da } \\
\text { compra } \\
(\mathrm{b})\end{array}$ & $\begin{array}{c}\text { preço } \\
\text { médio da } \\
\text { compra } \\
(\mathrm{c}=\mathrm{b} / \mathrm{a})\end{array}$ & $\begin{array}{c}\text { total } \\
(\mathrm{d})\end{array}$ & $\begin{array}{c}\text { valor da } \\
\text { variacão } \\
\text { Rebanho } \\
(\mathrm{e}=\mathrm{d} \text {.c })\end{array}$ \\
\hline 1970 & 54295 & 17561 & 0,32 & 87014 & 28144 \\
1975 & 64131 & 95048 & 1,48 & 149590 & 221706 \\
1980 & 124263 & 1472954 & 11,85 & 103068 & 1221719 \\
1985 & 136335 & 203261 & 1,49 & 204379 & 304707 \\
\hline
\end{tabular}

Fonte: IBGE - Censos Agropecuários da Paraíba

(1) idem tabela 3.29

(d) idem tabela 3.29

Tabela 3.38 - Valor da variação do rebanho suíno1, segundo os Censos Agropecuários - PARAíbA - 1970, 1975,1980 e 1985 .

\begin{tabular}{cccccc}
\hline ano & $\begin{array}{c}\text { número de } \\
\text { animais } \\
\text { comprados } \\
(\mathrm{a})\end{array}$ & $\begin{array}{c}\text { valor } \\
\text { da } \\
\text { compra } \\
(\mathrm{b})\end{array}$ & $\begin{array}{c}\text { preço } \\
\text { médio da } \\
\text { compra } \\
(\mathrm{c}=\mathrm{b} / \mathrm{a})\end{array}$ & $\begin{array}{c}\text { total } \\
(\mathrm{d})\end{array}$ & $\begin{array}{c}\text { valor da } \\
\text { variação } \\
\text { Rebanho } \\
(\mathrm{e}=\mathrm{d} . \mathrm{c})\end{array}$ \\
\hline 1970 & 16112 & 322 & 0,02 & 8767 & 175 \\
1975 & 39437 & 2804 & 0,07 & 26118 & 1857 \\
1980 & 63683 & 69741 & 1,10 & 26795 & 29344 \\
1985 & 60018 & 5527 & 0,09 & 64831 & 5970 \\
\hline
\end{tabular}

Fonte: IBGE - Censos Agropecuários da Paraíba

(1) idem tabela 3.29

(d) idem tabela 3.29 
Tabela 3.39 - Valor da variação do rebanho bovino1, segundo os Censos Agropecuários - BAHIA - 1970, 1975, 1980 e 1985 .

\begin{tabular}{cccccr}
\hline ano & $\begin{array}{c}\text { número de } \\
\text { animais } \\
\text { comprados } \\
(\mathrm{a})\end{array}$ & $\begin{array}{c}\text { valor } \\
\text { da } \\
\text { compra } \\
(\mathrm{b})\end{array}$ & $\begin{array}{c}\text { preço } \\
\text { médio da } \\
\text { compra } \\
(\mathrm{c}=\mathrm{b} / \mathrm{a})\end{array}$ & $\begin{array}{c}\text { total } \\
(\mathrm{d})\end{array}$ & $\begin{array}{c}\text { valor da } \\
\text { variação } \\
\text { Rebanho } \\
(\mathrm{e}=\mathrm{d} . \mathrm{c})\end{array}$ \\
\hline 1970 & 312896 & 94198 & 0,30 & 457427 & 137709 \\
1975 & 514857 & 617891 & 1,20 & 814219 & 977162 \\
1980 & 640495 & 7492698 & 11,70 & 864078 & 10108237 \\
1985 & 738839 & 774882 & 1,05 & 814723 & 854468 \\
\hline
\end{tabular}

Fonte: IBGE - Censos Agropecuários da Bahia

(1) idem tabela 3.29

(d) idem tabela 3.29

Tabela 3.40 - Valor da variação do rebanho suíno1, segundo os Censos Agropecuários - BAHIA - 1970, 1975, 1980 e 1985 .

\begin{tabular}{cccccc}
\hline ano & $\begin{array}{c}\text { número de } \\
\text { animais } \\
\text { comprados } \\
(\mathrm{a})\end{array}$ & $\begin{array}{c}\text { valor } \\
\text { da } \\
\text { compra } \\
(\mathrm{b})\end{array}$ & $\begin{array}{c}\text { preço } \\
\text { médio da } \\
\text { compra } \\
(\mathrm{c}=\mathrm{b} / \mathrm{a})\end{array}$ & $\begin{array}{c}\text { total } \\
(\mathrm{d})\end{array}$ & $\begin{array}{c}\text { valor da } \\
\text { variação } \\
\text { Rebanho } \\
(\mathrm{e}=\mathrm{d} . \mathrm{c})\end{array}$ \\
\hline 1970 & 83726 & 2685 & 0,03 & 181129 & 5809 \\
1975 & 133981 & 15165 & 0,11 & 453246 & 51302 \\
1980 & 147396 & 200021 & 1,36 & 203784 & 276541 \\
1985 & 183682 & 27373 & 0,15 & 349023 & 52013 \\
\hline
\end{tabular}

Fonte: IBGE - Censos Agropecuários da Bahia

(1) idem tabela 3.29

(d) idem tabela 3.29 
Tabela 3.41 - Valor da variação do rebanho bovino1, segundo os Censos Agropecuários - MINAS GERAIS $1970,1975,1980$ e 1985 .

\begin{tabular}{cccccc}
\hline ano & $\begin{array}{c}\text { número de } \\
\text { animais } \\
\text { comprados } \\
(\mathrm{a})\end{array}$ & $\begin{array}{c}\text { valor } \\
\text { da } \\
\text { compra } \\
(\mathrm{b})\end{array}$ & $\begin{array}{c}\text { preço } \\
\text { médio da } \\
\text { compra } \\
(\mathrm{c}=\mathrm{b} / \mathrm{a})\end{array}$ & $\begin{array}{c}\text { total } \\
(\mathrm{d})\end{array}$ & $\begin{array}{c}\text { valor da } \\
\text { variação } \\
\text { Rebanho } \\
(\mathrm{e}=\mathrm{d} . \mathrm{c})\end{array}$ \\
\hline 1970 & 865161 & 240735 & 0,28 & 1513989 & 421277 \\
1975 & 1940017 & 2025583 & 1,04 & 1430478 & 1493570 \\
1980 & 2468836 & 29200536 & 11,83 & 2131424 & 25209744 \\
1985 & 2500189 & 2112907 & 0,85 & 1916174 & 1619357 \\
\hline
\end{tabular}

Fonte: IBGE - Censos Agropecuários de Minas Gerais

(1) idem tabela 3.29

(d) idem tabela 3.29

Tabela 3.42 - Valor da variação do rebanho suíno1, segundo os Censos Agropecuários - MINAS GERAIS $1970,1975,1980$ e 1985 .

\begin{tabular}{cccccc}
\hline ano & $\begin{array}{c}\text { número de } \\
\text { animais } \\
\text { comprados } \\
(\mathrm{a})\end{array}$ & $\begin{array}{c}\text { valor } \\
\text { da } \\
\text { compra } \\
(\mathrm{b})\end{array}$ & $\begin{array}{c}\text { preço } \\
\text { médio da } \\
\text { compra } \\
(\mathrm{c}=\mathrm{b} / \mathrm{a})\end{array}$ & $\begin{array}{c}\text { total } \\
(\mathrm{d})\end{array}$ & $\begin{array}{c}\text { valor da } \\
\text { variação } \\
\text { Rebanho } \\
(\mathrm{e}=\mathrm{d} . \mathrm{c})\end{array}$ \\
\hline 1970 & 247229 & 11990 & 0,05 & 34470 & 1672 \\
1975 & 377797 & 70351 & 0,19 & 275853 & 51368 \\
1980 & 384136 & 747643 & 1,95 & 195042 & 379610 \\
1985 & 406075 & 79735 & 0,20 & 310854 & 61038 \\
\hline
\end{tabular}

Fonte: IBGE - Censos Agropecuários de Minas Gerais

(1) idem tabela 3.29

(d) idem tabela 3.29 
Tabela 3.43 - Variação do rebanho bovino (em número de cabeças), segundo os Censos Agropecuários BRASIL - 1970, 1975, 1980 e 1985 .

\begin{tabular}{|c|c|c|c|c|c|}
\hline ano & $\begin{array}{c}\text { nascidos } \\
\text { (a) }\end{array}$ & $\begin{array}{c}\text { vitimados } \\
\text { (b) }\end{array}$ & $\begin{array}{c}\text { abatidos e } \\
\text { vendidos } \\
\text { (c) }\end{array}$ & $\begin{array}{c}\text { comprados } \\
\text { (d) }\end{array}$ & $\begin{array}{l}\text { total } \\
\text { (e) }\end{array}$ \\
\hline 1970 & 14682938 & 2758751 & 10727861 & 5431608 & 6627934 \\
\hline 1975 & 20478874 & 3205308 & 18139632 & 9184251 & 8318185 \\
\hline 1980 & 24341236 & 3791983 & 20101689 & 12354560 & 12802124 \\
\hline 1985 & 26134342 & 4190445 & 23983593 & 13749736 & 11710040 \\
\hline
\end{tabular}

Fonte: IBGE - Censos Agropecuários do Brasil

nota: estimou-se o número de animais comprados (e o valor da compra) para o ano de 1970 (conforme as tabelas 3.57 a 3.61 de ESTIMATIVA).

$(e)=(a+d-b-c)$

Tabela 3.44 - Variação do rebanho suíno (em número de cabeÇas), segundo os Censos Agropecuários BRASIL - $1970,1975,1980$ e 1985.

\begin{tabular}{cccccc}
\hline ano & $\begin{array}{c}\text { nascidos } \\
(\mathrm{a})\end{array}$ & $\begin{array}{c}\text { vitimados } \\
(\mathrm{b})\end{array}$ & $\begin{array}{c}\text { abatidos } \\
\text { vendidos } \\
(\mathrm{c})\end{array}$ & $\begin{array}{c}\text { comprados } \\
(\mathrm{d})\end{array}$ & $\begin{array}{c}\text { total } \\
(\mathrm{e})\end{array}$ \\
\hline 1970 & 17851263 & 5231392 & 12449464 & 1842628 & 2013035 \\
1975 & 26103305 & 4832810 & 16996406 & 2515615 & 6789704 \\
1980 & 26122443 & 5004372 & 20684265 & 3123155 & 3556961 \\
1985 & 23717157 & 4058822 & 19643786 & 4701209 & 4715758 \\
\hline
\end{tabular}

Fonte: IBGE - Censos Agropecuários do Brasil

$(e)=(a+d-b-c)$

nota: idem tabela 3.43 
Tabela 3.45 - Variação do rebanho bovino (em número de cabeças), segundo os Censos Agropecuários RONDỐNIA - $1970,1975,1980$ e 1985.

\begin{tabular}{lccccc}
\hline ano & $\begin{array}{c}\text { nascidos } \\
(\mathrm{a})\end{array}$ & $\begin{array}{c}\text { vitimados } \\
\text { (b) }\end{array}$ & $\begin{array}{c}\text { abatidos } \\
\text { vendidos } \\
(\mathrm{c})\end{array}$ & $\begin{array}{c}\text { comprados } \\
\text { (d) }\end{array}$ & $\begin{array}{c}\text { total } \\
(\mathrm{e})\end{array}$ \\
\hline 1970 & 3950 & 938 & 1435 & 1664 & 3241 \\
1975 & 8715 & 1755 & 7662 & 8884 & 8182 \\
1980 & 46044 & 6810 & 36258 & 36638 & 39614 \\
1985 & 149883 & 19974 & 86597 & 113485 & 156797 \\
\hline
\end{tabular}

Fonte: IBGE - Censos Agropecuários de Rondônia $(e)=(a+d-b-c)$

nota: idem tabela 3.43

Tabela 3.46 - Variação do rebanho suíno (em número de cabeças), segundo os censos Agropecuários RONDÔNIA - 1970, 1975, 1980 e 1985.

\begin{tabular}{|c|c|c|c|c|c|}
\hline ano & $\begin{array}{c}\text { nascidos } \\
\text { (a) }\end{array}$ & $\begin{array}{l}\text { vitimados } \\
\text { (b) }\end{array}$ & $\begin{array}{c}\text { abatidos e } \\
\text { vendidos } \\
\text { (c) }\end{array}$ & $\begin{array}{c}\text { comprados } \\
\text { (d) }\end{array}$ & $\begin{array}{c}\text { total } \\
\text { (e) }\end{array}$ \\
\hline 1970 & 3086 & 1292 & 2626 & 729 & -103 \\
\hline 1975 & 65963 & 18466 & 25142 & 6983 & 29338 \\
\hline 1980 & 194911 & 71099 & 125426 & 34257 & 32643 \\
\hline 1985 & 262078 & 67709 & 153639 & 45392 & 86122 \\
\hline
\end{tabular}

Fonte: IBGE - Censos Agropecuários de Rondônia $(e)=(a+d-b-c)$

nota: idem tabela 3.43 
Tabela 3.47 - Variação do rebanho bovino (em número de cabeças), segundo os Censos Agropecuários PARÁ - 1970, 1975, 1980 e 1985.

\begin{tabular}{lccccc}
\hline ano & $\begin{array}{c}\text { nascidos } \\
\text { (a) }\end{array}$ & $\begin{array}{c}\text { vitimados } \\
\text { (b) }\end{array}$ & $\begin{array}{c}\text { abatidos } \\
\text { vendidos } \\
(\mathrm{c})\end{array}$ & $\begin{array}{c}\text { comprados } \\
\text { (d) }\end{array}$ & $\begin{array}{c}\text { total } \\
\text { (e) }\end{array}$ \\
\hline 1970 & 202260 & 52876 & 116016 & 69684 & 103052 \\
1975 & 284837 & 51156 & 179334 & 107715 & 162062 \\
1980 & 589600 & 83599 & 305536 & 163225 & 363690 \\
1985 & 683359 & 104021 & 550326 & 235687 & 264699 \\
\hline
\end{tabular}

Fonte: IBGE - Censos Agropecuários do Pará (e) $=(a+d-b-c)$

nota: idem tabela 3.43

Tabela 3.48 - Variação do rebanho suíno (em número de cabeÇas), segundo os Censos Agropecuários PARÁ - 1970, 1975, 1980 e 1985.

\begin{tabular}{|c|c|c|c|c|c|}
\hline ano & $\begin{array}{c}\text { nascidos } \\
\text { (a) }\end{array}$ & $\begin{array}{c}\text { vitimados } \\
\text { (b) }\end{array}$ & $\begin{array}{l}\text { abatidos e } \\
\text { vendidos } \\
\text { (c) }\end{array}$ & $\begin{array}{c}\text { comprados } \\
\text { (d) }\end{array}$ & $\begin{array}{c}\text { total } \\
\text { (e) }\end{array}$ \\
\hline 1970 & 291658 & 72255 & 138962 & 9999 & 90440 \\
\hline 1975 & 477400 & 92016 & 196186 & 14116 & 203314 \\
\hline 1980 & 557958 & 126255 & 298742 & 29851 & 162812 \\
\hline 1985 & 739742 & 187222 & 367961 & 57645 & 242204 \\
\hline
\end{tabular}

Fonte: IBGE - Censos Agropecuários do Pará $(e)=(a+d-b-c)$

nota: idem tabela 3.43 
Tabela 3.49 - Variação do rebanho bovino (em número de cabecas), segundo os censos Agropecuários CEARA - 1970, 1975, 1980 e 1985.

\begin{tabular}{|c|c|c|c|c|c|}
\hline ano & $\begin{array}{c}\text { nascidos } \\
\text { (a) }\end{array}$ & $\begin{array}{l}\text { vitimados } \\
\text { (b) }\end{array}$ & $\begin{array}{c}\text { abatidos e } \\
\text { vendidos } \\
\text { (c) }\end{array}$ & $\begin{array}{c}\text { comprados } \\
\text { (d) }\end{array}$ & $\begin{array}{c}\text { total } \\
\text { (e) }\end{array}$ \\
\hline 1970 & 356934 & 87437 & 235123 & 108525 & 142899 \\
\hline 1975 & 392621 & 91268 & 228547 & 105490 & 178296 \\
\hline 1980 & 481513 & 88196 & 313794 & 176507 & 256030 \\
\hline 1985 & 581559 & 91810 & 309646 & 178407 & 358510 \\
\hline
\end{tabular}

Fonte: IBGE - Censos Agropecuários do Ceará $(e)=(a+d-b-c)$

nota: idem tabela 3.43

Tabela 3.50 - Variação do rebanho suíno (em número de cabeÇas), segundo os Censos Agropecuários CEARÁ - 1970, 1975, 1980 e 1985.

\begin{tabular}{|c|c|c|c|c|c|}
\hline ano & $\begin{array}{c}\text { nascidos } \\
\text { (a) }\end{array}$ & $\begin{array}{l}\text { vitimados } \\
\text { (b) }\end{array}$ & $\begin{array}{c}\text { abatidos e } \\
\text { vendidos } \\
\text { (c) }\end{array}$ & $\begin{array}{c}\text { comprados } \\
\text { (d) }\end{array}$ & $\begin{array}{l}\text { total } \\
(e)\end{array}$ \\
\hline 1970 & 437318 & 181409 & 184541 & 29025 & 100393 \\
\hline 1975 & 822781 & 196021 & 427862 & 67296 & 266194 \\
\hline 1980 & 522276 & 135236 & 310789 & 68771 & 145022 \\
\hline 1985 & 883464 & 206750 & 426975 & 119168 & 368907 \\
\hline
\end{tabular}

Fonte: IBGE - Censos Agropecuários do Ceará $(e)=(a+d-b-c)$

nota: idem tabela 3.43 
Tabela 3.51 - Variação do rebanho bovino (em número de cabecas), segundo os Censos Agropecuários PARAIBA - 1970, 1975, 1980 e 1985.

\begin{tabular}{|c|c|c|c|c|c|}
\hline ano & $\begin{array}{c}\text { nascidos } \\
\text { (a) }\end{array}$ & $\begin{array}{l}\text { vitimados } \\
\text { (b) }\end{array}$ & $\begin{array}{c}\text { abatidos e } \\
\text { vendidos } \\
\text { (c) }\end{array}$ & $\begin{array}{c}\text { comprados } \\
\text { (d) }\end{array}$ & $\begin{array}{c}\text { total } \\
\text { (e) }\end{array}$ \\
\hline 1970 & 171273 & 34234 & 104320 & 54295 & 87014 \\
\hline 1975 & 249125 & 40447 & 123219 & 64131 & 149590 \\
\hline 1980 & 259528 & 52815 & 227908 & 124263 & 103068 \\
\hline 1985 & 306227 & 39807 & 198376 & 136335 & 204379 \\
\hline
\end{tabular}

Fonte: IBGE - Censos Agropecuários da Paraíba

$(e)=(a+d-b-c)$

nota: idem tabela 3.43

Tabela 3.52 - Variação do rebanho suíno (em número de cabeÇas), segundo os Censos Agropecuários PARAIBA - 1970, 1975, 1980 e 1985.

\begin{tabular}{|c|c|c|c|c|c|}
\hline ano & $\begin{array}{c}\text { nascidos } \\
\text { (a) }\end{array}$ & $\begin{array}{c}\text { vitimados } \\
\text { (b) }\end{array}$ & $\begin{array}{c}\text { abatidos e } \\
\text { vendidos } \\
\text { (c) }\end{array}$ & $\begin{array}{c}\text { comprados } \\
\text { (d) }\end{array}$ & $\begin{array}{c}\text { total } \\
\text { (e) }\end{array}$ \\
\hline 1970 & 62820 & 17984 & 52181 & 16112 & 8767 \\
\hline 1975 & 143129 & 28726 & 127722 & 39437 & 26118 \\
\hline 1980 & 130886 & 30568 & 137206 & 63683 & 26795 \\
\hline 1985 & 161566 & 30661 & 126092 & 60018 & 64831 \\
\hline
\end{tabular}

Fonte: IBGE - Censos Agropecuários da Paraíba $(e)=(a+d-b-c)$

nota: idem tabela 3.43 
Tabela 3.53 - Variação do rebanho bovino (em número de cabeças), segundo os Censos Agropecuários BAHIA - $1970,1975,1980$ e 1985.

\begin{tabular}{|c|c|c|c|c|c|}
\hline ano & $\begin{array}{c}\text { nascidos } \\
\text { (a) }\end{array}$ & $\begin{array}{l}\text { vitimados } \\
\text { (b) }\end{array}$ & $\begin{array}{c}\text { abatidos e } \\
\text { vendidos } \\
\text { (c) }\end{array}$ & $\begin{array}{c}\text { comprados } \\
\text { (d) }\end{array}$ & $\begin{array}{c}\text { total } \\
\text { (e) }\end{array}$ \\
\hline 1970 & 1039681 & 220119 & 675031 & 312896 & 457427 \\
\hline 1975 & 1661582 & 251486 & 1110734 & 514857 & 814219 \\
\hline 1980 & 1815212 & 335730 & 1255899 & 640495 & 864078 \\
\hline 1985 & 1832727 & 324204 & 1432639 & 738839 & 814723 \\
\hline
\end{tabular}

Fonte: IBGE - Censos Agropecuários da Bahia $(e)=(a+d-b-c)$

nota: idem tabela 3.43

Tabela 3.54 - Variação do rebanho suíno (em número de cabeÇas), segundo os Censos Agropecuários BAHIA - 1970, 1975, 1980 e 1985 .

\begin{tabular}{|c|c|c|c|c|c|}
\hline ano & $\begin{array}{c}\text { nascidos } \\
\text { (a) }\end{array}$ & $\begin{array}{c}\text { vitimados } \\
\text { (b) }\end{array}$ & $\begin{array}{c}\text { abatidos e } \\
\text { vendidos } \\
\text { (c) }\end{array}$ & $\begin{array}{c}\text { comprados } \\
\text { (d) }\end{array}$ & $\begin{array}{c}\text { total } \\
\text { (e) }\end{array}$ \\
\hline 1970 & 855250 & 343989 & 413858 & 83726 & 181129 \\
\hline 1975 & 1311089 & 329556 & 662268 & 133981 & 453246 \\
\hline 1980 & 936745 & 334946 & 545411 & 147396 & 203784 \\
\hline 1985 & 790034 & 184027 & 440666 & 183682 & 349023 \\
\hline
\end{tabular}

Fonte: IBGE - Censos Agropecuários da Bahia $(e)=(a+d-b-c)$

nota: idem tabela 3.43 
Tabela 3.55 - Variação do rebanho bovino (em número de cabeças), segundo os Censos Agropecuários MINAS GERAIS - 1970, 1975, 1980 e 1985.

\begin{tabular}{cccccc}
\hline ano & $\begin{array}{c}\text { nascidos } \\
\text { (a) }\end{array}$ & $\begin{array}{c}\text { vitimados } \\
\text { (b) }\end{array}$ & $\begin{array}{c}\text { abatidos } \\
\text { vendidos } \\
(\mathrm{c})\end{array}$ & $\begin{array}{c}\text { comprados } \\
\text { (d) }\end{array}$ & $\begin{array}{c}\text { total } \\
\text { (e) }\end{array}$ \\
\hline 1970 & 2921611 & 486288 & 1786486 & 865161 & 1513998 \\
1975 & 4139233 & 642798 & 4005974 & 1940017 & 1430478 \\
1980 & 4166971 & 657902 & 3846481 & 2468836 & 2131424 \\
1985 & 4307272 & 837146 & 4054141 & 2500189 & 1916174 \\
\hline
\end{tabular}

Fonte: IBGE - Censos Agropecuários de Minas Gerais $(e)=(a+d-b-c)$

nota: idem tabela 3.43

Tabela 3.56 - Variação do rebanho suíno (em número de cabeÇas), segundo os Censos Agropecuários MINAS GERAIS - 1970, 1975, 1980 e 1985.

\begin{tabular}{|c|c|c|c|c|c|}
\hline ano & $\begin{array}{c}\text { nascidos } \\
\text { (a) }\end{array}$ & $\begin{array}{l}\text { vitimados } \\
\text { (b) }\end{array}$ & $\begin{array}{c}\text { abatidos e } \\
\text { vendidos } \\
\text { (c) }\end{array}$ & $\begin{array}{c}\text { comprados } \\
\text { (d) }\end{array}$ & $\begin{array}{c}\text { total } \\
(e)\end{array}$ \\
\hline 1970 & 1380771 & 339027 & 1254503 & 247229 & 34470 \\
\hline 1975 & 2143891 & 328800 & 1917035 & 377797 & 275853 \\
\hline 1980 & 1996272 & 330916 & 1854450 & 384136 & 195042 \\
\hline 1985 & 2007153 & 291814 & 1810560 & 406075 & 310854 \\
\hline
\end{tabular}

Fonte: IBGE - Censos Agropecuários de Minas Gerais $(e)=(a+d-b-c)$

nota: idem tabela 3.43 
Tabela 3.57 - Estimativa do número de bovinos comprados e valor da compra de 1970 - Brasil e estados.

\begin{tabular}{|c|c|c|c|c|c|}
\hline Estados & ano & $\begin{array}{l}\text { Abatidos e } \\
\text { Vendidos }\end{array}$ & Comprados & $\begin{array}{c}\text { Valor venda } \\
\text { e abate }\end{array}$ & $\begin{array}{l}\text { Valor da } \\
\text { compra }\end{array}$ \\
\hline Brasil & $\begin{array}{l}1970 \\
1975\end{array}$ & $\begin{array}{l}10727861 \\
18139632\end{array}$ & $\begin{array}{l}5431608 \\
9184251\end{array}$ & $\begin{array}{r}3390093 \\
22502451\end{array}$ & $\begin{array}{l}1493526 \\
9913588\end{array}$ \\
\hline Rondônia & $\begin{array}{l}1970 \\
1975\end{array}$ & $\begin{array}{l}1435 \\
7662\end{array}$ & $\begin{array}{l}1664 \\
8884\end{array}$ & $\begin{array}{r}580 \\
17086\end{array}$ & $\begin{array}{r}636 \\
18742\end{array}$ \\
\hline Pará & $\begin{array}{l}1970 \\
1975\end{array}$ & $\begin{array}{l}116016 \\
179334\end{array}$ & $\begin{array}{r}69684 \\
107715\end{array}$ & $\begin{array}{r}37995 \\
252622\end{array}$ & $\begin{array}{r}18799 \\
124989\end{array}$ \\
\hline Ceará & $\begin{array}{l}1970 \\
1975\end{array}$ & $\begin{array}{l}235123 \\
228547\end{array}$ & $\begin{array}{l}108525 \\
105490\end{array}$ & $\begin{array}{r}54867 \\
264982\end{array}$ & $\begin{array}{r}27817 \\
134343\end{array}$ \\
\hline Paraiba & $\begin{array}{l}1970 \\
1975\end{array}$ & $\begin{array}{l}104320 \\
123219\end{array}$ & $\begin{array}{l}54295 \\
64131\end{array}$ & $\begin{array}{r}33448 \\
181036\end{array}$ & $\begin{array}{l}17561 \\
95048\end{array}$ \\
\hline Bahia & $\begin{array}{l}1970 \\
1975\end{array}$ & $\begin{array}{r}675031 \\
1110734\end{array}$ & $\begin{array}{l}312896 \\
514857\end{array}$ & $\begin{array}{r}224479 \\
1472468\end{array}$ & $\begin{array}{r}94198 \\
617891\end{array}$ \\
\hline M.Gerais & $\begin{array}{l}1970 \\
1975\end{array}$ & $\begin{array}{l}1786486 \\
4005974\end{array}$ & $\begin{array}{r}865161 \\
1940017\end{array}$ & $\begin{array}{r}547462 \\
4606441\end{array}$ & $\begin{array}{r}240735 \\
2025583\end{array}$ \\
\hline
\end{tabular}

Fonte: IBGE - Censos Agropecuários do Brasil e estados

(1) os valores estão expressos em "mil cruzeiros" nos anos de 1970, 1975 e 1980 e, em "mil cruzados" no ano de 1985 .

Nota: estimou-se o número de animais compradas (e o valor da compral para o ano de 1970 a partir da proporção do número dos animais comprados (e do valor da compra) em relação a "vendidos e abatidos" em 1975, pela qual se multiplicou o número dos animais "vendidos e abatidos" ( e o valor da venda mais abate) em 1970. 
Tabela 3.58 - Estimativa do número de suínos comprados e valor ${ }^{1}$ da compra de 1970 - Brasil e estados.

\begin{tabular}{|c|c|c|c|c|c|}
\hline Estados & ano & $\begin{array}{l}\text { Abatidos e } \\
\text { Vendidos }\end{array}$ & Comprados & $\begin{array}{c}\text { Valor venda } \\
\text { e abate }\end{array}$ & $\begin{array}{l}\text { Valor da } \\
\text { compra }\end{array}$ \\
\hline Brasil & $\begin{array}{l}1970 \\
1975\end{array}$ & $\begin{array}{l}12449464 \\
16996406\end{array}$ & $\begin{array}{l}1842628 \\
2515615\end{array}$ & $\begin{array}{l}1156525 \\
6008219\end{array}$ & $\begin{array}{l}101609 \\
527864\end{array}$ \\
\hline Rondônia & $\begin{array}{l}1970 \\
1975\end{array}$ & $\begin{array}{r}2626 \\
25142\end{array}$ & $\begin{array}{r}729 \\
6983\end{array}$ & $\begin{array}{r}177 \\
9125\end{array}$ & $\begin{array}{r}35 \\
1826\end{array}$ \\
\hline Pará & $\begin{array}{l}1970 \\
1975\end{array}$ & $\begin{array}{l}138962 \\
196186\end{array}$ & $\begin{array}{r}9999 \\
14116\end{array}$ & $\begin{array}{r}7752 \\
46373\end{array}$ & $\begin{array}{r}350 \\
2094\end{array}$ \\
\hline Ceará & $\begin{array}{l}1970 \\
1975\end{array}$ & $\begin{array}{l}184541 \\
427862\end{array}$ & $\begin{array}{l}29025 \\
67296\end{array}$ & $\begin{array}{r}7703 \\
72674\end{array}$ & $\begin{array}{r}639 \\
6025\end{array}$ \\
\hline Paraíba & $\begin{array}{l}1970 \\
1975\end{array}$ & $\begin{array}{r}52181 \\
127722\end{array}$ & $\begin{array}{l}16112 \\
39437\end{array}$ & $\begin{array}{r}2471 \\
21512\end{array}$ & $\begin{array}{r}322 \\
2804\end{array}$ \\
\hline Bahia & $\begin{array}{l}1970 \\
1975\end{array}$ & $\begin{array}{l}413858 \\
662268\end{array}$ & $\begin{array}{r}83726 \\
133981\end{array}$ & $\begin{array}{r}29529 \\
166764\end{array}$ & $\begin{array}{r}2685 \\
15165\end{array}$ \\
\hline M.Gerais & $\begin{array}{l}1970 \\
1975\end{array}$ & $\begin{array}{l}1254503 \\
1917035\end{array}$ & $\begin{array}{l}247229 \\
377797\end{array}$ & $\begin{array}{l}150413 \\
882572\end{array}$ & $\begin{array}{l}11990 \\
70351\end{array}$ \\
\hline
\end{tabular}

Fonte: IBGE - Censos Agropecuários do Brasil e estados nota: idem tabela 3.57

(I) idem tabela 3.57 
Tabela 3.59 - Estimativa do número de caprinos comprados e valor ${ }^{1}$ da compra de 1970 - Brasil e estados.

\begin{tabular}{lrrrrr}
\hline Estados & ano & $\begin{array}{c}\text { Abatidos } \\
\text { Vendidos }\end{array}$ & Comprados & $\begin{array}{c}\text { Valor venda } \\
\text { e abate }\end{array}$ & $\begin{array}{r}\text { Valor da } \\
\text { compra }\end{array}$ \\
\hline Brasil & 1970 & 1255776 & 107496 & 21909 & 2224 \\
& 1975 & 1489359 & 127491 & 117929 & 11969 \\
Rondônia & 1970 & 60 & 44 & 4 & 3 \\
& 1975 & 140 & 102 & 27 & 22 \\
Pará & 1970 & 3568 & 728 & 76 & 21 \\
& 1975 & 2226 & 454 & 200 & 55 \\
Ceará & 1970 & 158016 & 11615 & 2521 & 204 \\
& 1975 & 151252 & 11118 & 11506 & 932 \\
Paraíba & 1970 & 56948 & 4887 & 1192 & 122 \\
& 1975 & 82859 & 7111 & 7248 & 741 \\
Bahia & 1970 & 321653 & 20060 & 5704 & 398 \\
& 1975 & 486403 & 30334 & 37829 & 2642 \\
M.Gerais & 1970 & 15639 & 3977 & 298 & 84 \\
& 1975 & 19003 & 4832 & 1869 & 527 \\
\hline
\end{tabular}

Fonte: IBGE - Censos Agropecuários do Brasil e estados nota: idem tabela 3.57

(1) idem tabela 3.57 
Tabela 3.60 - Estimativa do número de ovinos comprados e valor da compra de 1970 - Brasil e estados.

\begin{tabular}{lrrrrr}
\hline Estados & ano & $\begin{array}{c}\text { Abatidos } \\
\text { Vendidos }\end{array}$ & Comprados & $\begin{array}{c}\text { Valor venda } \\
\text { e abate }\end{array}$ & $\begin{array}{c}\text { Valor da } \\
\text { compra }\end{array}$ \\
\hline Brasil & 1970 & 2702162 & 361558 & 63309 & 10650 \\
& 1975 & 3288829 & 440056 & 327648 & 55117 \\
Rondônia & 1970 & 449 & 145 & 25 & 11 \\
& 1975 & 229 & 74 & 36 & 16 \\
Pará & 1970 & 4042 & 600 & 97 & 22 \\
& 1975 & 3377 & 501 & 330 & 75 \\
Ceará & 1970 & 238623 & 19864 & 4322 & 360 \\
& 1975 & 230774 & 19211 & 19168 & 1596 \\
Paraiba & 1970 & 59437 & 5524 & 1371 & 127 \\
& 1975 & 77674 & 7219 & 7610 & 706 \\
Bahia & 1970 & 317466 & 24647 & 7193 & 555 \\
& 1975 & 461487 & 35829 & 45374 & 3502 \\
M.Gerais & 1970 & 18086 & 2998 & 395 & 77 \\
& 1975 & 16441 & 2725 & 1869 & 366 \\
\hline
\end{tabular}

Fonte: IBGE - Censos Agropecuários do Brasil e estados nota: idem tabela 3.57

(1) idem tabela 3.57 
Tabela 3.61 - Estimativa do número de galinhas, galos, frangos(as) e pintos comprados e valor da compra de 1970 - Brasil e estados.

\begin{tabular}{lrrrrr}
\hline Estados & ano & $\begin{array}{c}\text { Abatidos } \\
\text { Vendidos }\end{array}$ & Comprados & $\begin{array}{c}\text { Valor venda } \\
\text { e abate }\end{array}$ & $\begin{array}{c}\text { Valor da } \\
\text { compra }\end{array}$ \\
\hline Brasil & 1970 & 310971313 & 123796614 & 669682 & 97013 \\
& 1975 & 822353188 & 327375986 & 4756091 & 688990 \\
Rondônia & 1970 & 95866 & 1623 & 613 & 30 \\
& 1975 & 601492 & 50823 & 10181 & 500 \\
Pará & 1970 & 1534954 & 297667 & 5887 & 347 \\
& 1975 & 4635876 & 899015 & 50050 & 2954 \\
Ceará & 1970 & 8741498 & 1482136 & 11467 & 1343 \\
& 1975 & 13044282 & 2211680 & 74880 & 8767 \\
Paraiba & 1970 & 1504263 & 641019 & 5277 & 667 \\
& 1975 & 2923686 & 1245885 & 35542 & 4492 \\
Bahia & 1970 & 4585385 & 1259991 & 15309 & 1781 \\
& 1975 & 14861571 & 4083725 & 112618 & 13104 \\
\multirow{2}{*}{ M.Gerais } & 1970 & 27831522 & 8427992 & 56130 & 7955 \\
& 1975 & 105482284 & 31942335 & 519340 & 73604 \\
\hline
\end{tabular}

Fonte: IBGE - Censos Agropecuários do Brasil e estados nota: idem tabela 3.57

(1) idem tabela 3.57 


\section{3 - CONSUMO INTERMEDIÁRIO (CI)}

Tabela 3.62 - Consumo Intermediário (CI) Brasil - 1970, 1975, 1980 e 1985.

\begin{tabular}{cccc}
\hline ano & $\begin{array}{c}\text { despesas dos } \\
\text { estabelecimentos } \\
(\mathrm{a})\end{array}$ & $\begin{array}{c}\text { valor da compra } \\
\text { de } \\
\text { animais } \\
(\mathrm{b})\end{array}$ & $\begin{array}{c}\text { Consumo } \\
\text { intermediário } \\
(\mathrm{CI}=\mathrm{a}+\mathrm{b})\end{array}$ \\
\hline 1970 & 5727615 & 1705021 & 7432636 \\
1975 & 40180178 & 11197528 & 51377706 \\
1980 & 488087137 & 170120652 & 658207789 \\
1985 & 57353293 & 13860255 & 71213548 \\
\hline
\end{tabular}

Fonte: IBGE - Censos Agropecuários

nota: os valores estão expressos em "mil cruzeiros" nos anos de 1970, 1975 e 1980 e "mil cruzados" no ano de 1985. (a) Coluna "g" das tabelas 3.69 a 3.75: Despesas dos Estabelecimentos Agropecuários

(b) coluna "f" das tabelas 3.76 a 3.82: Valor da Compra de Animais

Tabela 3.63 - Consumo Intermediário (CI) Rondônia - 1970, 1975, 1980 e 1985 .

\begin{tabular}{cccc}
\hline $\begin{array}{c}\text { despesas dos } \\
\text { ano }\end{array}$ & $\begin{array}{c}\text { valor da compra } \\
\text { de }\end{array}$ & $\begin{array}{c}\text { consumo } \\
\text { (b) })\end{array}$ & $\begin{array}{c}\text { intermediário } \\
\text { (CI=a+b) }\end{array}$ \\
\hline 1970 & 4127 & 715 & 4842 \\
1975 & 81985 & 21106 & 103091 \\
1980 & 1368646 & 747939 & 2116585 \\
1985 & 165916 & 141765 & 307681 \\
\hline
\end{tabular}

Fonte: IBGE - Censos Agropecuários nota: idem tabela 3.62

(a) idem tabela 3.62

(b) idem tabela 3.62 
Tabela 3.63 - Consumo Intermediário (CI) Pará - 1970, 1975, 1980 e 1985.

\begin{tabular}{cccc}
\hline $\begin{array}{c}\text { despesas dos } \\
\text { entabelecimentos } \\
(\mathrm{a})\end{array}$ & $\begin{array}{c}\text { valor da compra } \\
\text { de }\end{array}$ & $\begin{array}{c}\text { consumo } \\
\text { (b) }\end{array}$ & $\begin{array}{c}\text { intermediário } \\
\text { (CI=a+b) }\end{array}$ \\
\hline 1970 & 84786 & 19539 & 104325 \\
1975 & 539331 & 130167 & 669498 \\
1980 & 8917223 & 2478023 & 11395246 \\
1985 & 883550 & 283833 & 1167383 \\
\hline
\end{tabular}

Fonte: IBGE - Censos Agropecuários

nota: idem tabela 3.62

(a) idem tabela 3.62

(b) idem tabela 3.62

Tabela 3.65 - Consumo Intermediário (CI) ceará - 1970, 1975, 1980 e 1985.

\begin{tabular}{cccc}
\hline ano & $\begin{array}{c}\text { despesas dos } \\
\text { estabelecimentos } \\
(\mathrm{a})\end{array}$ & $\begin{array}{c}\text { valor da compra } \\
\text { de }\end{array}$ & $\begin{array}{c}\text { consumo } \\
(\mathrm{b})\end{array}$ \\
\hline 1970 & 97696 & 30363 & $\begin{array}{c}\text { intermediário } \\
(\mathrm{CI}=\mathrm{a}+\mathrm{b})\end{array}$ \\
1975 & 469808 & 151663 & 128059 \\
1980 & 7622696 & 2553927 & 621471 \\
1985 & 624034 & 257697 & 10176623 \\
\hline
\end{tabular}

Fonte: IBGE - Censos Agropecuários nota: idem tabela 3.62

(a) idem tabela 3.62

(b) idem tabela 3.62 


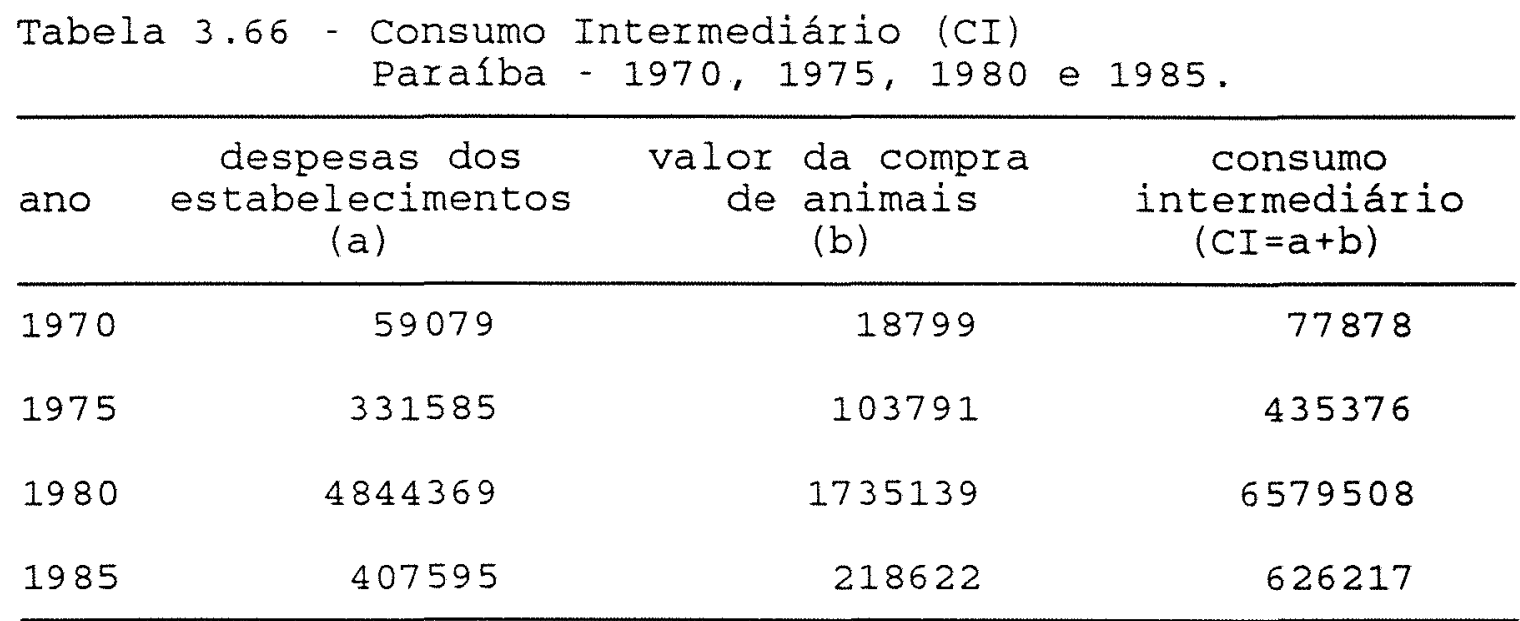

Fonte: IBGE - Censos Agropecuários

nota: idem tabela 3.62

(a) idem tabela 3.62

(b) idem tabela 3.62

Tabela 3.67 - Consumo Intermediário (CI) Bahia - 1970, 1975, 1980 e 1985.

\begin{tabular}{cccc}
\hline ano & $\begin{array}{c}\text { despesas dos } \\
\text { estabelecimentos } \\
(\mathrm{a})\end{array}$ & $\begin{array}{c}\text { valor da compra } \\
\text { de } \\
\text { animais } \\
(\mathrm{b})\end{array}$ & $\begin{array}{c}\text { consumo } \\
\text { intermediário } \\
(\mathrm{CI}=\mathrm{a}+\mathrm{b})\end{array}$ \\
\hline 1970 & 253387 & 99617 & 353004 \\
1975 & 1324730 & 652304 & 1977034 \\
1980 & 17189549 & 8026363 & 25215912 \\
1985 & 2182571 & 825803 & 3008374 \\
\hline
\end{tabular}

Fonte: IBGE - Censos Agropecuários nota: idem tabela 3.62

(a) idem tabela 3.62

(b) idem tabela 3.62 
Tabela 3.68 - Consumo Intermediário (CI) Minas Gerais - 1970, 1975, 1980 e 1985.

\begin{tabular}{|c|c|c|c|}
\hline ano & $\begin{array}{c}\text { despesas dos } \\
\text { estabelecimentos } \\
\text { (a) }\end{array}$ & $\begin{array}{l}\text { valor da compra } \\
\text { de animais } \\
\text { (b) }\end{array}$ & $\begin{array}{c}\text { consumo } \\
\text { intermediário } \\
(C I=a+b)\end{array}$ \\
\hline 1970 & 622184 & 260841 & 883025 \\
\hline 1975 & 4555283 & 2170431 & 6725714 \\
\hline 1980 & 58738014 & 31559852 & 90297866 \\
\hline 1985 & 7267342 & 2241706 & 9509048 \\
\hline
\end{tabular}

Fonte: IBGE - Censos Agropecuários nota: idem tabela 3.62

(a) idem tabela 3.62

(b) idem tabela 3.62

Tabela 3.69 - Despesas dos estabelecimentos agropecuários(1) - Brasil - 1970, 1975, 1980 e 1985.

\begin{tabular}{lrrrr}
\hline & \multicolumn{4}{c}{ ano } \\
\cline { 2 - 5 } despesa & 1970 & 1975 & 1980 & 1985 \\
\hline a. despesa total & 11291170 & 70036388 & 821262929 & 98904538 \\
b. salários & 2766521 & 13715229 & 166349207 & 18616760 \\
c. cota-produção & 476357 & 2061868 & 17273283 & 2178187 \\
d. arrend. parceiro & 687804 & 3996022 & 36987753 & 5240518 \\
e. serviço empreit. & 1143589 & 6428971 & 62357436 & 6736467 \\
f. juro/desp. banc. & 489284 & 3654120 & 50208113 & 8779313 \\
g. desp. estabelec. & 5727615 & 40180178 & 488087137 & 57353293 \\
\hline
\end{tabular}

Fonte: IBGE - Censos Agropecuários (Brasil)

(1) os valores estão expressos em "mil cruzeiros" nos anos de 1970, 1975 e 1980 e em "mil cruzados" no ano de 1985. $(g)=[a-(b+c+d+e+f)]$ 
Tabela 3.70 - Despesas dos estabelecimentos agropecuários(1) - Rondônia - 1970, 1975, 1980 e 1985.

\begin{tabular}{lcccr}
\hline & \multicolumn{4}{c}{ ano } \\
\cline { 2 - 5 } despesa & 1970 & 1975 & 1980 & 1985 \\
\hline a. despesa total & 8375 & 145423 & 2809360 & 450031 \\
b. salários & 1510 & 14624 & 545973 & 75971 \\
c. cota-produção & 205 & 459 & 12060 & 4827 \\
d. arrend. parceiro & 1042 & 3371 & 47849 & 50131 \\
e. serviço empreit. & 1028 & 43248 & 742314 & 140498 \\
E. juro/desp. banc. & 463 & 1736 & 92518 & 12688 \\
g. desp. estabelec. & 4127 & 81985 & 1368646 & 165916 \\
\hline
\end{tabular}

Fonte: IBGE - Censos Agropecuários (Rondônia)

(1) idem tabela 3.69

$(g)=[a-(b+c+d+e+f)]$

Tabela 3.71 - Despesas dos estabelecimentos agropecuários(1) - Pará - 1970, 1975, 1980 e 1985.

\begin{tabular}{lrrrr}
\hline & \multicolumn{4}{c}{ ano } \\
\cline { 2 - 5 } despesa & 1970 & 1975 & 1980 & 1985 \\
\hline a. despesa total & 165349 & 1116501 & 16686109 & 1616609 \\
b. salários & 44408 & 286277 & 3983590 & 460758 \\
c. cota-produção & 3006 & 4661 & 72823 & 4003 \\
d. arrend. parceiro & 2766 & 12556 & 210141 & 14516 \\
e. serviço empreit. & 26658 & 243473 & 2964313 & 194662 \\
f. juro/desp. banc. & 3725 & 30203 & 538019 & 59120 \\
g. desp. estabelec. & 84786 & 539331 & 8917223 & 883550 \\
\hline
\end{tabular}

Fonte: IBGE - Censos Agropecuários (Pará)

(1) idem tabela 3.69

$(g)=[a-(b+c+d+e+f)]$ 
Tabela 3.72 - Despesas dos estabelecimentos agropecuários(1) - Ceará - 1970, 1975, 1980 e 1985.

\begin{tabular}{lrrrr}
\hline & \multicolumn{4}{c}{ ano } \\
\cline { 2 - 5 } despesa & 1970 & 1975 & 1980 & 1985 \\
\hline a. despesa total & 224221 & 1052296 & 16055898 & 1268531 \\
b. salários & 71488 & 333427 & 5812086 & 412571 \\
c. cota-produção & 17141 & 91054 & 742344 & 36048 \\
d. arrend. parceiro & 10744 & 50258 & 380931 & 88199 \\
e. serviço empreit. & 20697 & 60888 & 754106 & 50318 \\
f. juro/desp. banc. & 6455 & 46861 & 743735 & 57361 \\
g. desp. estabelec. & 97696 & 469808 & 7622696 & 624034 \\
\hline
\end{tabular}

Fonte: IBGE - Censos Agropecuários (Ceará)

(1) idem tabela 3.69

$(g)=[a-(b+c+d+e+f)]$

Tabela 3.73 - Despesas dos estabelecimentos agropecuários(1) - Parába - 1970, 1975, 1980 e 1985.

\begin{tabular}{lrrrr}
\hline & \multicolumn{4}{c}{ ano } \\
\cline { 2 - 5 } despesa & 1970 & 1975 & 1980 & 1985 \\
\hline a. despesa total & 145945 & 758791 & 10259903 & 868804 \\
b. salários & 48706 & 219965 & 3753887 & 265477 \\
c. cota-produção & 12593 & 70480 & 317469 & 66215 \\
d. arrend. parceiro & 6583 & 29502 & 240116 & 29353 \\
e. serviço empreit. & 13498 & 74443 & 560292 & 53331 \\
f. juro/desp. banc. & 5486 & 32816 & 543770 & 46833 \\
g. despe. estabelec. 59079 & 331585 & 4844369 & 407595 \\
\hline
\end{tabular}

Fonte: IBGE - Censos Agropecuários (Paraíba)

(1) idem tabela 3.69

$(g)=[a-(b+c+d+e+f)]$ 
Tabela 3.74 - Despesas dos estabelecimentos agropecuários(1) - Bahia - 1970, 1975, 1980 e 1985.

\begin{tabular}{lrrrr}
\hline & \multicolumn{4}{c}{ ano } \\
\cline { 2 - 5 } despesa & 1970 & 1975 & 1980 & 1985 \\
\hline a. despesa total & 578680 & 3218278 & 41341650 & 5199537 \\
b. salários & 191773 & 1190664 & 14626638 & 1971545 \\
c. cota-produção & 8796 & 25889 & 317549 & 21459 \\
d. arrend. parceiro & 7312 & 22748 & 339590 & 50450 \\
e. serviço empreit. & 99179 & 537927 & 6815322 & 735986 \\
f. juro/desp. banc. & 18233 & 116320 & 2053002 & 237526 \\
g. desp. estabelec. 253387 & 1324730 & 17189549 & 2182571 \\
\hline
\end{tabular}

Fonte: IBGE - Censos Agropecuários (Bahia)

(1) idem tabela 3.69

$(g)=[a-(b+c+d+e+f)]$

Tabela 3.75 - Despesas dos estabelecimentos agropecuários(1)-Minas Gerais-1970, 1975, 1980 e 1985.

\begin{tabular}{lrrrr}
\hline & \multicolumn{4}{c}{ ano } \\
\cline { 2 - 5 } despesa & 1970 & 1975 & 1980 & 1985 \\
\hline a. despesa tota & 1445108 & 8773176 & 108532157 & 13086055 \\
b. salários & 404450 & 2063763 & 26498204 & 3118046 \\
c. cota-produção & 139547 & 432628 & 4685017 & 476921 \\
d. arrend. parceiro & 48861 & 273679 & 2566751 & 349022 \\
e. serviço empreit. & 156411 & 976588 & 9374548 & 1027650 \\
f. juro/desp. banc. & 73655 & 471235 & 6669623 & 847074 \\
g. desp. estabelec. 622184 & 4555283 & 58738014 & 7267342 \\
\hline
\end{tabular}

Fonte: IBGE - Censos Agropecuários (Minas Gerais)

(1) idem tabela 3.69

$(g)=[a-(b+c+d+e+f)]$ 
Tabela 3.76 - Valor da compra de animais BRASIL - 1970, 1975, 1980 e 1985.

\begin{tabular}{ccccccc}
\hline & \multicolumn{6}{c}{ Valor da compra(1) } \\
\cline { 2 - 7 } & $\begin{array}{c}\text { bovinos } \\
\text { (a) }\end{array}$ & $\begin{array}{c}\text { suinos } \\
\text { (b) }\end{array}$ & $\begin{array}{c}\text { caprinos } \\
\text { (c) }\end{array}$ & $\begin{array}{c}\text { ovinos } \\
\text { (d) }\end{array}$ & $\begin{array}{c}\text { frangos } \\
(\mathrm{e})\end{array}$ & $\begin{array}{c}\text { total } \\
(\mathrm{f})\end{array}$ \\
\hline 70 & 1493526 & 101609 & 2224 & 10650 & 97013 & 1705021 \\
75 & 9913588 & 527864 & 11969 & 55117 & 688990 & 11197528 \\
80 & 148913703 & 5636002 & 450510 & 1079129 & 14041308 & 170120652 \\
85 & 12742107 & 746666 & 43154 & 91219 & 237109 & 13860255 \\
\hline
\end{tabular}

Fonte: IBGE - Censos Agropecuários

nota: os valores de 1970 foram estimados (vide a tabela Estimativa do Valor da Compra de Animais para 1970) .

(1) os valores estão expressos em "mil cruzeiros" nos anos de 1970, 1975 e 1980 e em "mil cruzados" no ano de 1985.

(e) valor da compra de galinhas, galos, frangos(as) e pintos.

$(f)=(a+b+c+d+e)$

Tabela 3.77 - Valor da compra de animais RONDÔNIA - 1970, 1975, 1980 e 1985.

\begin{tabular}{ccccccc}
\hline ano & \multicolumn{5}{c}{ Valor da compra(1) } \\
\cline { 2 - 7 } & $\begin{array}{c}\text { bovinos } \\
\text { (a) }\end{array}$ & $\begin{array}{c}\text { suínos } \\
\text { (b) }\end{array}$ & $\begin{array}{c}\text { caprinos } \\
\text { (c) }\end{array}$ & $\begin{array}{c}\text { ovinos } \\
\text { (d) }\end{array}$ & $\begin{array}{c}\text { frangos } \\
(\mathrm{e})\end{array}$ & $\begin{array}{c}\text { total } \\
(\mathrm{f})\end{array}$ \\
\hline 70 & 636 & 35 & 3 & 11 & 30 & 715 \\
75 & 18742 & 1826 & 22 & 16 & 500 & 21106 \\
80 & 668524 & 55704 & 1628 & 1040 & 21043 & 747939 \\
85 & 131774 & 8207 & 258 & - & 1526 & 141765 \\
\hline
\end{tabular}

Fonte: IBGE - Censos Agropecuários

nota: idem tabela 3.76
(1) idem tabela 3.76
(e) idem tabela 3.76
(f) $=(a+b+c+d+e)$ 
Tabela 3.78 - Valor da compra de animais PARÁ - 1970, 1975, 1980 e 1985.

\begin{tabular}{ccccccr}
\hline \multirow{6}{*}{ ano } & \multicolumn{6}{c}{ Valor da compra(1) } \\
\cline { 2 - 7 } & $\begin{array}{c}\text { bovinos } \\
(\mathrm{a})\end{array}$ & $\begin{array}{c}\text { suínos } \\
(\mathrm{b})\end{array}$ & $\begin{array}{c}\text { caprinos } \\
(\mathrm{c})\end{array}$ & $\begin{array}{c}\text { ovinos } \\
(\mathrm{d})\end{array}$ & $\begin{array}{c}\text { frangos } \\
(\mathrm{e})\end{array}$ & $\begin{array}{r}\text { total } \\
(\mathrm{f})\end{array}$ \\
\hline 70 & 18799 & 350 & 21 & 22 & 347 & 19539 \\
75 & 124989 & 2094 & 55 & 75 & 2954 & 130167 \\
80 & 2184547 & 51644 & 2822 & 8582 & 230428 & 2478023 \\
85 & 263807 & 8761 & - & 894 & 10371 & 283833 \\
\hline
\end{tabular}

Fonte: IBGE - Censos Agropecuários

nota: idem tabela 3.76

(1) idem tabela 3.76

(e) idem tabela 3.76

$(f)=(a+b+c+d+e)$

Tabela 3.79 - Valor da compra de animais CEARÁ - 1970, 1975, 1980 e 1985.

\begin{tabular}{ccccccc}
\hline & \multicolumn{5}{c}{ Valor da compra(1) } \\
\cline { 2 - 7 } & $\begin{array}{c}\text { bovinos } \\
(\mathrm{a})\end{array}$ & $\begin{array}{c}\text { suinos } \\
\text { (b) }\end{array}$ & $\begin{array}{c}\text { caprinos } \\
\text { (c) }\end{array}$ & $\begin{array}{c}\text { ovinos } \\
(\mathrm{d})\end{array}$ & $\begin{array}{c}\text { frangos } \\
(\mathrm{e})\end{array}$ & $\begin{array}{c}\text { total } \\
\text { (f) }\end{array}$ \\
\hline 70 & 27817 & 639 & 204 & 360 & 1343 & 30363 \\
75 & 134343 & 6025 & 932 & 1596 & 8767 & 151663 \\
80 & 2037649 & 91044 & 71370 & 76614 & 277250 & 2553927 \\
85 & 229544 & 12113 & 4926 & - & 11114 & 257697 \\
\hline
\end{tabular}

Fonte: IBGE - Censos Agropecuários

nota: idem tabela 3.76
(1) idem tabela 3.76
(e) idem tabela 3.76
(f) $=(a+b+c+d+e)$ 
Tabela 3.80 - Valor da compra de animais PARAIBA - 1970, 1975, 1980 e 1985.

\begin{tabular}{ccccccc}
\hline ano & \multicolumn{6}{c}{ Valor da compra(1) } \\
\cline { 2 - 7 } & $\begin{array}{c}\text { bovinos } \\
(\mathrm{a})\end{array}$ & $\begin{array}{c}\text { suinos } \\
(\mathrm{b})\end{array}$ & $\begin{array}{c}\text { caprinos } \\
(\mathrm{c})\end{array}$ & $\begin{array}{c}\text { ovinos } \\
(\mathrm{d})\end{array}$ & $\begin{array}{c}\text { frangos } \\
(\mathrm{e})\end{array}$ & $\begin{array}{c}\text { total } \\
(\mathrm{f})\end{array}$ \\
\hline 70 & 17561 & 322 & 122 & 127 & 667 & 18799 \\
75 & 95048 & 2804 & 741 & 706 & 4492 & 103791 \\
80 & 1472954 & 69741 & 40254 & 20554 & 131636 & 1735139 \\
85 & 203261 & 5527 & 3491 & 3302 & 3041 & 218622 \\
\hline
\end{tabular}

Fonte: IBGE - Censos Agropecuários

nota: idem tabela 3.76
(1) idem tabela 3.76
(e) idem tabela 3.76
$(f)=(a+b+c+d+e)$

Tabela 3.81 - Valor da compra de animais

$$
\text { BAHIA - 1970, 1975, } 1980 \text { e } 1985 .
$$

\begin{tabular}{ccccccc}
\hline & \multicolumn{5}{c}{ Valor da compra(1) } \\
\cline { 2 - 7 } & $\begin{array}{c}\text { bovinos } \\
(\mathrm{a})\end{array}$ & $\begin{array}{c}\text { suinos } \\
(\mathrm{b})\end{array}$ & $\begin{array}{c}\text { caprinos } \\
(\mathrm{c})\end{array}$ & $\begin{array}{c}\text { ovinos } \\
(\mathrm{d})\end{array}$ & $\begin{array}{c}\text { frangos } \\
(\mathrm{e})\end{array}$ & $\begin{array}{c}\text { total } \\
(\mathrm{f})\end{array}$ \\
\hline 70 & 94198 & 2685 & 398 & 555 & 1781 & 99617 \\
75 & 617891 & 15165 & 2642 & 3502 & 13104 & 652304 \\
80 & 7492698 & 200021 & 58089 & 92948 & 182607 & 8026363 \\
85 & 774882 & 27373 & 6948 & 11055 & 5545 & 825803 \\
\hline
\end{tabular}

Fonte: IBGE - Censos Agropecuários

nota: idem tabela 3.76
(1) idem tabela 3.76
(e) idem tabela 3.76
(f) $=(a+b+c+d+e)$ 
Tabela 3.82 Valor da compra de animais MINAS GERAIS - 1970, 1975, 1980 e 1985.

\begin{tabular}{ccccccc}
\hline ano & \multicolumn{6}{c}{ Valor da compra(1) } \\
\cline { 2 - 7 } & $\begin{array}{c}\text { bovinos } \\
(\mathrm{a})\end{array}$ & $\begin{array}{c}\text { suínos } \\
(\mathrm{b})\end{array}$ & $\begin{array}{c}\text { caprinos } \\
(\mathrm{c})\end{array}$ & $\begin{array}{c}\text { ovinos } \\
(\mathrm{d})\end{array}$ & $\begin{array}{c}\text { frangos } \\
(\mathrm{e})\end{array}$ & $\begin{array}{c}\text { total } \\
(\mathrm{f})\end{array}$ \\
\hline 70 & 240735 & 11990 & 84 & 77 & 7955 & 260841 \\
75 & 2025583 & 70351 & 527 & 366 & 73604 & 2170431 \\
80 & 29200536 & 747643 & 12837 & 5995 & 1592841 & 31559852 \\
85 & 2112907 & 79735 & 1940 & - & 47124 & 2241706 \\
\hline
\end{tabular}

Fonte: IBGE - Censos Agropecuários

nota: idem tabela 3.76

(1) idem tabela 3.76

(e) idem tabela 3.76

$(f)=(a+b+c+d+e)$ 


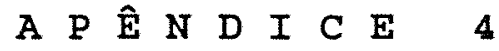

Salário médio nominal do servente da construção civil, do empregado permanente e temporário da agricultura e salário mínimo médio nominal 
Tabela 4.1 - Salário médio nominal - BRASIL, 1977 a 1987

\begin{tabular}{|c|c|c|c|c|}
\hline \multirow{2}{*}{ ano } & \multicolumn{3}{|c|}{ salário médio nominal } & \multirow[b]{2}{*}{$\begin{array}{l}\text { temporário } \\
\text { (Cr\$/dia) }\end{array}$} \\
\hline & $\begin{array}{l}\text { servente } \\
(\text { Cr } \$ / \text { hora })\end{array}$ & $\begin{array}{c}\text { mínimo } \\
\text { (Cr } \$ / m e ̂ s)\end{array}$ & $\begin{array}{l}\text { permanente } \\
\text { (Cr } \$ / \text { mês })\end{array}$ & \\
\hline 77 & 4,54 & 920,80 & 965,00 & 39,22 \\
\hline 78 & 6,44 & 1299,20 & 1411,50 & 53,50 \\
\hline 79 & 9,65 & 2489,60 & 2227,00 & 85,00 \\
\hline 80 & 18,51 & 5011,20 & 4293,50 & 174,50 \\
\hline 81 & 42,39 & 7158,00 & 9058,00 & 353,50 \\
\hline 82 & 86,92 & 14618,67 & 18145,50 & 645,00 \\
\hline 83 & 171,25 & 31980,00 & 40594,50 & 1454,00 \\
\hline 84 & 470,88 & 93862,67 & 122079,50 & 4392,50 \\
\hline 85 & 1623,83 & 322080,00 & 451488,00 & 16730,50 \\
\hline 86 & 4609,81 & 770000,00 & 1004730,00 & 46830,00 \\
\hline 87 & 15095,96 & 2008920,00 & 2897805,00 & 127805,00 \\
\hline
\end{tabular}

Fonte: SINAPI (IBGE), Centro de Estudos Agrícolas (IBRE, FGV) e Boletim DIEESE.

(1) salário mínimo para o Brasil é igual à média aritmética das regiões.

Tabela 4.2 - Salário médio nominal - RONDÔNIA, 1977 a 1987

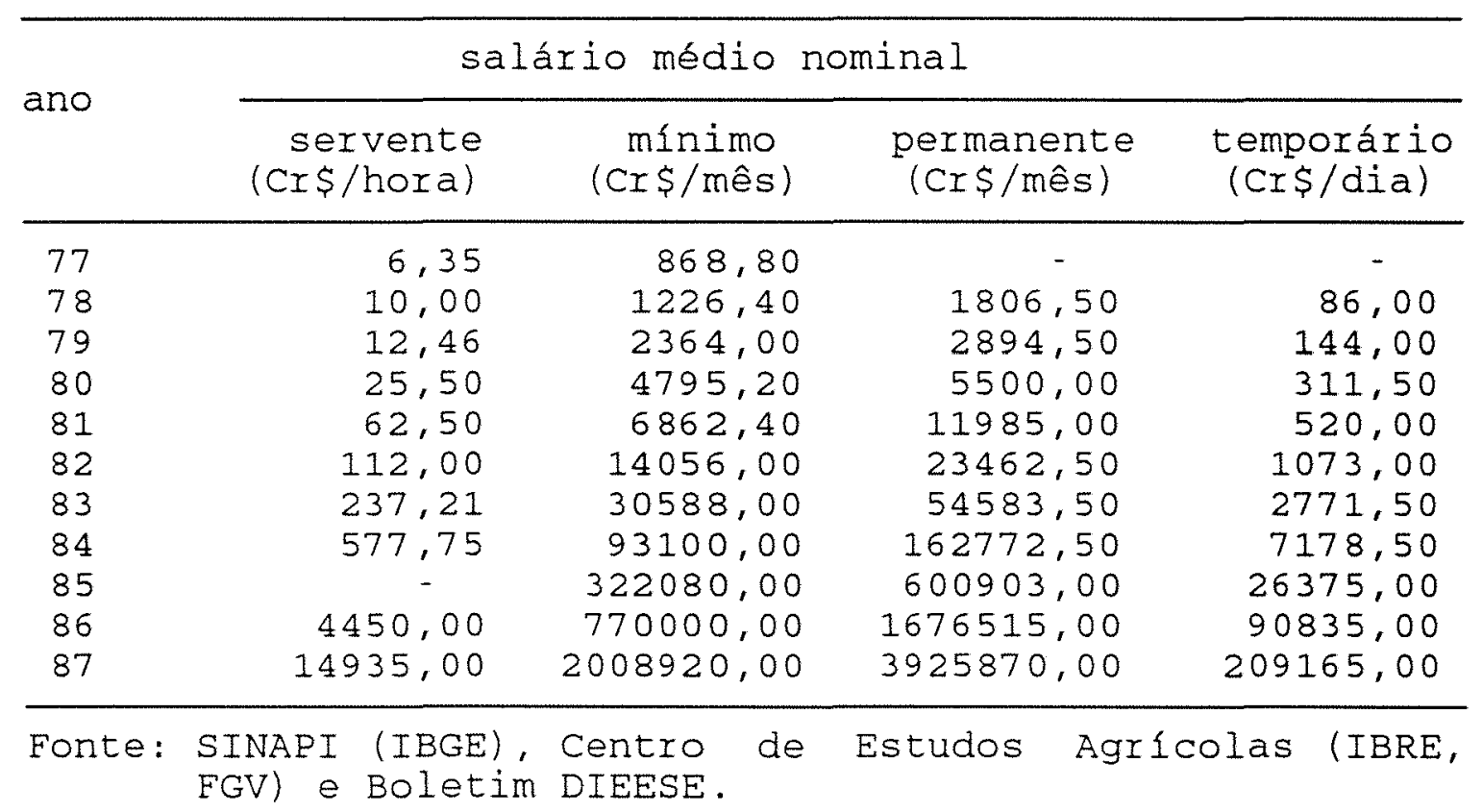


Tabela 4.3 - Salário médio nominal - PARÁ, 1977 a 1987

\begin{tabular}{|c|c|c|c|c|}
\hline \multirow{2}{*}{ ano } & \multicolumn{3}{|c|}{ salário médio nominal } & \multirow[b]{2}{*}{$\begin{array}{l}\text { temporário } \\
\text { (Cr\$/dia) }\end{array}$} \\
\hline & $\begin{array}{c}\text { servente } \\
\text { (cr\$/hora) }\end{array}$ & $\begin{array}{l}\text { mínimo } \\
\text { (Cr\$s/mês) }\end{array}$ & $\begin{array}{c}\text { permanente } \\
\text { (Cr\$/mês) }\end{array}$ & \\
\hline 77 & 3,25 & 868,80 & 885,00 & 34,11 \\
\hline 78 & 4,49 & 1226,40 & 1415,00 & 55,00 \\
\hline 79 & 7,36 & 2364,00 & 2130,00 & 79,50 \\
\hline 80 & 14,04 & 4795,20 & 4362,50 & 177,00 \\
\hline 81 & 33,89 & 6862,40 & 9382,00 & 334,50 \\
\hline 82 & 69,35 & 14056,00 & 17323,50 & 633,00 \\
\hline 83 & 170,54 & 30588,00 & 37645,50 & 1531,00 \\
\hline 84 & 449,42 & 93100,00 & 132448,00 & 4771,00 \\
\hline 85 & 1439,17 & 322080,00 & 475024,50 & 16783,00 \\
\hline 86 & 3609,17 & 770000,00 & 1014370,00 & 53395,00 \\
\hline 87 & 14745,00 & 2008920,00 & 3029870,00 & 127195,00 \\
\hline
\end{tabular}

Tabela 4.4 - Salário médio nominal - CEARÁ, 1977 a 1987

\begin{tabular}{|c|c|c|c|c|}
\hline \multirow{2}{*}{ ano } & \multicolumn{4}{|c|}{ salário médio nominal } \\
\hline & $\begin{array}{l}\text { servente } \\
\text { (Cr } \$ / \text { hora })\end{array}$ & $\begin{array}{l}\text { mínimo } \\
\text { (Cr } \$ \text { /mês })\end{array}$ & $\begin{array}{c}\text { permanente } \\
(\mathrm{Cr} \$ / \mathrm{mês})\end{array}$ & $\begin{array}{l}\text { temporário } \\
\text { (Cr\$/dia) }\end{array}$ \\
\hline 77 & 2,98 & 787,20 & 668,00 & 26,38 \\
\hline 78 & 4.03 & 1111,20 & 918,00 & 35,50 \\
\hline 79 & 6,35 & 2172,00 & 1577,00 & 55,50 \\
\hline 80 & 12,13 & 4449,60 & 3074,50 & 115,00 \\
\hline 81 & 28,80 & 6461,60 & 6131,00 & 241,00 \\
\hline 82 & 57,36 & 13592,00 & 11916,50 & 427,50 \\
\hline 83 & 127,98 & 30588,00 & 24375,50 & 912,00 \\
\hline 84 & 378,38 & 93100,00 & 80246,00 & 3020,00 \\
\hline 85 & 1540,00 & 322080,00 & 286099,50 & 10481,50 \\
\hline 86 & 3208,33 & 770000,00 & 757360,00 & 32220,00 \\
\hline 87 & 11605,00 & 2008920,00 & 2062190,00 & 75160,00 \\
\hline
\end{tabular}

Fonte: SINAPI (IBGE), Centro de Estudos Agrícolas (IBRE, FGV) e Boletim DIEESE. 
Tabela 4.5 - Salário médio nominal - PARAíBA, 1977 a 1987

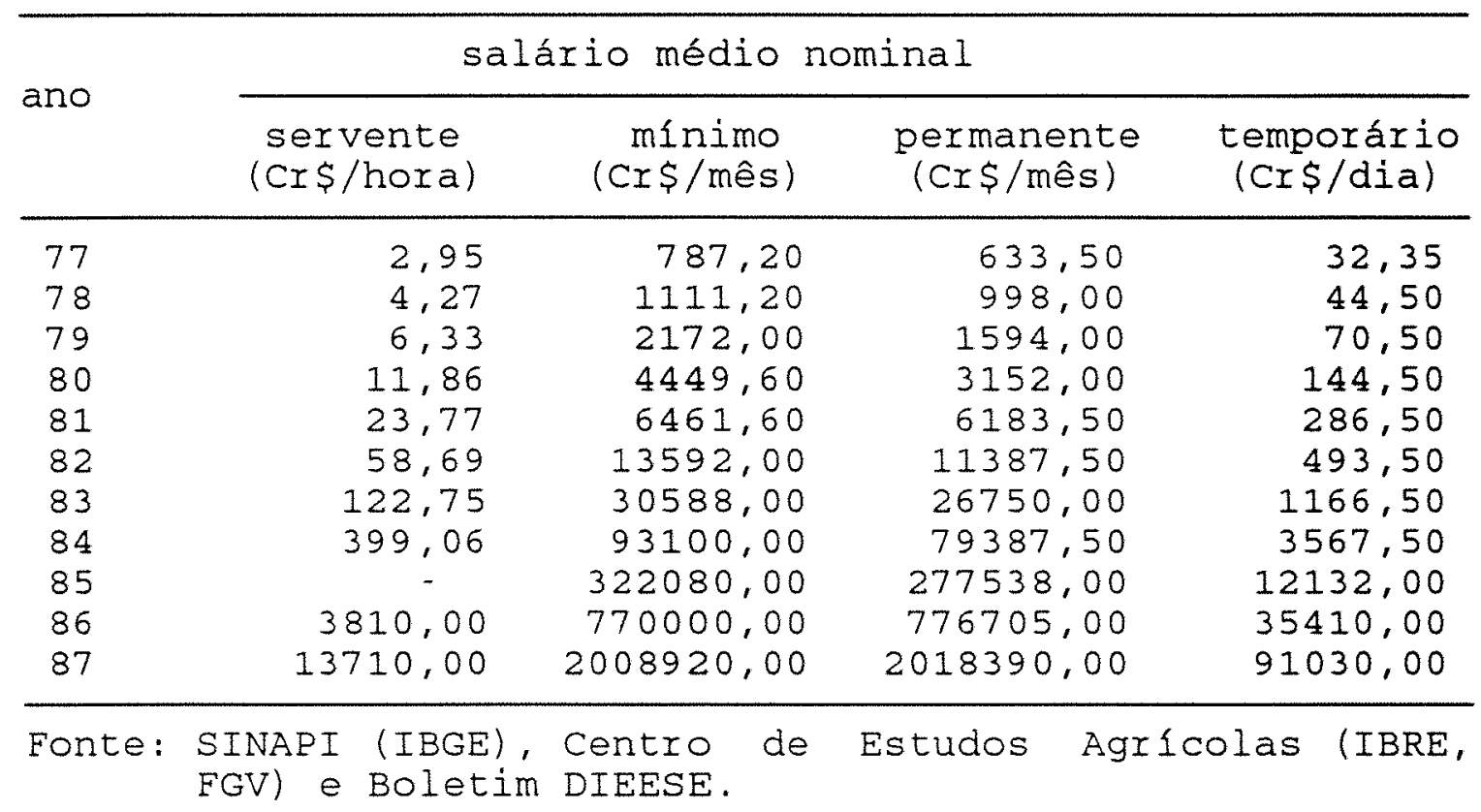

Tabela 4.6 - Salário médio nominal - BAHIA, 1977 a 1987

\begin{tabular}{|c|c|c|c|c|}
\hline \multirow{2}{*}{ ano } & \multicolumn{3}{|c|}{ salário médio nominal } & \multirow[b]{2}{*}{$\begin{array}{c}\text { temporário } \\
\text { (Cr\$/dia) }\end{array}$} \\
\hline & $\begin{array}{c}\text { servente } \\
\text { (Cr\$/hora) }\end{array}$ & $\begin{array}{l}\text { mínimo } \\
(\mathrm{Cr} \$ / \mathrm{mês})\end{array}$ & $\begin{array}{c}\text { permanente } \\
\text { (Cr\$/mês) }\end{array}$ & \\
\hline 77 & 3,58 & 787,20 & 875,50 & 36,41 \\
\hline 78 & 5,51 & 1111,20 & 1344,50 & 54,50 \\
\hline 79 & 7,88 & 2172,00 & 2227,00 & 91,00 \\
\hline 80 & 15,43 & 4449,60 & 3640,00 & 173,50 \\
\hline 81 & 30,82 & 6461,60 & 7633,00 & 335,00 \\
\hline 82 & 60,92 & 13592,00 & 14824,00 & 531,00 \\
\hline 83 & 117,01 & 30588,00 & 34195,00 & 1274,00 \\
\hline 84 & 371,86 & 93100,00 & 115252,00 & 4069,00 \\
\hline 85 & 1284,17 & 322080,00 & 429484,50 & 15681,00 \\
\hline 86 & 3316,67 & 770000,00 & 907970,00 & 41020,00 \\
\hline 87 & 11605,00 & 2008920,00 & 2611265,00 & 105380,00 \\
\hline
\end{tabular}


Tabela 4.7 - Salário médio nominal - MINAS GERAIS, 1977 a 1987

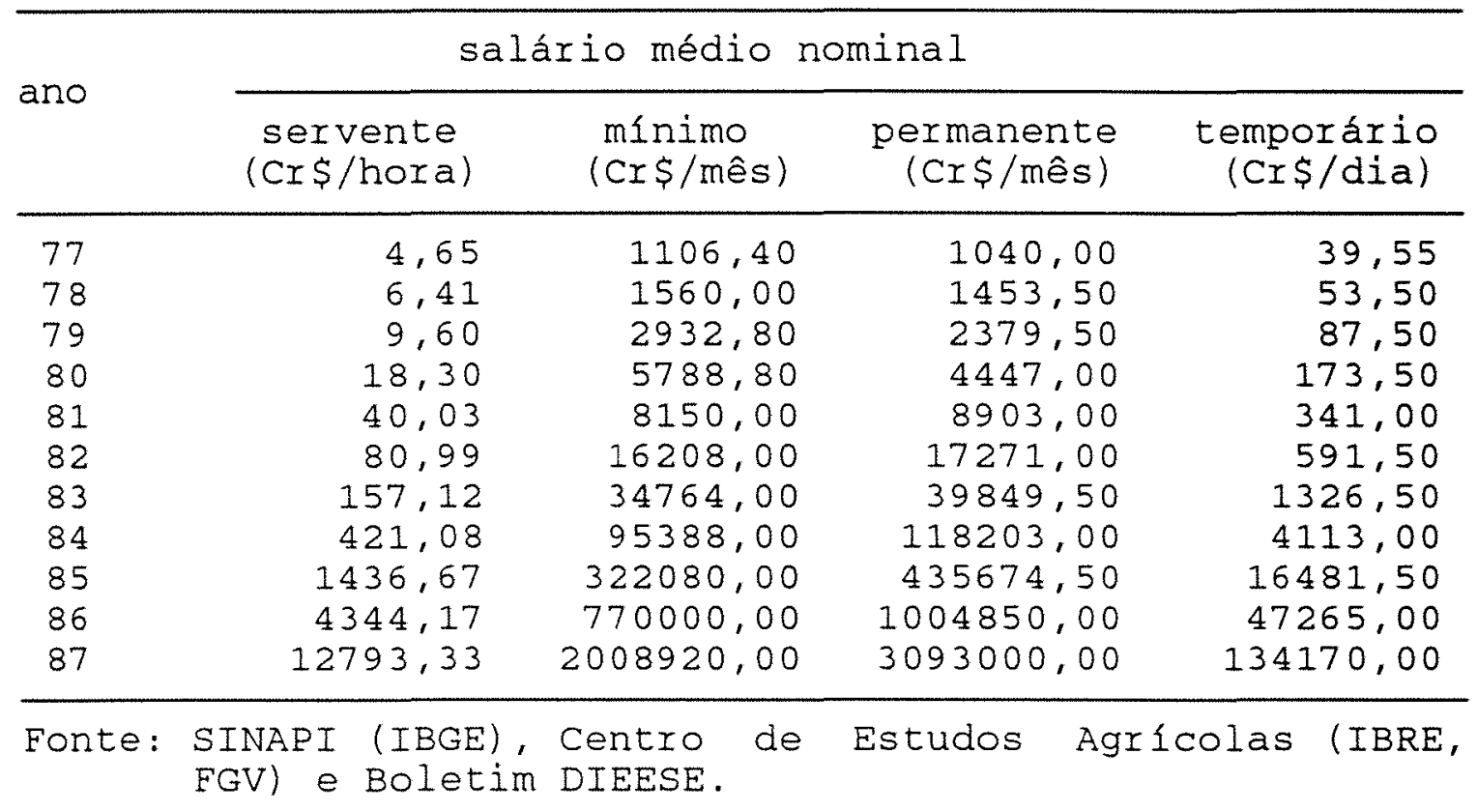

